\title{
ENGAGEMENT OF GEOGRAPHICALLY DIVERSE HEAD START FAMILIES
}

\section{A Dissertation}

presented to

the Faculty of the Graduate School

at the University of Missouri-Columbia

In Partial Fulfillment

of the Requirements for the Degree

Doctor of Philosophy

by

Amanda M. Keys

Dr. Colleen Galambos, Dissertation Supervisor

December 2013 
The undersigned, appointed by the dean of the Graduate School, have examined the dissertation entitled

\section{ENGAGEMENT OF GEOGRAPHICALLY DIVERSE HEAD START}

\section{FAMILIES}

presented by Amanda M. Keys, a candidate for the degree of doctor of philosophy, and hereby certify that, in their opinion, it is worthy of acceptance.

Professor Colleen Galambos

Professor Clark Peters

Professor Rebecca McCathren

Professor Dong Yoon 


\section{DEDICATION PAGE}

First, and foremost, to Him who makes all things possible thank you for opening this door for me and giving me daily strength to see it completed. Second, I would like to thank my family. To my brothers, who have been and always will be a pure joy in my life. To my sister, who spent every Friday night in my kitchen providing me with sanity and encouragement to make it through another week. To my grandfather, Dr. William Franklin, although you didn't get to see me reach the finish line, I am so thankful for the endless hours I spent listening to you passionately discuss academia. Your faith and belief in me will always be a source of strength and joy when I stand in front of students trying to grow and encourage the next generation. To my parents, Gary and Jan Lyons, there are not words to fully express my gratitude. Dad, thank you for the millions of times I have heard you tell me that you are proud of me. Although I didn't become the President like you always dreamed, I figured this career that started with a $\mathrm{P}$ as well was almost as good. Mom, thank you for your tireless dedication to your children. For the thousands of miles you journeyed with me to get me to this point. This is your degree as much as it is mine. You have definitely earned your $\mathrm{PhD}$ as my mom. Finally, this is dedicated to my precious little family. To my sweet son, Collin, may my example serve to show you all things are possible if you just believe in yourself. To my beautiful daughter, Grace, who has been with me through all three of my degrees. Thank you for being God's special reminder to me of why all of this has been important. Finally, to my husband, Ron, who would not let me give up on my life's desire. Thank you for believing in me when I didn't, especially at three in the morning. I couldn't think of anyone else I would rather be on this crazy ride with. You are my heart. 


\section{ACKNOWLEDGEMENTS}

I would like to begin by thanking Dr. Colleen Galambos who served as my teacher, advisor, and chair of my dissertation committee. For the past four years, Dr. Galambos has never failed to push me towards excellence and has engrained in me her passion for not just doing it to get it done, but doing it to do it well. Thank you for believing that I could always achieve excellence and not giving up on me on the days I fell short. I will forever feel fortunate for the day I met with you four years ago and you agreed to be my chair. It was the best decision I have made while at MU. I would also like to thank the rest of my committee members for their assistance in this process including: Dr. Dong Yoon, Dr. Clark Peters, and Dr. Rebecca McCathren. Specifically, I would like to thank Dr. Yoon for all of his statistical knowledge and wisdom. Thank you for inspiring students daily to be excited about statistics.

There are several members of the Head Start Community I would like to acknowledge. First, I would like to thank Teresa Sivils-Dickey who was willing to meet a stranger for coffee to talk about Head Start and graciously opened her program to this researcher. Second, I would like to thank Kimberly Shinn-Brown for her outstanding role as a leader in the Head Start Community. It has been an honor to watch you manage extremely difficult times in the Head Start community with grace and determination to be the best Head Start program in the country. Finally, I would like to thank all of the Head Start parents who took the time to fill out this survey. I was humbled by your responses and your love for your community. Thank you for entrusting Head Start with your children. Your sacrifice now will have a lasting impact on your child's lifelong growth and development. 


\section{Table of Contents}

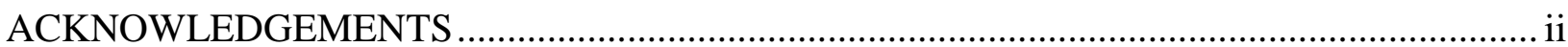

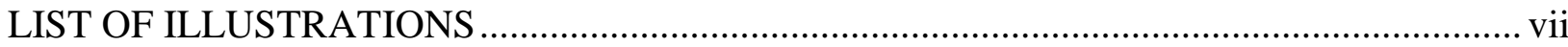

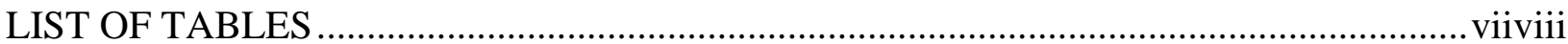

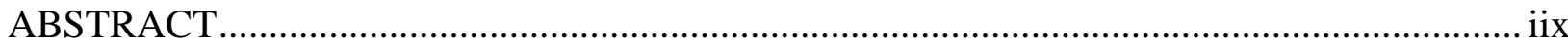

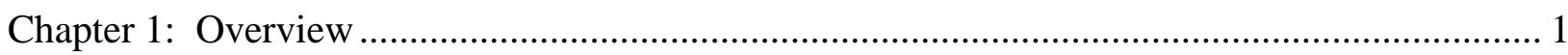

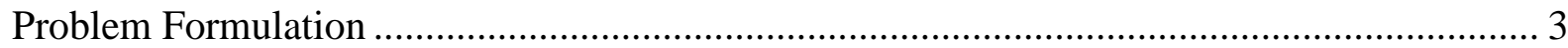

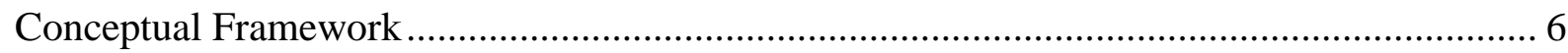

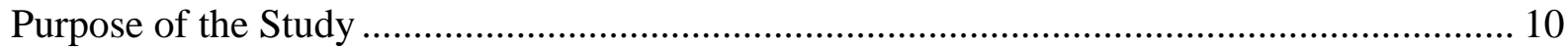

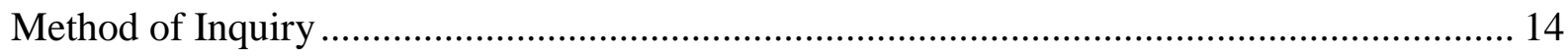

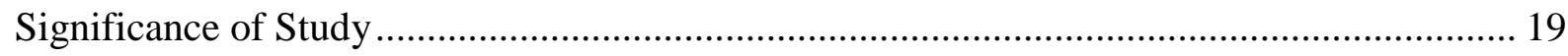

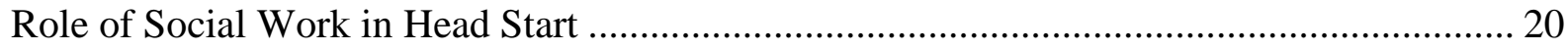

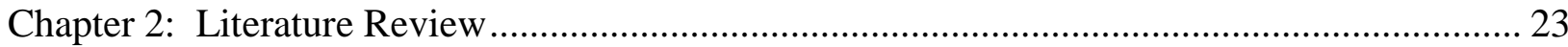

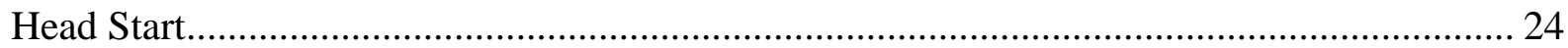

Head Start Services for Families......................................................................... 24

Head Start and Family Engagement. ..................................................................... 26

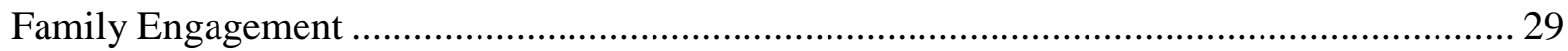

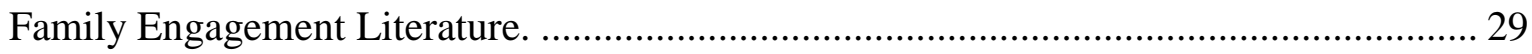

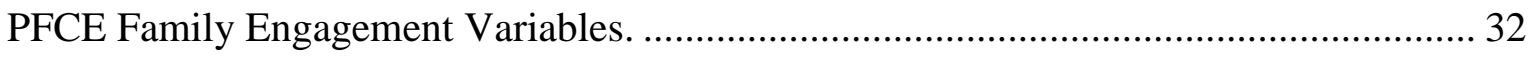




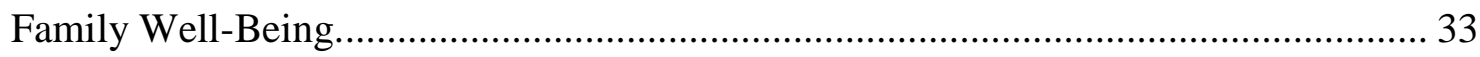

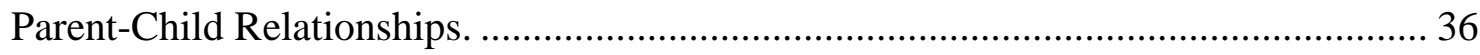

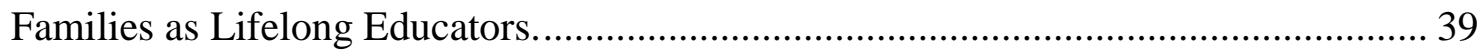

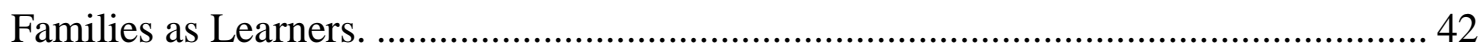

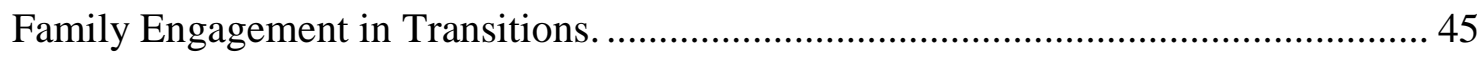

Family Connections to Peers and Community. ............................................................ 47

Families as Advocates and Leaders. .......................................................................... 50

Differences Found in Head Start Families in Rural and Urban Areas..................................... 52

Family Engagement with Rural and Urban Families......................................................... 56

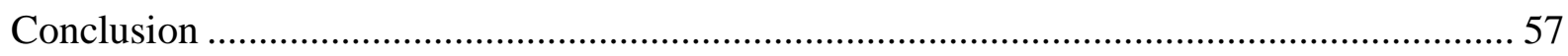

Chapter 3: Methods ............................................................................................................ 59

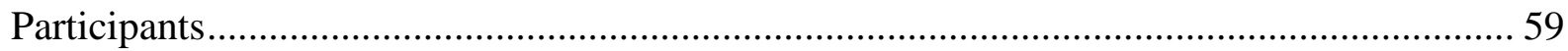

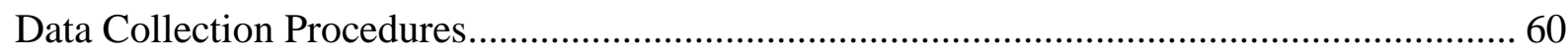

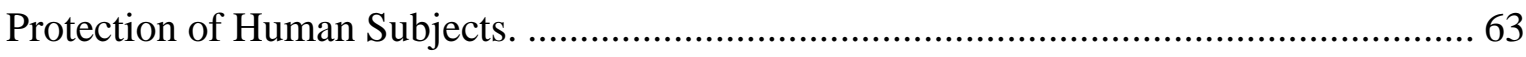

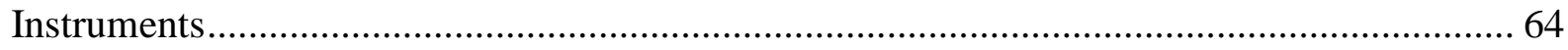

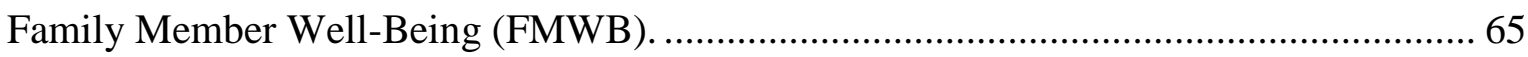

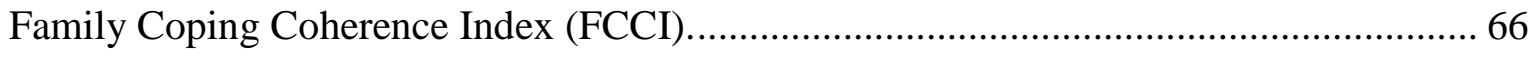

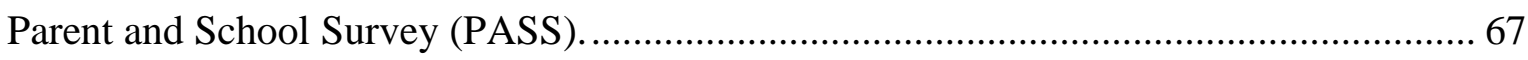

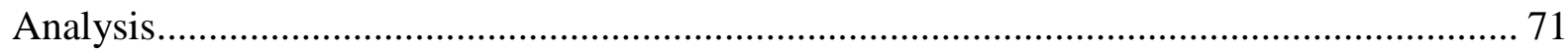

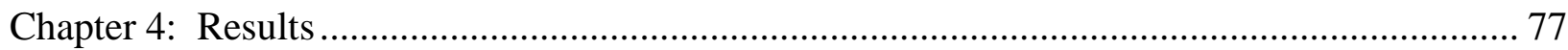




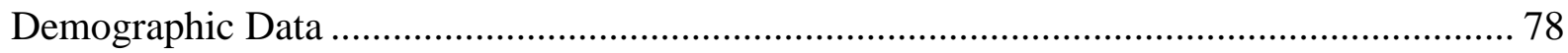

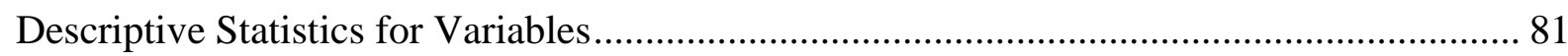

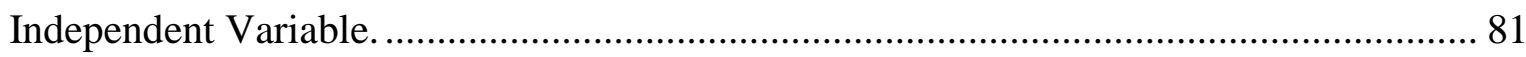

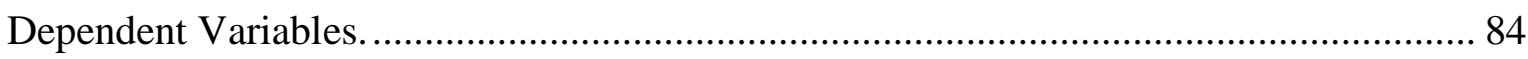

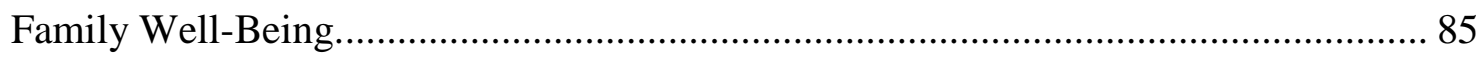

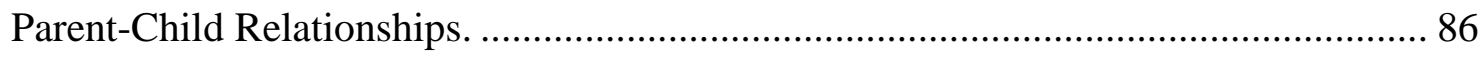

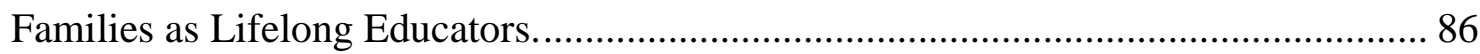

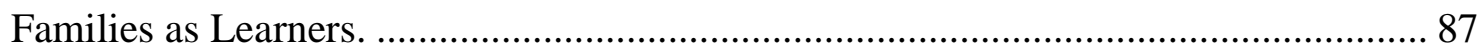



Family Connections to Peers and Community. .......................................................... 88

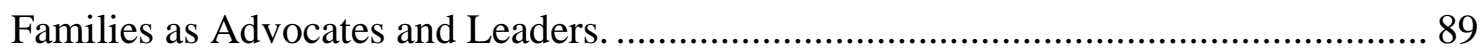

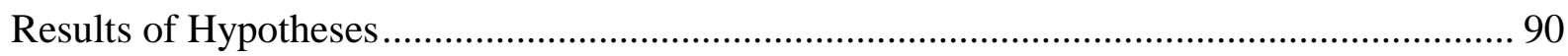

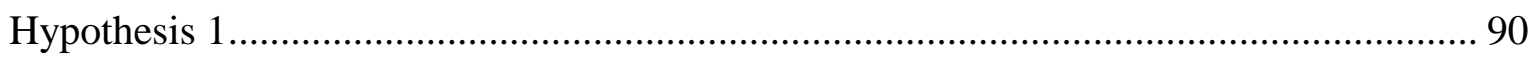

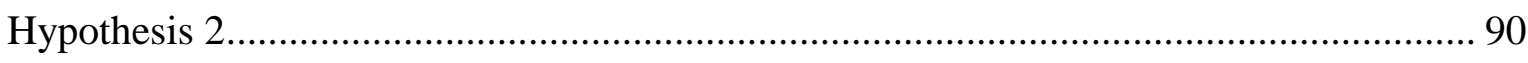

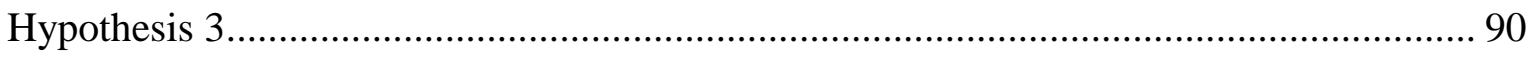

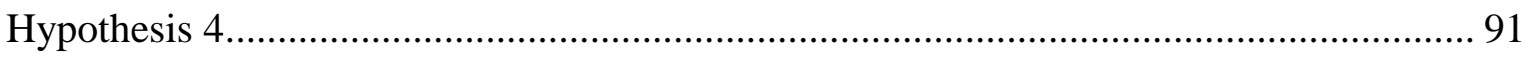

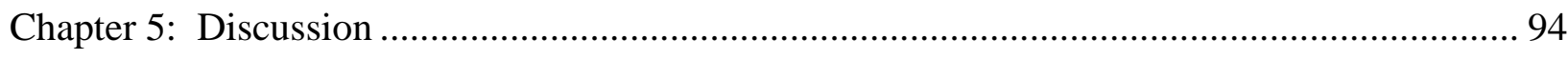

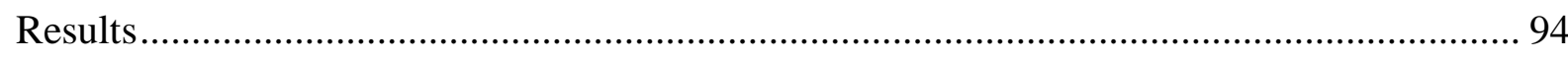

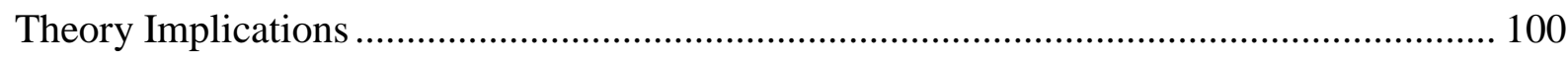

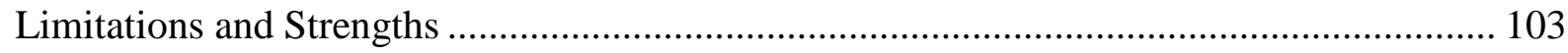




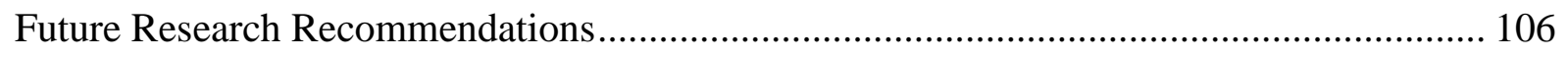

Practice and Policy Implications............................................................................ 109

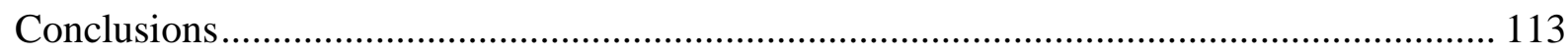

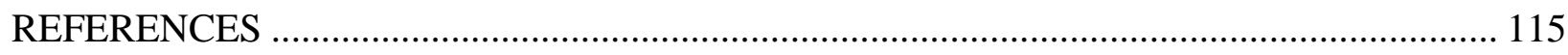

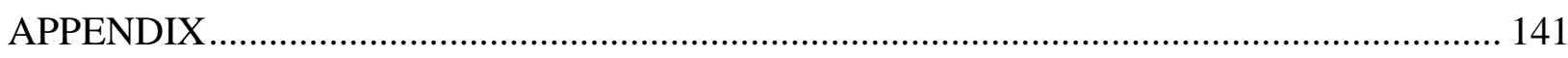

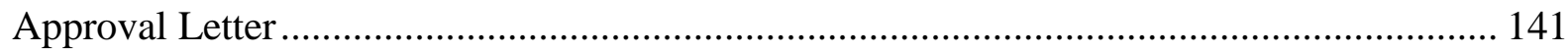

Email Notification to Head Start Sites ................................................................... 142

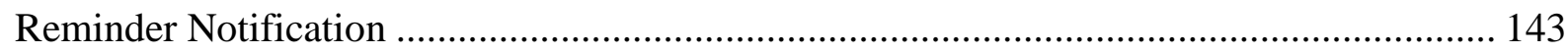

Consent to Participate in Research Study …........................................................... 144



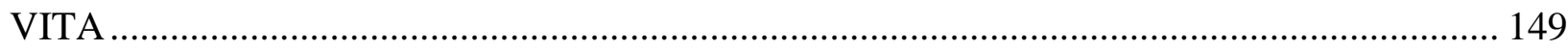




\section{LIST OF ILLUSTRATIONS}

Figure

Page

1. The Ecology of a Rural or Urban Head Start Child's Development.......... 9

2. Revised Framework for Programs Serving Infants and Toddlers............ 11

3. The Head Start Child Development and Early Learning Framework.......... 12

4. Parent, Family, and Community Engagement Framework................ 13

5. Mean Differences Between Rural and Urban Head Start Families............ 92 


\section{LIST OF TABLES}

Table

Page

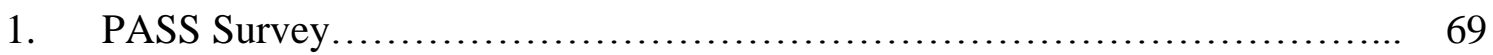

2. Survey Instruments and Hypotheses Used to Measure the Variables........... 71

3. Race Characteristics................................................ 79

4. Education Level.................................................... 80

5. Marital Status.......................................................... 81

6. Participants by Head Start Center Classroom............................ 83

7. Descriptive Statistics for Dependent Variables.......................... 84

8. Descriptive Statistics for Family Well-Being.......................... 85

9. Descriptive Statistics for Parent-Child Relationship..................................... 86

10. Descriptive Statistics for Families as Lifelong Educators................. 87

11. Descriptive Statistics for Family Engagement in Transition................ 88

12. Descriptive Statistics for Family Connections to Peers and Community........ 88

13. Descriptive Statistics for Families as Advocates and Leaders............... 89

14. Results of Hypotheses Testing.................................... 93 
ENGAGEMENT OF GEOGRAPHICALLY DIVERSE HEAD START FAMILIES

Amanda M. Keys

Dr. Colleen Galambos, Dissertation Supervisor

\begin{abstract}
This study examined the differences in family engagement in geographically diverse Head Start families using the new Parent, Family and Community Engagement (PFCE) Framework developed by the Office of Head Start. Participants included 419 urban and rural parents from the Midwest. All participants were surveyed using the Family Member Well-Being Index (FMWB), the Family Coping Coherence Index (FCCI), and the Parent and School Survey (PASS). There was one independent variable, geographic location, and seven dependent variables based upon the PFCE Framework's family engagement outcomes. Results indicated differences between two of the seven PFCE Framework's family engagement outcomes: families as lifelong educators and families as advocates and leaders. In addition, using the PASS instrument an overall difference in family engagement was found in rural and urban Head Start parents.
\end{abstract}




\section{Chapter 1: Overview}

Since 1965, the federal Head Start program has been woven into the fabric of poverty stricken families in the United States (Zigler \& Muenchow, 1992). This unique organization provides needed childcare services, educational opportunities, and community resources to the children and families it serves. Its mission is to promote leadership in students, families, and communities. Head Start's holistic approach of focusing on the child and the surrounding environmental system has been key in building family and community connections. In doing this, it has allowed the family to take ownership of its child's education and has empowered them to be an integral component in the child's ability to achieve lifelong academic success.

Head Start serves all children from 3 to 5 years of age in every state who meets the national poverty guidelines. This policy is based upon the number of people in a family and its household income. There are approximately one million children enrolled in Head Start and over 20 million children have been served by Head Start since its inception (U.S. Department of Health and Human Services, 2003). For generations, Head Start has supported income constrained families by providing educational services to pre-school aged children in communities nationwide. Head Start aims to provide quality school readiness educational opportunities and support to families as their children transition into public school systems (Washington, \& Oyemade-Bailey, 1995). They do this by recognizing the important connection of the family to the child's academic achievement. Since its origin, Head Start has found its niche as a key building block in developing healthy communities through its work with families. 
Head Start's philosophy highlights the parent partnership as a critical component to the achievement of their goals by recognizing a child's growth and development is dependent upon healthy, stable, and nurturing formative relationships (Zigler \& Muenchow, 1992). Head Start believes the parent and Head Start staff partnership is necessary in promoting current and future academic success as well as assisting in the child's overall school readiness (Office of Head Start National Center on Parent, Family and Community Engagement, 2011). To demonstrate their ideological commitment they have developed the Head Start Approach to School Readiness (US Department of Health and Human Services \& Administration for Children \& Families Office of Head Start [OHS], 2011). This approach includes three major frameworks to help encourage and develop an understanding for parents and families that promotes school readiness for children who attend Head Start programs (OHS, 2011).

Although Head Start has actively sought to keep parent and family involvement as a cornerstone of their program's curriculum, family engagement has undergone several transformations since its development (Scott, 2006). During this transformation, Head Start continues to recognize there are unique barriers in the family's role throughout the partnership. A noticeable impediment is how the neighborhood context impacts the Head Start classroom (Vaden-Kiernan et al., 2010). When specifically focusing on rural and urban neighborhoods, the availability of community resources impacts the process of family engagement to the Head Start program. Since all three Head Start frameworks emphasize family engagement as a critical component to a child's success, it is important to begin there when focusing on service delivery differences in rural and urban communities. Specifically, one of the three core Head Start frameworks focuses entirely 
on the importance of parent, family, and community engagement and will be the primary focus for this study ("The Head Start Parent", 2011). This framework will provide a foundation to explore differences found in family engagement in rural families compared to family engagement in urban families involved in the Head Start program.

\section{Problem Formulation}

Since its inception, over 1,000 research studies have been completed on the Head Start program (Kalifeh, Cohen-Vogel, \& Grass, 2011). Although spread throughout several decades, various studies have shrouded Head Start in controversy with findings that have indicated a lack of long term gains by children attending Head Start programs (Currie \& Thomas, 1995; McKay et al., 1985; The Westinghouse Learning Corporation and Ohio University, 1969). For pro-Head Start supporters, an argument to contradict these negative findings would be researchers have been remiss in the evaluation of one of the cornerstones in the Head Start program: family engagement. Throughout Head Start's history, family engagement provisions have been the foundation to Head Start. They have touted themselves as a unique program providing holistic services that extend to the child's family. These services involve ongoing shared responsibility between the family, school, and community from birth throughout the child's formal education and should take place wherever the child is learning (Weiss, Lopez, \& Rosenberg, 2011).

"While many national and state leaders agree that family engagement in children's early learning and development is critically important, there is increasing recognition that promoting this goal requires understanding of family context and supports for family well-being" (U.S. Department of Health and Human Services U.S. Department of Education, 2010, p. 49). By looking at ways to measure and improve how 
the family context impacts family engagement, a student's opportunity to be successful will be increased. Policy leaders and Head Start administrators support this belief through the development of new family engagement initiatives ("The Head Start Parent", 2011). In addition, new research has supported the role of family engagement by findings that state family engagement activities support children's overall educational attainment as well as increase their preparedness when entering formal education (Harvard Family Research Project [HFRP], 2006).

Research suggests that positive and trusting relationships between educators and parents helps to improve the success of the child in the school program (Bryk \& Schneider, 2003). In fact, a recent multi-disciplinary literature review of over 120 studies found improvements made in children's health and wellbeing, academic skills, social skills, and behavior when they were involved in programs that reinforced family-provider relational practices (Office of Planning Research and Evaluation [OPRE], 2011). This is consistent with Henderson and Mapp's (2002) synthesis of research studies finding that parent and community involvement benefits to students included: higher scores on standardized testing, better attendance, improved behavior at school and home, and better social and adaptive skills in the school setting.

In addition to gains made by the child whose family was actively engaged, current family involvement research has spent time focusing on characteristics of the parent that contributes to an increase in family engagement. These characteristics include: employment of parents, marital status, education level, income level, race and ethnicity differences, and positive social supports and attitudes of supports towards program goal achievement (Barnes, Guevara, Garcia, Levin, \& Connell, 1999; Castro, Bryant, Peisner- 
Feinberg, \& Skinner, 2004; Fantuzzo, Perry, \& Childs, 2006; McWayne, Campos, \& Owsianik, 2008). While family engagement research is making an effort to validate its importance, it has not translated as quickly into family engagement policy change.

In late 2010, in recognition of the need for further research and evaluation on family engagement, the Office of Head Start created The National Center on Parent, Family, and Community Engagement. Prior to this funding, local Head Start programs did not have the framework, nor the ability, to quantify markers of progress made towards family engagement. This has not been a unique concern to the Head Start program. Overall, "family engagement provisions in federal policies and programs have been piecemeal and insufficient. Efforts are often siloed within federal agencies and treated as simple to-do lists of activities to check off" (Weiss et al., 2011, p. 2).

There has been continued evidence to support the positive effects of family engagement (HFRP, 2006). Head Start has embraced this and has been pro-active in developing performance standards to call attention to the need for additional family engagement. However, the Head Start program faces multiple barriers when trying to increase the number of families involved in Head Start family engagement activities. One explanation for these continued barriers is the recognition that families are diverse and cannot be treated as if their all identical. Because of the unique characteristics found in each family, family engagement can be difficult for staff and volunteers trained to empower Head Start families towards the achievement of their personal goals. Additionally, there is limited knowledge of family characteristics associated with engagement that help to encourage or discourage parental involvement (Castro et al., 2004). 
Existing research has found barriers such as single parenthood, low education levels, minority status, and employment status as characteristics that may prevent productive family engagement (Fantuzzo et al., 2006). Present research has neglected a critical family characteristic in understanding engagement by minimizing the impact diversity in family environments has on family engagement levels. Two specific environmental variables are important in furthering family engagement: rural and urban families. Each environment creates challenges for families due to the lack of availability and diversity of resources as well as service providers. From its origin, the Head Start program has focused on the child's health, nutrition, education, social services, and parental involvement (Zigler \& Muenchow, 1992). However, it has failed to factor in a significant variable to address the needs of the physical environment. Presently, the American family looks and behaves vastly different based upon their geographical location. Research indicates there are specific variations between rural and urban families when focusing on economic, health, nutritional, educational, social and family variables (Bender, Fedor, \& Carlson, 2011; Canby, 2003; Durham \& Smith, 2006; Hulsey et al., 2011; O'Hare, Manning, Porter, \& Lyons, 2009; Thompson, 2005). This study recognizes these differences and serves to understand how these geographic locations impact family engagement levels.

\section{Conceptual Framework}

The theory used to develop this research was Urie Bronfenbrenner's ecological systems theory. Bronfenbrenner, who was an original member of the Head Start planning committee, "argued that there is a complex interrelationship among children, their families, and communities, so that an intervention must touch all of these areas to be 
effective" (Zigler \& Styfco, 1993, p. 4). Ecological systems theory is defined as "the scientific study of the progressive, mutual accommodation between an active, growing human being and the changing properties of the immediate settings in which the developing person lives, as this process is affected by relations between these settings, and by the larger contexts in which the settings are embedded" (Bronfenbrenner, 1979, p. 21).

This theory recognized the importance of moving past the Head Start child by examining how children are influenced by such things as their family, friends, educational system, neighborhood, and the broader society. Realizing the significance of the interplay among these settings is a key component in understanding family engagement. These interactional settings are referred to by Bronfenbrenner as the ecological environment. "The ecological environment is conceived topologically as a nested arrangement of concentric structures, each contained within the next. These structured are referred to as the micro-, meso-, exo-, and macrosystems" (Bronfenbrenner, 1979, p. 22).

"A microsystem is the complex of relations between the developing person and environment in an immediate setting containing that person" (Bronfenbrenner, 1977, p. 514). In applying this theory to Head Start children, examples of a microsystem would include children and their relationship to their immediate family, Head Start teachers, and peers. "The meso-system comprises the interrelations among the major settings containing the learner at a particular point in his or her life" (Bronfenbrenner, 1976, p. 5). For example, for a child attending Head Start the focus would be on the interaction among the child, family, and the local Head Start program. The third component of the 
ecological environment is the exo-system. "An exosystem refers to one or more settings that do not involve the developing person as an active participant, but in which events occur that affect, or are affected by, what happens in the setting containing the developing person" (Bronfenbrenner, 1979, p. 25). In applying this theory to Head Start children an example of a child's exosystem would be a Head Start child's neighborhood. For the purpose of this study, the exosystem will be used to describe whether the Head Start child lives in a rural or urban area. While Head Start children are not often aware of a neighborhood's direct impact on their lives, this setting often influences a child and family's behavior.

The final element of the Head Start child's ecological environment is the macrosystem. "A macrosystem refers to the overarching institutional patterns of the culture or subculture, such as the economic, social, educational, legal, and political systems, of which micro-, meso-, and exo-systems are the concrete manifestations" (Bronfenbrenner, 1977, p. 515). For the purpose of this study, the macrosystem will be used to describe how national Head Start policies effect family engagement in rural and urban communities and what impact they have on local Head Start centers and the children and families they serve.

Numerous researchers focusing on family engagement in Head Start have agreed with this theory's assertions and have identified ecological systems theory as a valuable framework for understanding family engagement in Head Start (Brinson, 2011; Fagan \& Iglesias, 1999). Presented in Figure 1 is an illustrative model of Bronfenbrenner's theory applied to a Head Start child that shows the significance of how relevant this theory is 
when seeking to focus on the child's environment, specifically a rural and urban child's environment, for the purpose of this study, when trying to engage the family.

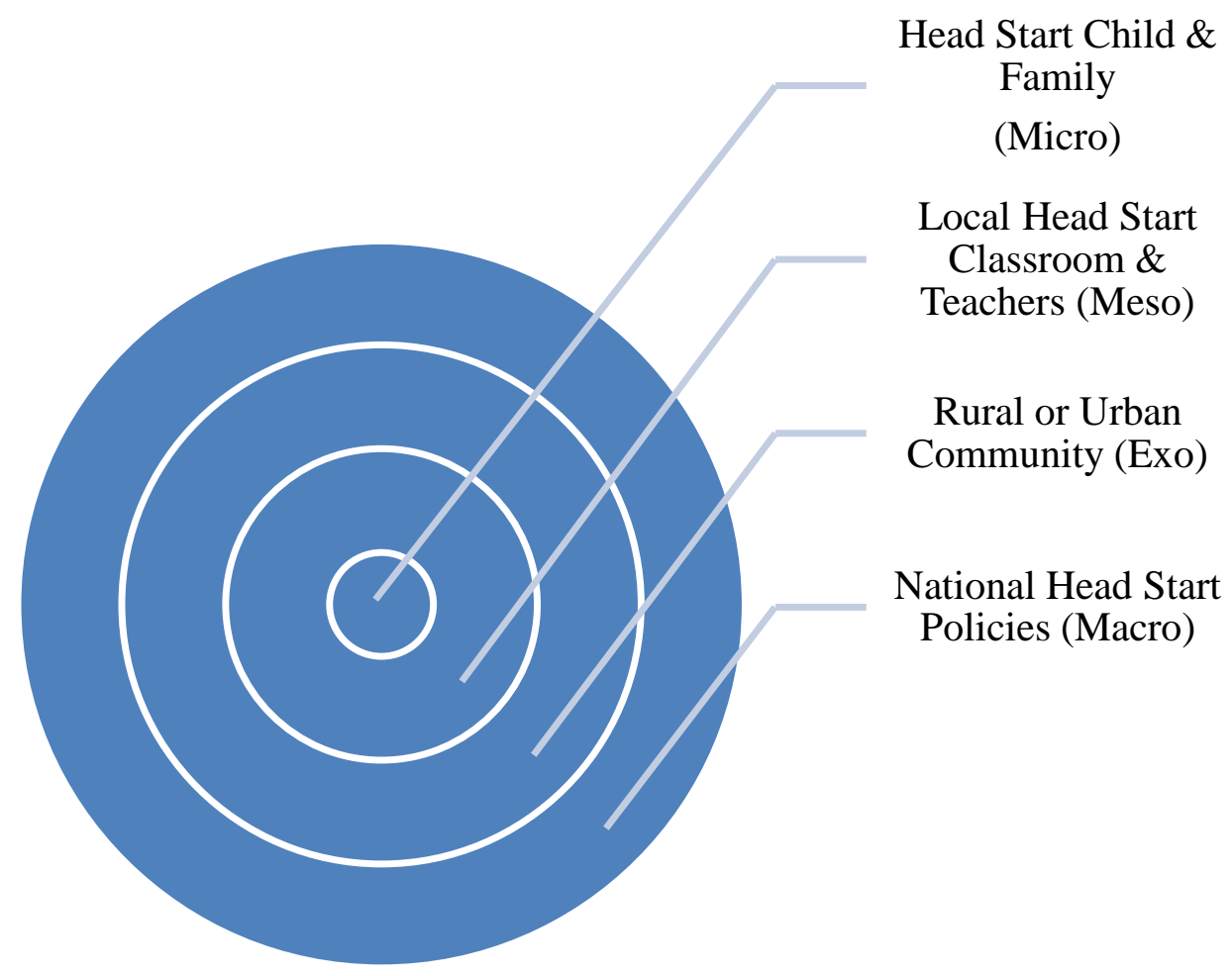

Figure 1. The ecology of a Rural or Urban Head Start Child's Development.

Using ecological systems theory, it is straightforward to see how demographic variables can impact the development of Head Start children, the interaction children have with their family, and the relationship among the family, the Head Start agency, and the community at large. To maximize family engagement it is important for Head Start to recognize "day care settings should not be cast in a single mold but reflect the particular characteristics of different regions and styles of life" (Brofenbrenner, 1971, p. 93). Bronfenbrenner's theory helps this study increase its understanding of family engagement by focusing on how the exo-system affects family engagement. 


\section{Purpose of the Study}

"The Head Start Approach to School Readiness means that children are ready for school, families are ready to support their children's learning, and schools are ready for children" (OHS, 2011, p. 1). The purpose of this research is to examine school readiness by providing an enriched understanding of how geographic locations are influencing family engagement outcomes using the new Head Start Parent, Family, Community Engagement (PFCE) Framework (“The Head Start Parent”, 2011). Historically, Head Start has recognized family engagement in children's learning as an essential component to a child's lifelong success. Presently, there are three frameworks used by Head Start to implement policy and procedures. All three frameworks emphasize family engagement. The first is the Revised Early Head Start Program Performance Measures Conceptual Framework. "This Conceptual Framework provides a guide for programs to develop and implement supports for the healthy growth and development of expectant families babies, and toddlers" (OHS, 2011, p. 4). In this framework one of the four foundations is the family. In focusing on the family, the goal of this framework is to engage the family by developing strong relationships with the parents. By doing this, Head Start's overall purpose is to support the parent-child relationship to enhance the child's overall wellbeing and competence. Below is the conceptual model of this framework. 


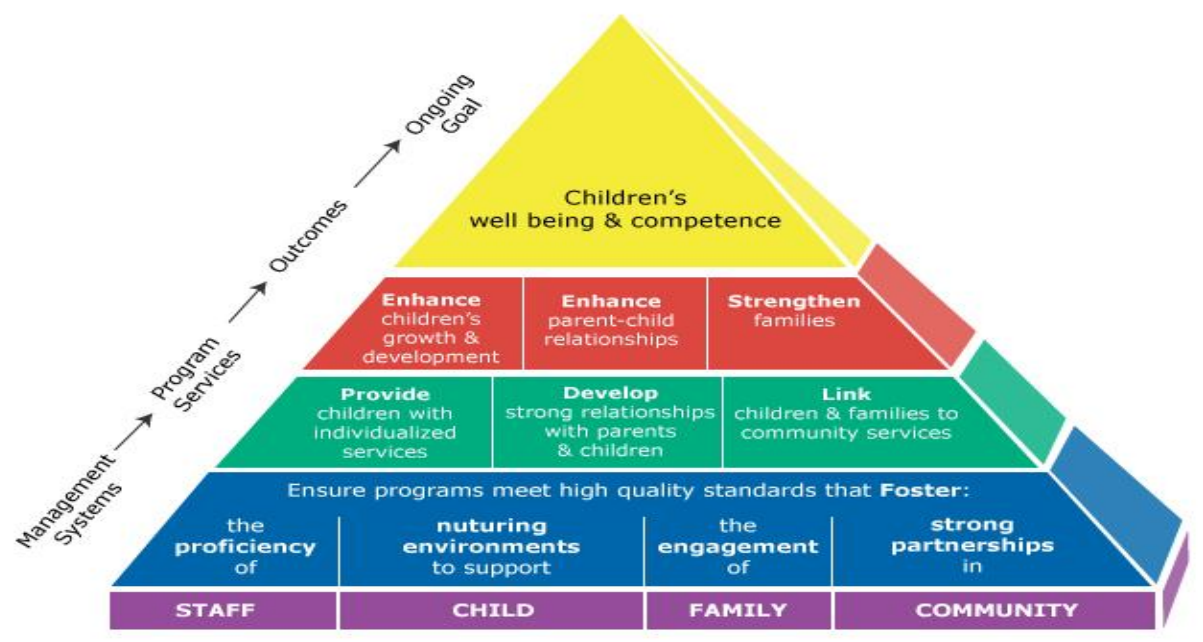

Figure 2. Revised Framework for Programs Serving Infants and Toddlers and Their Families. Retrieved from Head Start Approach to School Readiness. (2011). Retrieved from http://eclkc.ohs.acf.hhs.gov/hslc/sr/approach/pdf/OHSApproach-to-SchoolReadiness_complete.pdf

The second framework used by Head Start is known as The Head Start Child Development and Early Learning Framework. This "Framework represents the foundation of the Head Start Approach to School Readiness. It aligns with and builds from the five essential domains of school readiness. . . and lays out essential areas of learning and development" (OHS, 2011, p. 8). One of the domains in this framework is social studies knowledge and skills that incorporates family, community, people, and the environment as a domain element. The development and implementation of this framework continued to show the importance Head Start has had on family engagement. Below is the graphic representation of this framework. 


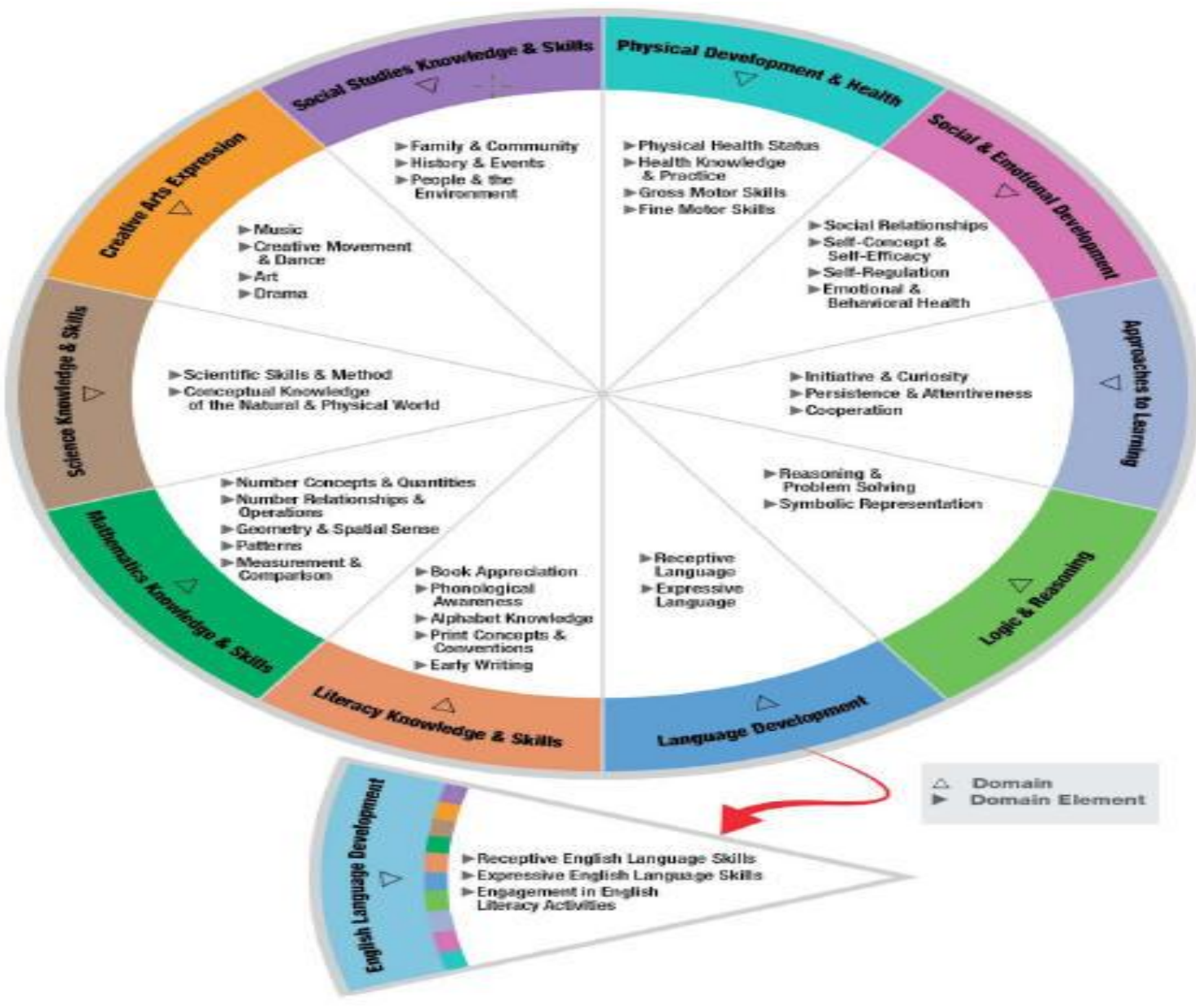

Figure 3. The Head Start Child Development and Early Learning Framework (2011). Retrieved from http://eclkc.ohs.acf.hhs.gov/hslc/sr/approach/pdf/OHSApproach-toSchool-Readiness_complete.pdf

The support for family engagement in Head Start was reconfirmed in 2011 when Head Start took these frameworks one step further by adding a third framework. The purpose of this framework was to solely focus on the importance of family engagement to the Head Start program and the community at large. They did this with the introduction of the Head Start Parent, Family and Community Engagement (PFCE) Framework. The framework provides Head Start sites with an organizational guide for implementing performance standards designed to improve and promote parent-child relationships, family well-being, and the cognitive development of preschoolers. "The Parent, Family 
and Community Engagement (PFCE) Framework is a road map for progress in achieving the kinds of outcomes that lead to positive and enduring change for children and families" ("The Head Start Parent", 2011, p. 1).

The PFCE Framework identifies seven family engagement outcomes that they believe are important for school readiness and sustained development through the first four years of elementary. These include: family well-being, parent-child relationships, families as lifelong educators, families as learners, family engagement in transitions, family connections to peers and communities, and families as advocates and leaders ("The Head Start Parent", 2011). The PFCE framework is presented in Figure 4.

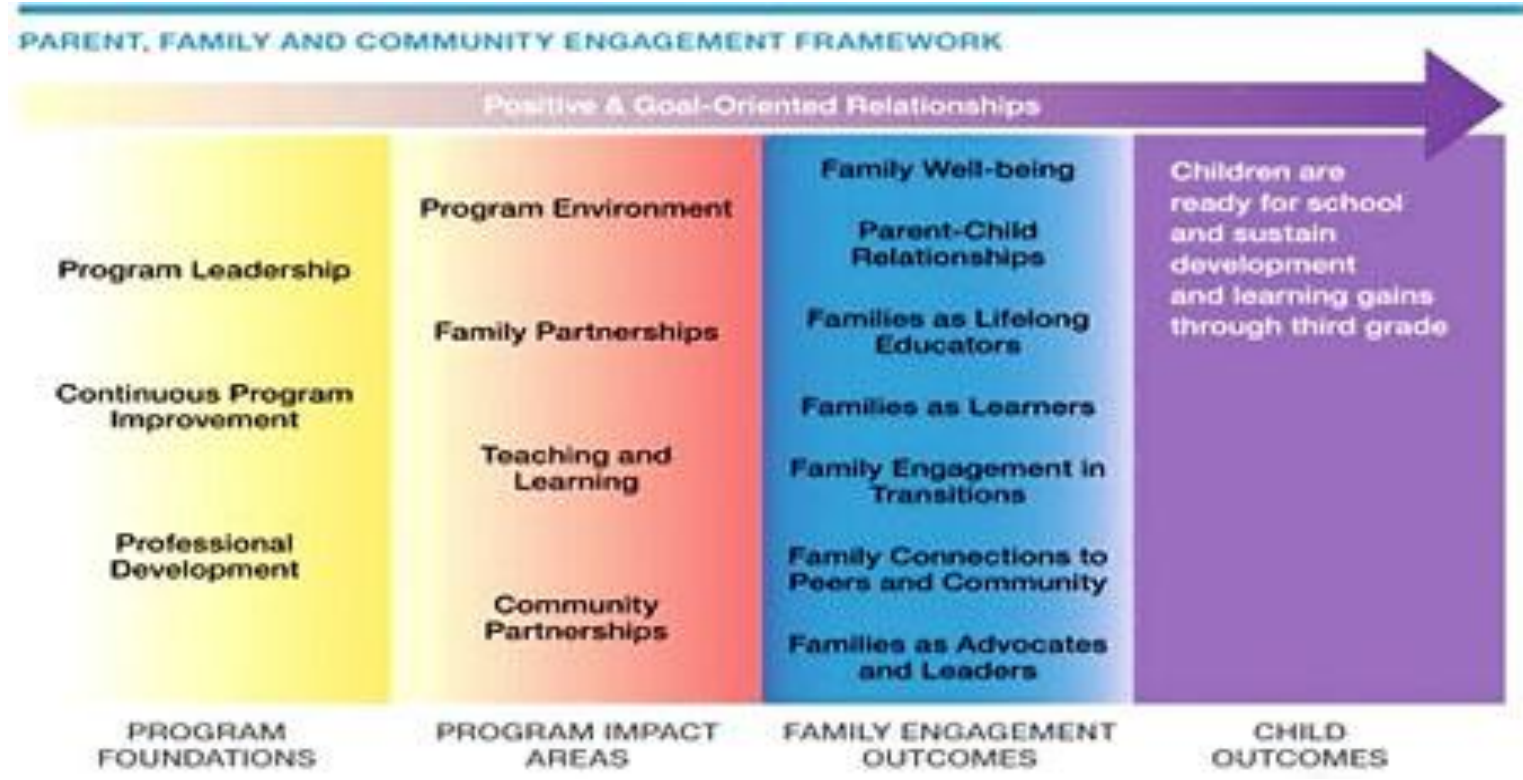

Figure 4. Parent, Family, and Community Engagement Framework. Retrieved from The Head Start parent, family, and community engagement framework: Promoting family engagement and school readiness, from prenatal to age 8. (2011). Retrieved from http://www.acf.hhs.gov/programs/ohs/policy/im2011/pfce-framework.pdf

This new framework allows researchers the opportunity to tangibly understand the theories and ideas that have been common in the daily activities and practices done in Head Start centers by introducing specific measurement markers used for systematic 
evaluation. While this is a positive step in the right direction in understanding how Head Start can make progress towards increased family engagement, there is still more work to be done. Although this framework provides a model, it does not give Head Start providers an individual assessment and understanding for specific children, families, and communities to be successful. The purpose of this research is to do this by moving Head Start family engagement beyond parental sign-in sheets that confirm family engagement through attendance, to an enriched understanding of geographic locations as a characteristic that effects purposeful family engagement when using the seven PFCE family engagement outcomes as a guide. In doing this, a greater understanding of the significant role environmental factors play in influencing a child's school achievement will be gained. This study will begin this process by providing research that offers technical support to Head Start programs that shows what effect geographic locations, specifically rural and urban areas, have on family engagement outcomes. With this understanding, Head Start will be better equipped to adapt policies and practices to meet the specific needs of the community to enhance family engagement of its members.

\section{Method of Inquiry}

To collect information on rural and urban Head Start families to create a better understanding of family engagement data were obtained through a survey. This survey was provided to all Head Start families in the southwest region of Missouri. For the purpose of this study, the entity analyzed included all households with one or more children who were currently receiving Ozarks Area Community Action Corporation Head Start services. "OACAC Head Start is a program of Ozarks Area Community Action Corporation (OACAC), a community action agency dedicated to serving low income 
families and individuals with a range of services. OACAC serves ten counties spread over almost six thousand square miles in the southernmost tier of Missouri" (ShinnBrown \& Bauer, 2009, p. 2). There are 35 Head Start centers in ten counties. The populations of these ten counties range from 7,523 people in the smallest county to 263,980 in the largest county (Shinn-Brown \& Bauer, 2009). Each household will be distinguished based upon two geographical units defined as families living in rural areas or urban areas in southwest Missouri. This sample was chosen because of the uniqueness offered from collecting data in southwest Missouri in both rural and urban areas. Unlike other areas in Missouri, the population of southwest Missouri is predominately white (91.8\% or greater) in both rural and urban areas (U.S. Department of Commerce United States Census Bureau [U.S. Census Bureau], 2013). By using rural and urban locations that have similar characteristics in their demographic information, the study will have more significance if findings indicate differences in rural and urban family engagement. This is because these findings would be less likely to be contributed to other things, such as race and ethnicity, that are found to effect family engagement as well (McWayne et al., 2008).

An exploratory research design will be used called cross-sectional survey design. Because the Head Start Parent, Family and Community Engagement Framework is new this researcher felt it was important to begin with an exploratory study. The purpose of an exploratory study "is to build a foundation of general ideas and tentative theories, which can be explored later with more precise and hence more complex designs, and their corresponding data-gathering techniques" (Williams, Unrau, \& Grinnell, 1998, p. 
130). The data will be collected by distributing a survey using purposive non-probability sampling of two groups of Head Start families: rural and urban.

In this study, there will be one independent variable: geographic location. This independent variable will have two categories: rural and urban families whose children attend Head Start. A specific definition designed for this study will be used in determining these two categories based upon the 2010 Census Bureau's urban-rural classification system. According to this definition:

To qualify as an urban area, the territory identified according to criteria must encompass at least 2,500 people, at least 1,500 of which reside outside institutional group quarters. . "Rural" encompasses all population, housing, and territory not included within an urban area (http://www.census.gov/geo/www/ua/2010urbanruralclass.html).

These definitions will be used to compare differences between rural and urban areas when looking at family engagement.

For this study, family engagement will be defined using the outcomes provided by the PFCE Framework. This framework identifies seven family engagement outcomes. These include: family well-being, parent-child relationships, families as lifelong educators, families as learners, family engagement in transitions, family connections to peers and community, and families as advocates and leaders ("The Head Start Parent", 2011). The following were definitions provided by the Head Start PFCE Framework (2011) for each outcome used to define family engagement:

1. Family Well-Being- Parents and families are safe, healthy, and have increased financial security. 
2. Positive Parent-Child Relationships- Beginning with transitions to parenthood, parents and families develop warm relationships that nurture their child's learning and development.

3. Families as Lifelong Educators- Parents and families observe, guide, promote, and participate in everyday learning of their children at home, school, and in their communities.

4. Families as Learners- Parents and families advance their own learning interests through education, training and other experiences that support their parenting, careers, and life goals.

5. Family Engagement in Transitions-Parents and families support and advocate for their child's learning and development as they transition to new learning environments, including EHS to HS, EHS/HS to other early learning environments, and HS to kindergarten through elementary school.

6. Family Connections to Peers and Communities-Parents and families form connections with peers and mentors in formal or informal social networks that are supportive and/or educational that enhance the social well-being and community life.

7. Families as Advocates and Leaders- Parents and families participate in leadership development, decision making, program policy development, or in community and state organizing activities to improve children's development and learning experiences. ("The Head Start Parent", 2011, p. 5)

To measure the aforementioned family engagement outcomes seven dependent variables will be used. The first dependent variable, overall family-well being, will be 
measured by eight questions focusing on a family member's overall emotional, social, interactional, and physical well-being during the past month (McCubbin \& Patterson, 1983). The second dependent variable, parent-child relationships, will be measured by 4 items on a 30 item instrument that focuses on six dimensions of family involvement (Ringenberg, Funk, Mullen, Wilford, \& Kramer, 2005). The third dependent variable, families as lifelong educators, will be measured by 8 items on a 30 item family involvement instrument (Ringenberg et al., 2005). The fourth dependent variable, families as lifelong learners, will be measured using a question provided by the demographic information obtained in the survey. The fifth dependent variable, family engagement in transitions, will be evaluated by asking four questions related to how families cope during life changes (McCubbin, Larsen, \& Olson, 1982). The sixth variable, family connections to peers and communities, will be measured by 4 items on a 30 item instrument that focuses on six dimensions of family involvement (Ringenberg et al., 2005). The final dependent variable, families as advocates and leaders, will be measured by 8 items on a 30 item parental involvement instrument (Ringenberg et al., 2005).

To explore these variables this research will focus on what, if any differences, in family engagement can be found in rural and urban areas. To do this a survey was designed to answer the following research question: Do Head Start families from rural areas or urban areas have different family engagement outcomes based upon the PFCE framework?

Hypothesis 1: Urban Head Start families will rate themselves higher than rural families on their level of educational attainment. 
Hypothesis 2: Urban Head Start families will rate themselves higher than rural families on their perceived overall emotional, social, and physical well-being.

Hypothesis 3: Rural Head Start families will identify more problems or difficulties when facing transitions than urban Head Start families.

Hypothesis 4: Urban Head Start families will exhibit higher levels of perceived family engagement by scoring themselves higher overall on the parental involvement survey and each of the four individual PFCE family engagement outcomes the survey measures: parent-child relationships, families as lifelong educators, family connection to peers and community, and families as advocates.

\section{Significance of Study}

When Head Start children enter the public school system for the first time it is important for them to have the skills and knowledge base needed to be as successful as their non-Head Start counterparts. To obtain this, research indicates the need to encourage family engagement as a way to effectively encourage a child's learning and socio-emotional development (HFRP, 2006). Embracing this idea, Head Start has made strides in their policy and curriculum development by recognizing the instrumental role families play in making this happen. Although family engagement has been a cornerstone in the Head Start program, in 2011 Head Start implemented the PFCE Framework as a tool and a measurement to guide the family engagement process. Head Start administrators believe "the Parent, Family and Community Engagement (PFCE) Framework is a road map for progress in achieving the kinds of outcomes that lead to positive and enduring change for children and families" ("The Head Start Parent", 2011, p. 1). 
This framework has been a significant step in the right direction to provide researchers and administrators the tools needed to identify and measure family engagement activities. However, more information is necessary to understand the role individual family characteristics have on the family engagement process. Previous research has neglected family characteristics as a critical consideration in working towards overcoming barriers and creating partnerships with families. This is because there is a continued lack of understanding on differences found in individuals based upon diversity in their family backgrounds, cultures, and communities and how these characteristics impact family engagement (U.S. Department of Health and Human Services U.S. Department of Education, 2010). Two specific environmental variables are important in furthering family engagement: rural and urban families. Each geographic location creates new challenges for families due to the availability and diversity of resources and service providers.

With continued budget shortfalls caused by several years of economic recession and a program that has been shrouded in controversy from its inception due to negative publicity brought out by unfavorable research findings it is the belief of this researcher it is imperative to provide the Head Start program with specific environmental characteristics that can enhance or impede their work towards family engagement. In looking at how geographic locations impact family engagement, Head Start will be better equipped to meet the needs of the children, families, communities, and nation it serves.

\section{Role of Social Work in Head Start}

"The primary mission of the social work profession is to enhance human wellbeing and help meet the basic human needs of all people, with particular attention to 
the needs and empowerment of people who are vulnerable, oppressed, and living in poverty" (National Association of Social Workers [NASW], 2008, para. 1). Using this mission as a foundation for social work practice, it is easy to see how social work and Head Start should fit together with their parallel focus on a vulnerable population: preschool children living in poverty. Since the development of Head Start, social workers have been an absent voice in the support, maintenance, and growth of the program (Frankel, 1997).

However, if Head Start is committed to strengthening a core component of their framework, family engagement, now more than ever, it is critical for the social work community to align around early childhood educators. This is because social workers provide a unique field of experience, knowledge, and research on how to best engage families. This is clearly seen when looking at the role of a generalist social work practitioner. One of the key elements in their work with the family, also known as the planned change process, is engagement. Using this knowledge, social workers can help Head Start professionals recognize family needs, identify family barriers, and advocate for changes that are core components in social work training. Additionally, given the social work professions "understanding of the interconnectedness of children with their families and the systems that contain them, social workers can and should play leadership roles in advocating for polices that adequately address a diverse array of needs of young children, their families, and their caregivers" (Azzi-Lessing, 2010, p. 260). To empower change and provide the best resources and services to the vastly evolving Head Start family, social workers must consider joining with preschool professionals as they serve to 
create new ways to engage families for the betterment of the micro, mezzo, and macro systems surrounding the child. 


\section{Chapter 2: Literature Review}

This chapter focuses on the review of the literature from three main subject areas identified in this research study related to family engagement. These three topics provide the support for this research and will offer a detailed discussion of each area. The first section focuses on Head Start and their role in family engagement. This section will begin by providing a brief overview on Head Start and the current services Head Start programs provide to families whose children are enrolled in Head Start. The next part of this section will provide an overview of Head Start's role in family engagement.

The second section focuses on family engagement literature by providing an overview of current family engagement research. In addition, a detailed synopsis of previous research on family engagement using the seven PFCE outcomes will be discussed. These outcomes include: family well-being, parent-child relationships, families as lifelong educators, families as learners, family engagement in transitions, family connections to peers and community, and families as advocates and leaders.

The final section looks at the differences between geographic locations and family engagement. With regard to the last topic listed, since family engagement of geographic locations is the primary focus of this research study, it is important to note there is limited findings and implications for Head Start researchers on this topic. The body of knowledge known about rural and urban families and their engagement in Head Start is a new area of study. Therefore, the purpose of this literature review is to examine this limited body of knowledge in relationship to Head Start and family engagement to show the importance in developing a connection between how geographic locations impact family engagement in Head Start programs. 


\section{Head Start}

Head Start services for families. The Head Start program is the United States largest federally funded provider of early educational services developed to transform the lives of one of the most vulnerable populations in our society-America's children. Head Start was established in 1964 when President Lyndon B. Johnson declared a war to eliminate poverty by encouraging the passage of the Economic Opportunity Act (http://www.acf.hhs.gov/programs/ohs/about/history-of-head-start). The goal of this program became to provide a "head start" for children living in poverty to catch up to their middle-class peers. Over forty years later, it has continued to remain true to its mission as "a national program that promotes school readiness by enhancing the social and cognitive development of children through the provision of educational, health, nutritional, social and other services to enrolled children and families" (http://www.acf.hhs.gov/programs/ohs/).

To meet its mission, Head Start has been proactive in recognizing the children they serve come from diverse populations of low-income families. Data provided by the Head Start Family and Child Experiences Survey (FACES) in 2009 revealed over half of all newly entering children were from single-parent homes. More than three-quarters of Head Start parents worked full-time, the average income for non-white Head Start children was less than their white counterparts, and the median annual income for Head Start families was $\$ 22,714$ (Hulsey et al., 2011). To support the unique needs of each family system, Head Start has recognized that engaging families through parental involvement must be an "ongoing process, and how parents choose to become involved may vary from individual to individual. . . Some involvement is formal and occurs in 
planned activities or programs such as Head Start, while other involvement is informal and occurs in the home (http://www.acf.hhs.gov/programs/ohs/).

In recognition of the individuality of each family, Head Start offers four primary avenues for families to engage in the program.

First, parents join in making decisions about what kind of program to have and how it will operate. Second, parents participate in the classroom as paid employees, volunteers, and observers. Third, parents participate in adult activities which they have planned. Fourth, parents, as prime educators, work with their own children, with the support of the Head Start staff. (http://www.bmcc.org/Headstart/Involving//chapter1.html)

An example of parental participation can be seen in data collected in 2008-2009 that found " 26 percent of Head Start program staff members were parents of current or former Head Start children. More than 850,000 parents volunteered in their local Head Start program" (U.S. Department of Health and Human Services, Administration for Children \& Families, Office of Head Start, 2010, para. 2). In addition to the work parents have done within the Head Start center, there have also been allowances made by the Head Start program to meet the individual needs of each parent. These services have included job training, assistance in obtaining a GED (General Equivalency Diploma), and literacy skills to strengthen parents as the primary nurtures for their children (U.S. Department of Health and Human Services, Administration for Children and Families, 2006). Overall, parents participating in Head Start services maintain a high level of satisfaction with the services provided by Head Start (Barnes, Guevara, Garcia, Levin, \& Connell, 1999). 
Head Start and family engagement. Ongoing parental participation is a key to family engagement. Head Start has recognized this and created a set of performance standards regarding parental involvement in their program. Standard 1304.40 was established to discuss family partnerships in Head Start. This standard states parental involvement includes developing mutual trust to obtain active participation from parents in program policy-making and operations, finding educational activities that are responsive to the ongoing needs of the parents, and identifying family goals, strengths, and necessary services and supports and timetables and strategies for achieving these goals (Head Start Performance Standard, 1304.40, (2012). In addition to the Head Start Performance Standards there are three frameworks used to guide policy and procedures in Head Start programs. All three frameworks value family engagement as a core component in school readiness. These frameworks include: the Revised Early Head Start program Performance Measures Conceptual Framework, The Head Start Child Development and Early Learning Framework, and the Parent, Family, Community, Engagement Framework (OHS, 2011). The expected outcome of family engagement for children and families is to strengthen parents as the primary nurturers of their children, support and enhance parent-child relationships, and enhance children's growth and development (USD HHS \& ACF, 2006).

Head Start defines family engagement as "building relationships with families that support family well-being, strong relationships between parents and their children, and ongoing learning and development for both parents and children" (Office of Head Start National Center on Parent, Family and Community Engagement, 2011, p. 1). The term family engagement has recently been used to refocus the term parental involvement 
in research and policy. This is "in recognition that grandparents and other family members may also be responsible for the care and upbringing of children" (Redding, Murphy, \& Sheley, 2011, p. 6). Additionally, the term family engagement evokes an idea of a deeper commitment to understanding families and what they feel is important. This knowledge helps to create more family-centered goal development that motivates the families towards long term achievement not just completion of short term agency goals. Although we recognize the slight difference in terminology, for the purpose of this section we will use the terms family engagement and parental involvement interchangeably.

Presently, Joyce Epstein's work on parental involvement has been cited as a major influence in Head Start policies and practices (Zeak, 2006). Epstein identified six types of parental involvement effective in connecting families, schools, and communities (Epstein, 1995). These include: parenting, communicating, volunteering, learning at home, joint decision making, and collaborating with the community. She describes a good program as one that includes a "recognition of the overlapping spheres of influence on student development; attention to various types of involvement that promote a variety of opportunities for schools, families, and communities to work together; and an Action Team for School, Family, and Community Partnerships to coordinate each school's work and progress" (Epstein, 1995, p. 704). These six steps are reflected in the new Head Start PFCE Framework whose program impact areas include: program environment, family partnerships, teaching and learning, and community partnerships. Each program outcome is designed "to work in partnership with parents, families, and the community on 
activities that promote family engagement and work toward family goals" (Office of Head Start National Center on Parent, Family and Community Engagement, 2011, p. 3).

To develop effective parental involvement it is important to recognize potential barriers. Current research has identified several barriers in successful family engagement. The NCJR Center for the Child asked 68 Head Start mothers to be interviewed using the Barriers to Parental Involvement Survey (Lamb-Parker et al., 2001). Results revealed depression, health problems, work, school, scheduling conflicts, housing difficulties, and family responsibilities as possible barriers in parental involvement (Lamb-Parker et al., 2001). Lamb and colleagues recommended further research be done on parents regarding their life events and barriers to parental involvement to understand the unique challenges Head Start parents face.

Barnes and colleagues (1999) collected information for the Family and Child Experiences Survey (FACES) conducted for the U.S. Department of Health and Human Services, Administration on Children, Youth, and Families on Head Start staff in approximately 180 Head Start locations. They found four family characteristics that were barriers to parental involvement. First, children who were enrolled in Head Start services for a shorter period of time were less likely to have parents engaged in the Head Start program. Second, parents with lower educational levels were less likely to be engaged. Third, unemployed parents reported higher levels of engagement than employed parents. Fourth, black and Hispanic families were less engaged than their white counterparts. These findings were consistent with Castro and colleagues (2004) who found parental employment as a barrier in family engagement. Parents who were unemployed were more likely to be involved in their children's education than parents who were employed. 
Overall, they found "parents' reports of their involvement with Head Start were negatively associated with their reports about barriers to involvement, so that those who reported fewer barriers were more involved" (Castro et al., 2004, p. 422). For the purpose of this study, it is important to continue research on family characteristics that serve as barriers in successful family engagement. Using community characteristics in determining barriers is another step in understanding the affect the exo-system has on successful family engagement.

\section{Family Engagement}

Family engagement literature. Head Start has been a pioneer in recognizing family engagement as a key component in a child's educational outcomes. Researchers over the past several decades have used family engagement as a topic for numerous research studies. Presently, there are hundreds of published books, peer- reviewed journal articles, and technical reports on the subject of family engagement in a child's education (Cotton \& Wikelund, 1989). One notable and significant time period for the evolution of parental involvement research took place in the 1980's. Research during this time period began to focus on how the home environment, instead of the school environment, impacted a child's educational achievement (Ascher, 1988). A report funded by the U.S. Department of Education supported this paradigm shift through findings that stated "the research overwhelmingly demonstrates that parent involvement in children's learning is positively related to achievement. Further, the research shows that the more intensively parents are involved in their children's learning, the more beneficial are the achievement effects" (Cotton \& Wikelund, 1989, p. 2). 
Since the 1980 's, family engagement research has continued to support these findings. In 2011, the National Policy Forum for Family, School, \& Community Engagement published a report stating for the U.S. Department of Education to be effective they must "recognize family and community engagement as an essential ingredient of student success and meaningful education reform" (Weiss et al., 2011, p. 2). However, an essential ingredient often missing in developing family and community engagement to support a child's educational attainment is the impact family diversity variables have on these outcomes. One way to recognize these family diversity variables is by focusing on the individuality of family engagement techniques.

The range of strategies to increase family engagement techniques is one area in family engagement literature that builds upon the importance of expanding research focusing on specific family characteristics that might influence engagement outcomes. The need for individualized family engagement activities can be found in several previous studies. A longitudinal quantitative study by Driessen, Smit, and Sleegers (2005) focusing on parental involvement collected data from a questionnaire provided to students, parents, and school district employees of over 500 schools and 12,000 schoolaged children. The goal of the research was to learn more about the school, child, and parent to determine which characteristics correlated with parental involvement. Although they found few significant correlations, researchers did find there were family characteristics that influenced parental involvement, specifically when looking at ethnic minority students compared to their white counterparts. Schools serving predominately ethnic minority children felt parental involvement was more important and devoted more effort in engaging parents. Findings from this study indicated the importance of looking 
individually at schools to determine the most appropriate techniques for engaging families.

In the same year, Hong and Ho (2005) published findings from a longitudinal quantitative study randomly selecting 6,000 students, teachers, and parents from a national educational study conducted by the U.S. Department of Education. The data collected information from a questionnaire focusing on parental involvement and student characteristics. The goal of this research was to explore what affect the family characteristics of race and ethnicity had on parental involvement that contributed to student achievement. Findings from this study indicated there were significant ethnic differences when looking at parental involvement. Results from this research supported the need for more research on family characteristics and their effect on engagement by highlighting the differential influences family characteristics can have on a child's academic success measured by levels of parental involvement.

To develop individuality in family engagement strategies it is important to have teachers who understand family engagement in the context of their community. One way to accomplish this goal is by focusing on the role of the educator. Prior to engaging families, it is important for teachers to have a solid understanding of how to effectively engage families. Findings from a qualitative study completed on 28 early childhood practitioners over a 2 year period found professional development training was integral in helping educators feel confident in their family engagement role (Brown, Knoche, Edwards, \& Sheridan, 2009). Concurrently, the more training obtained by early childhood educators on family engagement the more likely they will be to feel comfortable in spending time engaging families. 
In addition to training, there are certain characteristics teachers must demonstrate to encourage family engagement. This idea was supported by a study of two hundred eighty-eight families whose children attended an early childhood program (Mendez, 2010). Results from this study confirmed the study's hypothesis that was teachers were more apt to feel connected to families when they interact more frequently with them. The previous two studies echoed Lawson's (2003) qualitative study using semi-structured interviews to address teachers' and parents' perceptions of parental involvement. He found teachers and parents must develop partnerships and the ability to collaborate to effectively provide their children an environment conducive to school success. In the same year, another qualitative study interviewing 18 parents on why and how they were involved in their child's education was published (Mapp, 2003). In the interviews, parents disclosed they were more likely to connect to the school community when their children's teachers used welcoming practices to help engage them as well as promoted activities that honored their contribution to their children's classrooms learning and achievement. The aforementioned research supports the idea of the need to focus on the specific needs of families and educators to help facilitate an individualized, familyfocused, understanding of family engagement in the school setting. The current research study does this by expanding the understanding of environmental characteristics that may influence family engagement outcomes.

PFCE family engagement variables. One way to show the importance of individuality when looking at family engagement outcomes was done by the new Head Start PFCE framework by detailing seven necessary components in creating successful family engagement outcomes. To this researcher's knowledge, these variables have yet 
to be studied together. However, it is important to recognize the research that has been done on each specific variable prior to this study.

Family well-being. One of the seven variables in successful family engagement identified by the PFCE Framework was family well-being. The Head Start PFCE Framework defined family well-being as "parents and families are safe, healthy, and have increased financial security" (Office of Head Start National Center on Parent, Family and Community Engagement, 2011, p. 5). The need for overall family well-being to enhance family engagement has been supported in previous research. Marjoribanks (2005) in his discussion of theoretical orientations and research studies that examined the relationship between children's success and their home environments felt it was important for researchers to develop an enriched understanding of how the nuances of family environments impact the overall success of a child's school related outcomes. He coined the term family educational capital. Family educational capital was used to describe the social, cultural, and economic resources that influenced a child's school success. Marjoribanks (2005) felt future research needed to spend more time focusing on how family well-being indicators influenced the opportunities and limitations found in a child's school setting.

Marjoribanks research was expanded by Jacobs and Harvey (2005) surveying 432 parents and 534 students using an adaptation of Marjoribanks (1994) Parent Attitudes to School Environment Questionnaire (PASEQ). In their research, they focused on how family characteristics, specifically parental attitudes and expectations, related to a child's academic success. Their sample was obtained from three types of schools based upon overall standardized student achievement scores. These included: low, medium, and 
high achieving schools. Using the 29-item PASEQ researchers assessed how a parent's attitudes and expectations correlated with their child's achievement. A one-way between groups ANOVA was run and findings indicated parents with higher expectations were more likely to have children in high achieving schools.

These results were notable when focusing on family well-being because results indicated high-achieving schools were more likely to have higher educated parents. When specifically focusing on Head Start, this research supports Head Starts policy that provides financial mechanisms to Head Start parents to pursue academic endeavors. Using this research, one could infer increasing a Head Start parent's level of academic achievement is important in overall family well-being related to greater family engagement outcomes. As important, findings from this study found the sampled families socio-economic status and marital status did not affect the child's level of achievement. This is significant when focusing on Head Start families because all Head Start families are considered to be living in poverty and there are a significant number of single parent households. The study indicated these family characteristics, often negatively associated with overall family well-being, were not directly correlated with a child's achievement.

Mental health has been found to be a key component when focusing on overall family well-being. This is because Head Start recognizes "the mental health of young children is intimately and inextricably linked to the well-being of their caregivers" (Center for Early Childhood Mental Health Consultation Georgetown University Center for Child and Human Development, n.d., para. 1). LaForett, Mendez, and Porter (2010) researched the psychological well-being of parents and how they influenced family 
engagement outcomes. They sampled 203 families from three Head Start centers to measure the association between family engagement, parental depression, and program satisfaction. They used two instruments found to be reliable (Chronbach's alpha over .80) known as the Center for Epidemiologic Studies-Depression Scale and the Family Involvement Questionnaire (Fantuzzo et al., 2000; Radloff, 1977). A one-way ANOVA was conducted to measure predictor variables: depression and parental involvement. Findings indicated parents who did not suffer from depression were more likely to be engaged in their child's education than their depressed counterparts, $p=.039$. This study's findings reinforced the importance of understanding parental psychological health as a family well-being variable linked to parental involvement activities. However, there is a need for continued research in this area.

LaForett and colleagues (2010) research supported the original research findings completed on depression and parental involvement done ten years prior. Kohl, Lengua, and McMahon (2000) in the first known research study on depression and parental involvement identified depression as a risk factor that could influence overall family well-being. This research sampled 387 children with a mean age of 6.36 from four neighborhoods. They used six parent involvement factors (parent-teacher contact, parent involvement at school, quality of parent-teacher relationship, teacher's perception of the parent, parent involvement at home, and parent endorsement of school) to research the demographic risk factor of maternal depression. Researchers from this study used the same instrument to measure depression as the aforementioned study. However, the original study used the Parent-Teacher Involvement Questionnaire instead of the Family Involvement Questionnaire (Conduct Problems Prevention Research Group, 1995). 
Using path analyses, findings indicated maternal depression was significantly correlated to parent endorsement of school, parent involvement at home, the teacher's perception of the parent, quality of the parent and teacher relationship, and parent involvement at school. This research introduced the idea of depression as a demographic factor in family involvement that continues to be used in discussing family well-being today.

Specifically focusing on rural and urban families, overall family well-being has been shown to be different based upon the health differences between the two groups. Thompson (2005) in a longitudinal study of 269 urban children from ages 2 to 7 , who were predominately African American, researched the treatment needs and utilization services of child mental health care. Over the six years examined by researchers, findings indicated almost half of the children who participated in the study were identified by their parents as needing mental health services. In one of the few studies on this topic completed ten years prior by Cohen and Hesselbart (1993), they turned their attention to the mental health concerns of rural children. In their longitudinal study using data collected from interviews of mothers and children from an original sample of 976 families and a follow-up sample of 760 families in 28 different states they found the opposite to be true of rural children. They found children and youth living in rural settings with diagnosed mental health disorders were less likely to use mental health services. Findings from these studies suggested differences in the use of mental health services for rural and urban children. These findings support the present study by suggesting geographic location will contribute to a families overall well-being.

Parent-child relationships. The second outcome variable used in this study provided by the PFCE Framework is positive parent-child relationships. This is defined 
as "beginning with transitions to parenthood, parents and families develop warm relationships that nurture their child's learning and development" (Office of Head Start National Center on Parent, Family and Community Engagement, 2011, p. 5). Similar to other variables focusing on family engagement, there have been few research studies completed on how parent-child relationships influence parental involvement. However, research does clearly find a family's overall level of cohesion is often attributed to positive parent-child relationships.

Annunziata, Hogue, Faw, and Liddle (2006) recognized this in their research by focusing on parent-child relationships by using family cohesion as a predictor of familyschool engagement. A sample of 211 adolescents and their caregivers were sampled by using three survey instruments measuring school engagement, family cohesion, and parental monitoring. These surveys were administered by trained assessors almost always in the child's home or office. Each instrument was found to have an internal consistency of .54 or higher. Regression and hierarchical analyses were run to measure school engagement, family cohesion, and parental monitoring. Results indicated a family reporting stronger cohesion levels was more likely to engage in the school setting, especially when associated with good parental monitoring. This research supports the idea of the current study by reinforcing how differences found in families contribute to successful family engagement. However, this study only sampled African American children and their caregivers. Therefore, cultural and community differences could play a significant role in the analysis.

Although the previous research provides information on the overall family relationship, it is important to define further the family relationship by focusing on the 
individual parent-child relationship and its influence on engagement. Simpkins, Weiss, McCartney, Kreider, and Dearing (2006) focused on the effect of the mother-child relationship on parental involvement by examining kindergartners' math and literacy achievement. One hundred and seventy-five low-income children and their mothers participated in three sites considered ethnically and geographically diverse through interviews at the child's school. To measure parental involvement instruments measuring the parent child relationship and the family's involvement with education were used. Both instruments used yielded an appropriate level of test-retest reliability of over .75. In addition to these instruments, several standardized tests focusing on math and literacy to measure achievement were used.

Results were tested using hierarchical ordinary least-squares regression to determine the association between the parent-child relationship on family engagement and the child's achievement. Findings indicated there was a significant association between the parent-child relationship on family engagement and a child's achievement. Mothers who were considered to be warm based upon their test scores were more likely to have a significant effect on parental involvement and child's achievement scores than mother's who were not considered warm. One flaw in this research was it did not examine the father-child relationship.

However, a similar study completed several years earlier did examine mothers and fathers. Kim and Rohner (2002) researched the relationship between parenting characteristics, academic achievement, and parental involvement in 245 Korean American adolescents. The researchers interviewed these adolescents in school and church settings using three measures. First, was the Parental Acceptance- 
Rejection/Control Questionnaire (PARQ/Control) used to measure the youth's perception of their parent's warmth, affection, acceptance, and rejection of them (Rohner, 1990). The PARQ had been previously tested and found to have test-retest reliability levels of .81 and higher. The second measure focused on parent's involvement in school. It was assessed using a 12-item scale with alphas ranging from .54 to .86 . The final measure focused on academic achievement. The child's current GPA was used to measure this. Findings using separate hierarchical multiple regression for mothers and fathers regressing GPA on parental involvement and parental warmth found significant results. This indicated the importance of parental warmth on parental involvement and a child's academic achievement. Although this research focused on mother's and father's relationships with their children, it only sampled Korean American adolescents that might influence the generalizability of the study due to effect of culture, ethnicity, and age on these results. Presently, there has been sparse and sporadic attention paid to how the parent-child relationship influences family engagement outcomes. Additionally, there has not been any emphasis on how rural and urban parent-child relationships effect family engagement. However, previous research studies discussed above indicate the need for continued research in this area by emphasizing how different cultures and family characteristics are positively associated with the parent-child relationship and family engagement outcomes.

Families as lifelong educators. The PFCE framework developed the families as lifelong educators outcome because they believe "parents and families observe, guide, promote, and participate in the everyday learning of their children at home, school, and in their communities" ("The Head Start Parent", 2011, p. 5). Like other outcomes used in 
the PFCE Framework, there has been little research on the impact families have on children's outcomes when families are engaged in lifelong learning with their children. However, there have been a few articles directly pointing to the positive impact family guidance has on a child's educational outcomes. New research has begun to understand how families' impact lifelong educational attainment by focusing their attention on the impact of parental aspiration's on their child's motivation in the academic setting.

Fan and Williams (2010) conducted a nationwide survey to measure parental involvement focusing on the impact of parental aspirations on their child's motivation in the academic setting. The instruments used in this survey included: the Academic SelfEfficacy Scale, the Intrinsic Motivation Scale, and the Student Engagement Scale (Fan, 2001; Hill \& Craft, 2003; Yan \& Lin, 2005). All three instruments had Chronbach's alpha values ranging from .59 to .93 . There were eleven independent variables measured: student academic self-efficacy, intrinsic motivation, engagement, parental advising, parent participation in extracurricular activities with children, parent-school communication concerning students' school problems, school-and parent-initiated contacts, parent participation in school functions, parental aspiration for students' postsecondary education, family rules, and socio-economic status and gender. Regression analysis was done using a sample size of 15,325 tenth graders. A positive correlation between parental aspirations for a child's educational attainment was found to be significantly associated with a child's educational outcomes in math and English. In addition, findings from this study indicated the more school-initiated contact there was the higher the level of educational attainment for the student. Unique to this study, were 
findings that indicated parent's involvement in extracurricular activities as well as in school functions positively correlated to higher levels of academic achievement.

Fan and Williams (2010) findings reinforced research completed the year prior by Spera, Wentzel, and Matto (2009). Spera and colleagues found parental aspirations to be positively correlated with a child's educational attainment as well. The purpose of their study was to begin to focus on how contextual factors influenced a child's academic achievement. The variables they use to begin this understanding included: parental education, ethnicity, and parental perceptions of the school climate. A parent survey was administered to parents in a large public school system in a culturally diverse area. The survey was used to measure parent's perception of six constructs. These included: academic instruction, school informs parents, school empowers parents, school safety and discipline, health education, and guidance. In addition to the six constructs measured in the survey, parental ethnicity, parental education, children's academic performance, and aspirations for educational attainment were measured. For the sample measured, the survey had an internal consistency of above .70 for each of the six constructs. The sample was obtained by surveying 13,577 parents.

Using several one-way ANOVA's, a factorial ANOVA, and hierarchical regression the researchers found several significant findings. First, parents' ethnicity was a significant indicator in their aspirations for their child to obtain a college degree. Asian American parents were found to have significantly higher college aspirations for their children than other ethnicities surveyed. Second, parents who had obtained a higher level of education were more likely to emphasize the need for their children to attend college than parents with lower educational attainments. Finally, parents' perceptions of their 
children's school were significantly correlated to parents' academic aspirations for their children. For example, the more parents liked their children's schools, the more emphasis the parents had on their children's educational attainments.

This article, and the previous one completed by Fan and Williams (2010) are important for the current research study because they emphasize how contextual factors can impact parents' involvement in their children's educational attainment. Although these researchers did not use the demographic variables used in this study, Spera and colleagues (2009) did stress the need for continued research focusing on how contextual variables impact these findings. They pointed out since their study sampled an urban population their findings may not generalize to rural and urban communities. However, the idea that these types of communities might impact this study is something to consider. They state "the notion that community effects might influence parental aspirations and thus mediate the impact of schools on children is intriguing. Multi-level studies that consider the role of the broader community. .. would contribute to our understanding (Spera et al., 2009, p. 1150). The current study supports their research by focusing on how the community contributes to educational attainment.

Families as learners. Families as learners has been defined as "parents and families advance their own learning interests through education, training, and other experiences that support their parenting, careers, and life goals" ("The Head Start Parent“, 2011, p. 5). For this family engagement outcome to be reached there are two factors important to consider. First, parents' perception of their roles in their children's learning, and second, the impact training has on this outcome. Current research indicates parents' perception of who should play an active role in their children's learning is 
significantly correlated to children's academic achievement as well as their participation in family involvement training.

Weigel, Martin, and Bennett (2006) supported this idea by focusing on the impact a child's home environment played on a child's academic achievement. In this study, a survey was administered to 151 families in the first data collection period and 80 families in the second collection period with pre-school aged children. Several measures were used in this survey including: the Parental Reading Belief Inventory, the Wide Range Achievement Test-3, the Child's Emergent Literacy Task, and questions pertaining to the demographic characteristics of the child's home (Burgess et al., 2002; DeBaryshe and Binder, 1994; Wilkinson, 1993). Each instrument had internal consistency values ranging from $.66-.81$.

The findings from these measures were clustered into two categories. The first category was facilitative parents. These parents believed taking an active role in their children's learning at home helped to facilitate opportunities for their children to do better in school. The second category was conventional parents. This category of parents thought it was the schools responsibility, rather than the parents, to assist in their children's learning. Multivariate logistic regression was used to determine the influence conventional and facilitative parents had on their children's print knowledge, reading interest, and emergent writing. Results indicated facilitative parents' children made greater gains in print knowledge and reading interest than conventional parents' children. This article is important because the results indicate families who advance their own learning in the home environment are more likely to have children with higher achievement than families who feel it is the school's sole responsibility. This research 
supports the idea when parents are active participants in their children's learning their children's outcomes will be higher which is the goal of successful family engagement. In addition to the home environment, family engagement outcomes are shown to improve when family learning takes place through collaborative training between the school and parents. St. George (2010) completed a qualitative study to explore how to improve collaboration between parents and teachers to support children's literacy development. The researcher focused on understanding barriers to a successful parentteacher partnership, how these barriers can be overcome, and how participating in a parent-teacher training can change the teacher's understanding of parent-teacher partnerships. St. George used grounded theory to understand themes by collecting data through journals, written work completed in the parent-teacher training, and audiotapes. The sample included 10 teachers and 10 parents of elementary students.

Themes found in this study indicated a lack of resources, time constraints related to effective communication, and confusion over the parent and teachers' roles and responsibilities were challenges in family engagement. To overcome these barriers teachers and parents believed it was important for the school system to offer training for both parents and teachers to help develop their communication skills and their roles in their children's education.

In previous research, St. Clair and Jackson (2006) had similar findings related to training. The main idea of their research was to understand the effect family involvement training had on a child's language skills. A quasi-experimental research design was used surveying families who participated in the Migrant Even Start Family Literacy Program compared to a control group of families with similar characteristics who did not complete 
the training. A total of 29 children participated in the study. The Woodcock-Munoz Language Survey was used to compare the language skills of children whose parents participated in the training to a child whose parents didn't participate in the training on their language attainment (Woodcock \& Muñoz-Sandoval, 2001).

A one-way analysis of variance (ANOVA) was completed to understand a child's language scores. Findings indicated children whose parents participated in the program had higher scores in language development over the two-year training than children whose parents did not participate in the training. This study reinforces the families as learners outcome used in the PFCE framework by drawing attention to the impact parent participation in their home and school has on their child's overall achievement. However, these studies did not focus on how families as learners can be impacted by a child's community. More research still needs to be done in this area to expand what variables impact families as learners.

Family engagement in transitions. One of the most critical periods in children's academic careers is their transition into kindergarten. This is because it is the child's first impression of formal education and her view on this new experience can either pave the way for future academic success, or set her up for many years of discouragement and failure. Head Start's PFCE framework recognized this concern by including in their family engagement outcomes the variable family engagement in transitions. They define this as "parent and families support and advocate for their child's learning and development as they transition to new learning environments, including EHS to HS, EHS/HS to other early learning environments, and HS to kindergarten through elementary school" ("The Head Start Parent", 2011, p. 5) 
McIntyre and colleagues (2007) confirmed Head Start's recognition of this outcome by studying parents' experiences and involvement in their children's transitions into kindergarten. They surveyed 132 parents of children transitioning into kindergarten from early childhood education programs in an urban area in the Northeast. Findings indicated the majority of parents expressed concerns about their children's acclimation to kindergarten and would like more information regarding their children's transitions. In addition, the survey indicated parents from lower socio-economic backgrounds reported less involvement in transition activities with their children.

If the parents' desire is to be involved in their children's kindergarten transition, it is important to understand how developing transition policies and practices impact children's academic outcomes. Schulting, Malone, and Dodge (2005) examined secondary data on kindergartners. A sample of 17,212 children and 2,991 teachers from 992 schools was obtained. Several measures were used to collect information from the sample including: a cognitive assessment battery, parents reports on parent-initiated involvement, teachers reports on teacher initiated involvement, and teachers identification of the transition policies implemented in their school.

In addition to these measures, several demographic questions were asked to ascertain information regarding parental household information and their teacher's beliefs and experiences with the school and classroom. The researchers reported moderate to high levels of internal consistency ranging from .44 to .85 in the instruments used. Hierarchical linear modeling was completed focusing on the relationship between transition practices and kindergarten outcomes. Findings indicated using transition practices in the school setting was a significant predictor of a child's academic 
achievement, $\mathrm{p}<.001$. Findings also indicated these transition policies helped in parental involvement that in turn leads to higher academic achievement as well.

In both studies, researchers found parents have a desire to be involved in transitions and their involvement in transitions is linked to their children's academic success. One barrier found in these studies was related to socio-economic status. The less income a family reported the lower the amount of engagement in transition activities took place. For the purpose of this research, it is important to reiterate how demographic variables impact every aspect of the engagement continuum. These articles reinforce the importance of identifying family variables that might contribute to barriers in successful family engagement.

Family connections to peers and community. One variable often overlooked in family engagement policy is the importance of family connections to the community. Bronfenbrenner's theory on the ecology of development recognized this and he felt "the larger systems of cultural beliefs, societal values, and 'community happenings' act as a powerful source of energy in our lives" (Swick \& Williams, 2006, p. 372). Head Start supports this idea by including family connections to peers and communities as one of the seven outcome variables in successful family engagement. They defined this outcome as "parents and families form connections with peers and mentors in formal or informal social networks that are supportive and/or educational and enhance social well-being and community life" ("The Head Start Parent", 2011, p. 5). Although Head Start is taking an active role in recognizing the need for community involvement, it is important to note, the impact of the community on family engagement is a very limited area of study. 
Woolley and Grogan-Kaylor (2006) shed light on this subject by researching the importance of the community on positive school outcomes. In their nationally representative sample of 2,099 high school students using the School Success Profile, the FBI Uniform Crime Report, and the U.S. Census as measures they found several factors that influenced school outcomes (Raudenbush \& Bryk, 2002). One connection important for this study includes a correlation between community conditions and a child's achievement. Using hierarchical linear modeling, Woolley and Grogan-Kaylor (2006) found children's perception of the safety of their community was positively correlated with higher academic achievement. However, this study did not find any association between the levels of child poverty in the community to a child's school outcomes. This is significant for our current study because rural communities have more children living in poverty than urban areas and this study did not find any difference in poverty levels to a child's school outcomes (Mattingly, Johnson, \& Schaefer, 2011).

Not only is a child's perception of the community important, a parent's perception of the community is crucial as well. Wiseman (2009) completed a qualitative study of three mothers' experiences with their kindergartner's school and how it affects their feelings towards their middle class metropolitan community. She found parents perceptions of their community were affected by their children's school experience. Through her findings, Wiseman (2009) believed it was important for school systems to recognize and consider ways they are connecting parents to their communities and how parent's perceptions of the communities are impacted by their beliefs surrounding the school system. Understanding how to develop a positive perception of the community 
and how the school plays a part in this is critical in providing us important knowledge in the engagement and development of children and families.

Hiatt-Michael (2006) recommended the direction of future research should "study the effects of connecting community agencies with the school on family involvement issues and student educational outcomes" (p. 25). For the purpose of this research study, it is important to recognize the effects rural and urban community influences have on family engagement. Brown, Copeland, Costello, Erkanli, and Worthman (2009) in their pioneer study on this subject began by examining rural areas and the impact of these areas on educational goals and attainment from a longitudinal study sampling youth from the Appalachian mountain region. Participants in this study included 200 white males and females who were part of a longitudinal study. To measure this population the Life Trajectory Interview for Youth (LTI-Y) was completed as well as data from the U.S. Census (Brown, Worthman, Costello, \& Erkanli, 2006; U.S. Census Bureau, 2000). The researchers did not provide reliability and consistency measures for the LTI-Y instrument.

Hierarchical linear modeling was used with this data. Findings indicated less educational attainment in those youth who reported more exposure to family poverty. These researchers felt the rural community context may have a significant impact on a rural youth's educational goals. However, they did not find a significant difference between educational attainment using the community context as a variable. This research felt future research should consider focusing on "families as sites for educational capacity building, rather than efforts to change school or community practices regarding education” (Brown et al., 2009, p. 804). This is significant for the current research study 
because it used the community as a variable to predict a child's educational outcomes. Although it does not specifically focus on family engagement, it does provide this study with validity in comparing the community context and a child's educational outcomes which is the ultimate goal in the new PFCE Framework.

Families as advocates and leaders. The final PFCE family engagement variable used in this research is families as advocates and leaders. This has been defined as "parents and families participate in leadership development, decision-making, program policy development, or in community and state organizing activities to improve children's development and learning experiences"("The Head Start Parent", 2011, p. 5). Head Start has played an active role in incorporating this variable in their program since its inception. Currently, the Head Start Policy Council is used as a forum for parents to be a part of the decision-making and program policy development for Head Start. However, like the other PFCE variables, this outcome is an understudied area in family engagement literature and in reviewing research there has been a perplexing disconnect between parental involvement and shared leadership partnerships between school systems and families.

Auerbach (2007) reinforces this idea in one of the few studies devoted to understanding leadership and parental involvement. This qualitative study focused on the role of leaders in developing parental engagement, how administrators promote parent engagement in their school system, and what variables influence leadership activities for parental engagement. The sample consisted of 30 administrators from two urban schools. The data was collected through two hours of semi-structured interviews. Findings from her interviews indicated school administrators fell short of providing a comprehensive 
approach to shared leadership and were more comfortable with family-friendly delegation than developing shared governance, democratic principles, and parent empowerment opportunities.

Auerbach (2008) continued her research agenda in a qualitative study focusing on how school administrators can promote meaningful family engagement. The researcher reiterates in this study the limited information on leadership and family engagement and the need for more focus on atypical ways to increase leadership and family engagement. Participants in this study included two males and two females in school administration roles. Auerbach (2008) collected data through in-depth, semi-structured interviews. Her findings indicated to be a successful leader in developing a comprehensive approach to parent engagement that empowers parents to take an active role in their child's education several things need to take place. First, the school leader must place value on the importance of family engagement. Second, the school leader must be an active participant, along with the families, in developing, planning, and implementing family engagement activities. Third, a leader must believe involving the parent is a social justice issue of educational equity to promote authentic dialogue to develop and encourage parental advocacy. Fourth, school leaders must know their community and have insight and compassion for the families living there. In addition to these things, administrators must be aware of existing models on parental involvement as well as creating bilingual opportunities for parents who are non-English speaking.

To create this family-school partnership idea among all school leaders Auerbach (2010) argued a new model of school-family partnerships must include authentic partnerships. She defined authentic partnerships "as mutually respectful alliances among 
educators, families, and community groups that value relationship building, dialogue, and power sharing as part of socially just, democratic schools" (Auerbach, 2010, p. 734). To develop authentic partnerships Auerbach (2010) provided descriptive data from current school leaders to show other leaders how this process can be done in the school system. Although her ideas reinforce Head Start's belief in families' participation in the school, more information and research is needed to ascertain correlations between this type of school-family partnership and family engagement outcomes. It should be noted there is little research on how to develop family advocacy and leadership in the school system and Head Start has not been used as a sample to study. This current study will add to this body of knowledge by recognizing differences between geographic locations in developing leadership in Head Start communities.

\section{Differences Found in Head Start Families in Rural and Urban Areas}

To begin to understand the complexity, context, and variables in family engagement outcomes using the new PFCE framework variables it is important for researchers to identify demographic indicators that influence family engagement to encourage an individualized approach for Head Start centers. This study begins this process by recognizing the understudied role of the community in family-school engagement outcomes. This idea supports our theoretical framework that states "different settings or conditions in which children attend day care should reflect major ecological differences between the settings, as revealed by contrasting patterns of activities, roles and relations" (Bronfenbrenner, 1979, p. 183). Two settings that greatly differ in terms of population size, socio-economic level, and health are known as rural 
and urban communities. Families living in rural areas often differ in their environmental settings and experiences than their urban counterparts.

Social service professionals agree with this by stating that there is often a difference in policy implementation in rural and urban areas (Arsneault, 2006). In addition to public policy issues, rural communities have often found themselves "neglected in research studies and public consciousness" (Maher \& Frestedt, 2008, p. 2). To show the need for more research in this area this section will provide a broad overview of differences found in research completed on rural and urban Head Start families. It is important to note there was significantly more research found on urban families than rural families. In addition, research comparing rural and urban families related to family engagement activities has yet to be developed in the literature. Most research articles only cited rural or urban as the area they sampled with little thought given to how these individual geographic locations affected their family engagement outcomes. Below is a detailed understanding of the research currently done on differences found in rural and urban Head Start children to show the need for broadening the rural/urban study to incorporate more variables, such as family engagement.

Bender, Fedor, and Carlson (2011) examined protective and risk factors in Head Start preschoolers using rural and urban geographic locations as their independent variables to determine the association between communities and Head Start children's behavior. Their study included 232 parents of children attending Head Start in urban communities and 231 parents of children attending Head Start in rural communities. A survey was administered to Head Start parents to identify protective and risk factors in Head Start children. Internal reliability for subscales used in this survey were in 
acceptable ranges between .71 to .96 . The definition of rural and urban locations was taken from the United States Census Bureau which is the same definition used in the current study. Multiple analysis of variance procedures were done to analyze the data collected. The results of this study indicated a positive correlation between the type of community a child resided in and their levels of protective and risk factors. Children living in urban areas exhibited higher levels of self-control than their rural counterparts. However, rural children exhibited higher levels of attachment than their rural peers. Researchers felt future research in this area should continue to explore the differences between rural and urban communities and their relationship to enhancing the Head Start child's development. This is important to our current research study because it indicates there are differences found between rural and urban Head Start families.

This study reiterated findings from a previous study focusing on understanding the behavioral differences in rural and urban children. Hope and Bierman (1998) completed a cross-sectional study administering surveys to teachers and parents regarding 310 rural and urban children entering kindergarten. Results found significant differences between behavioral problems of rural and urban children. Rural children were more likely to exhibit home-only behavioral problems; whereas, urban children were prone to more school-only behavioral problems. This research reinforced current research by suggesting a more comprehensive understanding of how urban and rural communities affect young children.

Although very few studies on Head Start children use rural and urban communities as variables, the few studies that have primarily focused on the medical differences between rural and urban Head Start children. Allen (2008) did this by 
comparing services provided by early childhood mental health consultants (ECMHC) who were the primary professionals used to address the social and emotional needs of children and families in the Head Start program. Allen (2008) completed a qualitative focus group on rural and urban ECMHC's and found differences between rural and urban Head Start programs. Mental health professionals who provided services in rural areas must be more cognoscente of the role the community played in services compared to consultants working in urban areas. Allen (2008) felt it was crucial for mental health consultants to understand the lifestyle and relationship differences found in rural and urban communities and to work to overcome the challenges that they present.

Focusing on medical differences, dental hygiene is another area of research that has been done focusing on the differences of Head Start children in rural and urban areas. In a multi-state longitudinal study from 1998-2008 researchers found specific challenges to the oral health of rural low-income families' related to the low rates of mothers and spouses who reported seeing the dentist (Simpson \& Braun, 2007). Recommendations from this report encouraged the expansion of dental care programs throughout the Head Start program (Simpson \& Braun, 2007). Vargas and colleagues (2002) in a survey of 562 Head Start children found problems with dental hygiene as well. Their research indicated cavities were highly prevalent in the Head Start population despite the policy expectations of Head Start for their children to receive regular dental checkups. Of importance to this review, significant differences between rural and urban children were found. Findings indicated rural Head Start children were more likely to have cavities and decaying teeth than urban Head Start children (66\% vs 51\%) (Vargas, Monajemy, Khurana, \& Tinanoff, 2002). These findings confirmed an earlier study that suggested 
that the prevalence of baby bottle tooth decay in rural Head Start children was more than double compared to their non-rural counterpart (Barnes, Parker, Lyon, Drum, \& Coleman, 1992). These studies support the current research by finding differences in Head Start children when using geographic location as the dependent variable.

The academic achievement of Head Start children is a well-researched area of study. This research area has not extended to why outcomes differ between rural and urban Head Start children in multiple areas of a child's developmental system. Furthermore, most research that examines differences between rural and urban children focus on children already in the school system and do not value how rural and urban environments, specifically in early childhood settings, could impact a student's school readiness (Durham \& Smith, 2006). There have been even fewer studies focusing on the educational differences in rural and urban Head Start children. One study by Ray (200809) found staff in rural Head Start programs to be less educated and trained compared to staff in urban programs. This research is concerning when comparing it to findings from research done on 35 Head Start classrooms using a clustered-randomized controlled trial design. These researchers found one of the characteristics in reducing problematic behaviors of Head Start preschoolers is placing them in a classroom with more qualified teachers (Raver et al., 2009). Although the aforementioned rural and urban Head Start literature does not include family engagement as a variable, the literature does support the idea there are significant differences in rural and urban communities that supports the current research study.

Family engagement with rural and urban families. Studies focusing on the aforementioned variables have provided a framework for showing differences between 
rural and urban Head Start families and the importance of valuing the community setting in future research. However, specific research on these differences and how they contribute to family engagement have been lacking. In 2004, Fantuzzo and colleagues highlighted this in their study on how family involvement influences the behavioral and learning achievement of low-income, urban children. They concluded that future studies on family involvement and child attainment should focus on the outcomes with other populations, specifically citing rural or suburban samples. This supports current quantitative research by Vaden-Kiernan and colleagues (2010). They sampled 2,258 Head Start parents, children, and teachers over a two year period to determine how neighborhood factors, including structure, composition, social, and educational, influenced a child's developmental outcomes. Using multilevel regression they found neighborhood factors were significantly related to a child's developmental outcomes. This research does not focus on family engagement, but it continues to show the differences between rural and urban areas as a variable to consider when working with Head Start families. It does this by drawing attention to the importance of factoring in the ecological dimensions of childhood development as well as the necessity of moving past one-dimensional policies and practices to meet the individual needs of Head Start children in multidimensional environments.

\section{Conclusion}

This literature review provides an overview of the Head Start program and its services to families. It gives a background on the importance of family engagement, specifically focusing on the family engagement variables discussed in the PFCE framework. The review illustrates the infinite differences and challenges found in rural 
and urban families and the impact they have on Head Start children, families, and programs. Additionally, it highlights the need for research to determine differences found between rural and urban communities and how they affect family engagement in Head Start programs. To date, studies specifically looking at these geographic differences in Head Start children and families have been missing from empirical research done on Head Start family engagement. More information about how rural and urban geographic locations impact family engagement is important in developing new Head Start policies and procedures. Furthermore, it conveys to constituents and politicians the need to develop and support individualized family centered services in creating healthy communities. 


\section{Chapter 3: Methods}

The purpose of this exploratory, cross-sectional study was to examine family engagement of Head Start families from different geographic locations. Data collected from this study were obtained from a survey provided to Head Start families from rural and urban areas in southwest Missouri who had one or more children who were currently receiving OACAC Head Start services. To measure family engagement seven dependent variables derived from the PFCE framework were used. These included: overall familywell being, parent and child relationships, family engagement in transitions, families as learners, families as lifelong educators, family connections to peers and communities, and families as advocates and leaders. In this study, one independent variable was used: geographic location. This independent variable had two categories: rural and urban families whose children attended Head Start. The following sections outline the study participants, data collection procedures, instrumentation used, and analyses selected.

\section{Participants}

For the purpose of this study, the entity analyzed included all households with one or more children who were currently receiving OACAC Head Start services in a rural or urban geographic location. "OACAC Head Start is a program of Ozarks Area Community Action Corporation (OACAC), a community action agency dedicated to serving low income families and individuals with a range of services. OACAC serves ten counties spread over almost six thousand square miles in the southernmost tier of Missouri” (Shinn-Brown \& Bauer, 2009, p. 2). OACAC Head Start currently maintains 35 locations. Sixteen locations were chosen to participate in this study based upon the population of the city the Head Start center was located. Nineteen OACAC Head Start 
centers were not asked to participate because they did not meet the parameters

established to be classified as a rural or urban area set forth by this study. Of the 16 Head Start locations that met the geographic location parameters, all parents whose children attended OACAC Head Start were targeted for this research. A parent was defined as the legal guardian for the child and/or a member of the child's main residence who took primary responsibility for parenting.

\section{Data Collection Procedures}

Data collection took place from March 18-21, 2013. Prior to this research study being developed, this researcher interviewed Head Start administrators, Head Start family advocates, and Head Start parents to obtain their opinions on important areas of study. Additionally, this researcher reviewed current family engagement literature and Head Start policy and procedures related to family engagement to ascertain a research question and hypotheses. Permission was obtained from the Director of OACAC Head Start to conduct this research study through OACAC Head Start (see Appendix A for permission letter).

Purposive sampling was used for this study. Sampling was completed in $16 \mathrm{Head}$ Start centers, on 29 classrooms, in 10 communities located in southwest Missouri. Springfield, Missouri was designated as the urban location. Based upon the 2010 Census Bureau's urban-rural classification system Springfield's population of 160,660 met the qualifications to be considered an urban area (http://www.census.gov/geo/www/ua/2010urbanruralclass.html). There were nine communities in southwest Missouri chosen to be rural sites. These included: Ashgrove, Butterfield, Crane, Fairgrove, Fordland, Greenfield, Kissee Mills, Reed Springs, and 
Seymour. The population of these rural communities ranged from 470 to 1,921 with an average population of 1,212 for the nine communities surveyed (http://quickfacts.census.gov/qfd/states/29000.html).

Recruitment of parents took place in 10 communities and 16 urban/rural Head Start centers located in southwest Missouri. At the time of data collection, there were 848 children attending the 16 OACAC Head Start locations (Shinn-Brown, 2012). Using a table developed by Bartlett, Kotrlik \& Higgins (2001) for determining minimum returned sample size for a population size of approximately 800 participants, using categorical data, with a margin of error $=.05, \mathrm{p}=.50$, and $\underline{\mathrm{t}}=1.96$ the minimum return sample for this survey should have been 260 returned surveys. The goal for this research study was to collect at least 300 surveys. The return rate for this study was 419 surveys that exceeded the minimum returned sample size needed to infer research findings back to the general Head Start community.

To obtain these surveys, this researcher went to each Head Start center designated for this study. Prior to visiting each center, an email was sent out on March 4, 2013 by the Family and Community Partnerships Director informing each Head Start location of their upcoming voluntary participation in this research study (see Appendix B for a copy of this email). To obtain these surveys this researcher visited each Head Start center over a four day period. At each Head Start location, this researcher introduced herself as a doctoral student from the University of Missouri-Columbia, stated the Family and Community Partnerships Director had sent them an email about the visit, and asked permission to distribute the survey packet to each Head Start child using the child's take home folder. 
Of the 16 centers surveyed, nine of the centers did not feel comfortable having this researcher put the surveys directly into the child's take home folder. Therefore, the individual classroom teacher was asked to do this. The seven remaining Head Start locations allowed this researcher to put the survey packet directly into the child's take home folder. In addition to putting the surveys in each child's take-home folder, the researcher met with each site director and/or classroom teacher to reiterate the purpose of the study and inform each center how families can contact the researcher directly with questions. On the instructions, families were provided a deadline to return surveys by March 28, 2013. To follow-up on the survey, each Head Start teacher was asked by the researcher to put a note in every child's backpack on March 25, 2013. This was used to remind every parent to turn in their survey, if they hadn't already, by the deadline for completion (see Appendix C for a copy).

There were several items included in the survey packet. The first was the consent to participate in the study. The consent included an overview of the following: an introduction to the study, the purpose of the study, the description of procedures, the potential risks and benefits of the study, how the participants' privacy would be protected, and a signature space for the participant to voluntarily agree to participate in the study (see Appendix D for a copy of the consent to participate form). In addition, the deadline for completion was bolded and dated as March 28, 2013.

On each survey distributed, 29 individual codes were placed on the top of each survey to identify the classroom location of the participant's child. The 29 individual codes were placed on surveys because there was a reward provided to the top three centers with the most participants. This award was based upon percentage of students at 
each site. Three rewards were provided. The classroom with the highest percentage of return rate was given a $\$ 100.00$ check for classroom materials. The classroom with the second highest percentage of return rate was given a $\$ 75.00$ check for classroom materials. The classroom with the third highest percentage of return rate was given a $\$ 25.00$ check for classroom materials. In addition, each center was assigned a geographic location by a code of either $1=$ urban or $2=$ rural. Included with the consent to participate form and the family engagement survey was a manila envelope stapled to each packet. The purpose of this envelope was to encourage parents to return their survey in a sealed manila envelope to help maintain their confidentiality.

The Head Start parents were asked to return the sealed manila envelope to their Head Start teacher by March 28, 2013. The Head Start teacher was provided a large selfaddressed, stamped, envelope to put all the surveys collected. The Head Start teacher was asked to return all surveys in the self-addressed envelope to the investigator by April 1, 2013. All 16 Head Start locations and 29 classrooms returned the self-addressed envelope with parent surveys inside.

Protection of human subjects. The protection of human subjects was sought for this study, prior to study administration, though the approval of University of Missouri's Institutional Review Board (IRB). The IRB approved this study on March 5, 2013. A copy of the IRB approval and a written notification in the survey instructions pertaining to participation and protection of parent's rights were provided to OACAC Head Start administrators. In addition, included in the survey instructions was a paragraph to each participant detailing how their rights were protected and how confidentiality was maintained as well as how the information they provided would inform early childhood 
educators, researchers, and policy makers on ways to provide better services to their families. The instructions clearly informed the participants that the survey was optional for their family and would not influence or affect their relationship with their Head Start center's staff.

\section{Instruments}

One survey was provided to each family at a single point in time. This survey was used to collect basic demographic information, determine if the family was from a rural or urban area, and measure seven family engagement outcomes (see survey in Appendix E). Specific demographic information was ascertained from each family including: age and gender of the family member filling out the survey, race/ethnicity, level of education achieved, and marital status.

The independent variable was geographic location. Geographic location was divided into two categories: rural and urban. To obtain this information each survey was numbered either one or two. The researcher provided all rural locations with surveys coded as two. Surveys coded with the number 1 were provided to urban Head Start families. This coding allowed the researcher to identify the independent variable without including this on the demographic questionnaire. The purpose of this was to ensure accuracy of this variable by predetermining the sites that received urban or rural surveys based upon the Census Bureau's definition of rural or urban areas. Therefore, the participants did not have to understand the numerical difference that determines whether they were living in a geographic location that was urban or rural in the demographic information obtained. 
Understanding family engagement in rural and urban families was the research question asked in this study. To understand family engagement seven dependent variables were measured by the survey through scales that focused on the seven family engagement outcomes obtained by the PFCE Framework. These outcomes included: overall family member well-being, parent-child relationships, families as lifelong educators, families as learners, family engagement in transitions, family connections to peers and communities, and families as advocates and leaders.

There were three instruments used to measure six out of the seven dependent variables. The seventh dependent variable, families as learners, was ascertained through the demographic questionnaire by asking "what is the highest degree or level of education you have completed (a) less than high school (b) high school graduate (includes equivalency) (c) some college, no degree (d) Associate's degree (e) Bachelor's degree (f) $\mathrm{PhD}(\mathrm{g})$ graduate or professional degree". This question was used to answer hypothesis 1: Urban Head Start families will rate themselves higher than rural families on their level of educational attainment. The remaining six dependent variables identified through the PFCE Framework's family engagement outcomes used the below instruments to determine the engagement levels of Head Start families in rural and urban areas.

Family member well-being (FMWB). The dependent variable family wellbeing was defined by the PFCE Framework as "parents and families are safe, healthy, and have increased financial security" ("The Head Start Parent", 2011, p. 5). The Family Member Well-Being Index (FMWB) was used to measure the overall well-being of the Head Start family (McCubbin \& Paterson, 1982). “(FMWB) Index was developed by Hamilton McCubbin and Joan Paterson (1982e) to measure the degree to which a family 
member is adjusted" (p. 753). It is an 8-item instrument that uses a 10-point Likert scale that measure a family member's overall emotional, social, interactional, and physical well-being during the past month including (a) how concerned or worried about your health have you been? (b) how relaxed or tense have you been? (c) how much energy, pep, vitality have you felt? (d) how depressed or cheerful have you been? (e) how afraid have you been? (f) how angry have you been? (g) how sad have you been? (h) how concerned or worried about the health of another family member have you been (McCubbin \& Patterson, 1983). The answers range on a scale from not concerned at all to very concerned. The test-retest reliability of this instrument was not available at this time. However, "the FMWB has very good internal consistency with an alpha of .85" (Corcoran \& Fischer, 2000, p. 329). The FMWB has been validated "through numerous studies including studies on farm families, investment executive families, rural bank employee families, and military families" (McCubbin, Thompson, \& McCubbin, 1996, p. 754). This scale measured hypothesis 2: Urban Head Start families will rate themselves higher than rural families on their perceived overall emotional, social, and physical wellbeing.

Family coping coherence index (FCCI). Family engagement in transitions was another dependent variable. The PFCE Framework defined family engagement in transitions as "parents and families support and advocate for their child's learning and development as they transition to new learning environments" ("The Head Start Parent", 2011, p. 5). The Family Coping Coherence Index was used to measure how Head Start families dealt with transitions (McCubbin, Larsen, \& Olson, 1982). The Family Coping Coherence Index (FCCI) was created by McCubbin, Larsen, and Olson (1982) as a four- 
item 5-point Likert scale instrument that asks when you face problems or difficulties in your family how your family copes by (a) accepting stressful events as a fact of life (b) accepting that difficulties occur unexpectedly (c) defining the family problem in a more positive way so that we do not become too discouraged (d) having faith in God. The instrument was used to measure "a sense of coherence which families call upon to manage life changes and stresses" (Corcoran \& Fischer, 2000, p. 252). The Chronbach's alpha for this measure was .71 which is in the acceptable range (McCubbin et al., 1996). The test-retest reliability for this measure is .83 and no additional validity checks were available for this instrument (McCubbin et al., 1996). This scale specifically focused on hypothesis 3: Rural Head Start families will identify more problems or difficulties when facing transitions than urban Head Start families.

Parent and school survey (PASS). The four remaining dependent variables were measured using the Parent and School Survey (PASS) (Westmoreland, Bouffard, O’Carroll, \& Rosenberg, 2009). These dependent variables included: parent-child relationships, families as lifelong educators, family connections to peers and community, and families as advocates. The first dependent variable measured by the PASS instrument was positive parent-child relationships. The PFCE Framework defined this outcome as "beginning with transitions to parenthood, parents and families develop warm relationships that nurture their child's learning and development" ("The Head Start Parent", 2011, p. 5). The second dependent variable was families as lifelong educators. The PFCE defined this as "parents and families observe, guide, promote, and participate in the everyday learning of their children at home, school, and in their communities" ("The Head Start Parent", 2011, p. 5). 
The third dependent variable measured using the PASS survey was family connections to peers and communities. This outcome was defined by the PFCE Framework as "parents and families form connections with peers and mentors in formal or informal social networks that are supportive and/or educational that enhance social well-being and community life" ("The Head Start Parent", 2011, p. 5). The final dependent variable measured by the PASS survey was families as advocates and leaders. This outcome was defined by the PFCE Framework as "parents and families participate in leadership development, decision making, program policy development, or in community and state organizing activities to improve children's development and learning experiences" ("The Head Start Parent", 2011, p. 5).

These four dependent variables were measured using the Parent and School Survey that is a 30-item scale used to measure six dimensions of family involvement. In addition to these four dependent variables, rural and urban families were measured using the overall score of all items on this instrument. The PASS measures structure consists of two sections: The first section is " 24 items about parent involvement behaviors and beliefs on a 5-point Likert scale (strongly disagree to strongly agree)" (Westmoreland, Bouffard, O'Carroll, \& Rosenberg, 2009, p. 6). The second section is " 6 items about level of difficulty certain barriers present to involvement on a 3-point Likert scale (a lot to not an issue)" (Westmoreland et al., 2009, p. 6). This survey uses six sub-constructs derived from Epstein's (1992) work on parental involvement. Table 1 illustrates each construct the PASS survey measures, the definition of the construct gleaned from Epstein's (1992) parental involvement concept, the corresponding question number in the PASS instrument, and the PFCE Framework outcome measured by each parent 
involvement construct to help conceptualize how this survey will measure the abovementioned dependent variables and the overall score of rural and urban families.

Table 1

Pass Survey

\begin{tabular}{|c|c|c|c|}
\hline PASS Construct & $\begin{array}{l}\text { PASS Construct } \\
\text { Definition }\end{array}$ & $\begin{array}{l}\text { PASS Survey } \\
\text { Item Number }\end{array}$ & $\begin{array}{l}\text { PFCE Outcome } \\
\text { Measured by } \\
\text { PASS Construct }\end{array}$ \\
\hline 1. Parenting & $\begin{array}{l}\text { The creation of a home } \\
\text { environment } \\
\text { supportive of child } \\
\text { cognitive development } \\
\text { and children as } \\
\text { learners. }\end{array}$ & $4,14,16,19$ & $\begin{array}{l}\text { Parent-Child } \\
\text { Relationships }\end{array}$ \\
\hline 2. Communicating & $\begin{array}{l}\text { The home-school } \\
\text { communication } \\
\text { specifically about the } \\
\text { child's academic } \\
\text { progress, school } \\
\text { programs, and other } \\
\text { information that is } \\
\text { academically relevant } \\
\text { about the child. }\end{array}$ & $3,6,7,17$ & $\begin{array}{l}\text { Families as } \\
\text { Advocates and } \\
\text { Leaders }\end{array}$ \\
\hline 3. Volunteering & $\begin{array}{l}\text { A variety of school } \\
\text { activities in which the } \\
\text { parent is present, } \\
\text { whether larger school } \\
\text { events or classroom } \\
\text { activities. }\end{array}$ & $1,12,15,23$ & $\begin{array}{l}\text { Families as } \\
\text { Lifelong } \\
\text { Educators }\end{array}$ \\
\hline 4. Learning at Home & $\begin{array}{l}\text { Encouraging children } \\
\text { in their roles as student } \\
\text { by actively helping } \\
\text { with schoolwork and } \\
\text { encouraging hard work } \\
\text { in school. }\end{array}$ & $2,5,9,18$ & $\begin{array}{l}\text { Families as } \\
\text { Lifelong } \\
\text { Educators }\end{array}$ \\
\hline 5. Decision-Making & $\begin{array}{l}\text { The degree to which } \\
\text { parents actively shape } \\
\text { the school } \\
\text { environment. }\end{array}$ & $8,13,21,22$ & $\begin{array}{l}\text { Families as } \\
\text { Advocates }\end{array}$ \\
\hline $\begin{array}{l}\text { 6. Collaborating with } \\
\text { the Community }\end{array}$ & $\begin{array}{l}\text { The degree to which } \\
\text { parents know about } \\
\text { and use community } \\
\text { resources. }\end{array}$ & $10,11,20,24$ & $\begin{array}{l}\text { Family } \\
\text { Connection to } \\
\text { Peers and } \\
\text { Community }\end{array}$ \\
\hline
\end{tabular}


Note. Adapted from "The Test-Retest Reliability of the Parent and School Survey (PASS)" by Ringenberg, Funk, Mullen, Wilford, \& Kramer, 2005, The School Community Journal, 15, p. 3, "Cultural Capital Theory and Predicting Parental Involvement in Northwest Indiana Schools” by Ringenberg, McElwee, \& Isreal, 2009, The South Shore Journal, 3, p. 97.

The PASS survey is a newer survey and one of the few instruments used to measure parental involvement. The only reliability and validity checks done on this instrument were completed using 40 participants to help refine the 24 items used to measure parental involvement. Researchers Ringenberg, Funk, Mullen, Wilford, and Kramer (2005) found:

Of the 24 PASS items, 20 had at least fair ICC's [intraclass correlation coefficients], with 18 reaching the good or excellent criteria. Eighteen of the items had acceptable ranges of scores. Two additional items were altered due to feedback from the open-ended questions. Thirteen of the 24 items had acceptable reliability and variance as well as no observable problems detected by the openended questions. The remaining 11 items were altered for flaws identified in this study.

This scale was used to specifically measured hypothesis 4: Urban Head Start families will exhibit higher levels of perceived family engagement by scoring themselves higher overall on the parental involvement survey and each of the four individual PFCE family engagement outcomes the survey measures: parent-child relationships, families as lifelong educators, family connection to peers and community, and families as advocates. Table 2 illustrates how each of the aforementioned instruments will be used in the survey to measure each of the seven PFCE Framework's family engagement outcomes.

Table 2 
Survey Instruments and Hypotheses Used to Measure the Seven Family Engagement

Variables

\begin{tabular}{|c|c|c|}
\hline $\begin{array}{l}\text { PFCE Family Engagement } \\
\text { Outcomes }\end{array}$ & Survey Instruments Used to Measure & $\begin{array}{l}\text { Hypotheses } \\
\text { Number }\end{array}$ \\
\hline 1. Family Well-Being & $\begin{array}{l}\text { 1. Family Member Well-Being Index } \\
\text { (FMWB) }\end{array}$ & 2 \\
\hline 2. Parent-Child Relationships & $\begin{array}{l}\text { 2. Parent and School Survey (PASS)- } \\
\text { Items } 4,14,16,19\end{array}$ & 4 \\
\hline $\begin{array}{l}\text { 3. Families as Lifelong } \\
\text { Educators }\end{array}$ & $\begin{array}{r}\text { 3. Parent and School Survey (PASS)- } \\
\text { Items } 1,2,5,9,12,15,18,23\end{array}$ & 4 \\
\hline 4. Families as Learners & 4. Demographic Survey Questionnaire & 1 \\
\hline $\begin{array}{l}\text { 5. Family Engagement in } \\
\text { Transitions }\end{array}$ & 5. Family Coping Coherence Index (FCCI) & 3 \\
\hline $\begin{array}{l}\text { 6. Family Connections to Peers } \\
\text { and Community }\end{array}$ & $\begin{array}{l}\text { 6. Parent and School Survey (PASS)- } \\
\text { Items } 10,11,20,24\end{array}$ & 4 \\
\hline $\begin{array}{l}\text { 7. Families as Advocates and } \\
\text { Leaders }\end{array}$ & $\begin{array}{r}\text { 7. Parent and School Survey (PASS)- } \\
\text { Items } 3,6,7,8,13,17,21,22\end{array}$ & 4 \\
\hline
\end{tabular}

\section{Analysis}

After the surveys were collected from each Head Start site, data from these surveys were coded and entered into IBM SPSS 18.0. Before the surveys were entered into SPSS, twenty-two surveys were shredded. Five surveys were shredded due to a copying error not caught by the researcher that had eliminated one full page of the survey. Eleven surveys were shredded because the participants did not complete over half of the survey and six surveys were shredded because the participants circled more than one response on the survey. After those surveys were destroyed, 397 surveys were entered into SPSS. To assure the accuracy of the data collected a preliminary data screening were conducted. Data screenings were done using both descriptive statistics and frequency distributions to examine the range of values to be sure there were no values outside the possible range of coded values for the categorical variables used. This 
researcher examined the range of values and found the data set did not have any values outside the range of possible values for each variable coded.

Second, missing data were examined to determine if the missing values were randomly or non-randomly found throughout the data set. The data were found to be randomly distributed throughout the dataset and less than $5 \%$ of each categorical variables were found to have cases missing. If a categorical variable has less than $5 \%$ of the cases missing, statisticians recommend for those cases to be listwise deleted (Mertler \& Vannatta, 2005). Of the categorical variables measured by the 397 surveys, 12 participants had at least one missing item on one or more of the instruments used to measure rural and urban family engagement. Data were missing on the following instruments: (a) five participants did not provide their educational level and (b) six participants did not complete the family coping coherence index. After listwise deletion took place, 386 surveys were left to analyze.

The third pre-analysis data screening that took place was assessing the effects of outliers on the data. By creating a boxplot for each variable the following outliers were found (a) 13 rural and urban participants had higher levels of education than their counterparts (b) four rural and urban families scored reported extremely low scores on family member well-being (c) four rural and urban families scored extremely high on parent-child relationships (d) one family scored extremely high on the variable families as lifelong educators (e) 11 families scored extremely high on their overall PASS score (f) four families scored extremely low on the Family Coping Coherence Index (g) four families scored high on family connections to peers and community (h) four families scored high and two families scored extremely low on families as advocates and leaders. 
There were a small number of outliers; therefore, it was appropriate to delete the severe outliers (Mertler \& Vannatta, 2005). After the extreme outliers were deleted, 338 surveys were left to analyze.

After addressing the outliers through deletion, skewness and kurtosis were examined through descriptive statistics using SPSS. "For a normal distribution kurtosis and skewness values will be close to zero but can range between -1 and +1 " (Mertler \& Vannatta, 2005, p. 44). When examining the skewness and kurtosis statistics for urban and rural families each dependent variables skewness and kurtosis values were between the +1 and -1 values. However, for normal distribution some variables, although in the appropriate range, were skewed because they were closer to 1 and -1 then zero. This was supported by the Q-Q plots because visually some values deviated from the straight line provided by the Q-Q plot in SPSS. Three variables (education level, family member well-being, family engagement in transitions) were moderately negatively skewed. Four variables (parent-child relationships, families as lifelong educators, family connections to peers and community, and families as advocates and leaders) were moderately positively skewed.

A test of normality was conducted using the Kolmogorov-Smirinov test in SPSS. The following variables indicated a non-normal distribution: urban education level, $\mathrm{D}(241)=.23, \mathrm{p}<.05$, rural education level $\mathrm{D}(97)=.21, \mathrm{p}<.05$, urban family member well-being $\mathrm{D}(241)=.06, \mathrm{p}<.05$, urban parent-child relationships $\mathrm{D}(241)=.16, \mathrm{p}<.05$, rural parent-child relationships $\mathrm{D}(97)=.20, \mathrm{p}<.05$, urban families as lifelong educators $\mathrm{D}(241)=.09, \mathrm{p}<.05$, urban family engagement in transitions $\mathrm{D}(241)=.12, \mathrm{p}<.05$, rural family engagement in transitions $\mathrm{D}(97)=.12, \mathrm{p}<.05$, urban family connections to peers 
and community $\mathrm{D}(241)=.11, \mathrm{p}<.05$, rural family connections to peers and community $\mathrm{D}(97)=.11), \mathrm{p}<.05$, urban families as advocates and leaders $\mathrm{D}(241)=.13, \mathrm{p}<.05$, and rural families as advocates and leaders $\mathrm{D}(97)=.10, \mathrm{p}<.05$.

Two variables were not significant which indicated a normal distribution. These variables were: rural family member well-being $\mathrm{D}(97)=.08, \mathrm{p}>.05$ and rural families as lifelong educators $\mathrm{D}(97)=.08, \mathrm{p}>.05$. It should be noted there is a limitation of the Kolmogorov-Smirinov test when using it with large sample sizes $(>200)$ because "it is very easy to get significant results from small deviations from normality, and so a significant test doesn't necessarily tell us whether the deviation from normality is enough to bias any statistical procedure" (Field, 2009, p. 144). Testing for homogeneity of variance was completed using Levene's test. Using Levene's test, homogeneity of variance was found because each family engagement variable had a non-significant value, $\mathrm{p}>.05$.

After completing all pre-analysis data screening through examining frequency and descriptive statistics, the following statistical tests were conducted. To determine hypothesis 1: Urban Head Start families will rate themselves higher than rural families on their level of educational attainment a t-test for independent samples was used. An independent t-test was selected because there was one independent variable, geographic location, divided into two categories: rural and urban families. There was also one dependent variable, families as learners, which was a quantitative variable. To meet the criteria for an independent t-test the hypothesis must include one independent variable, divided into two categories, one quantitative dependent variable, and each participant can only be tested once. This test was used to see if there was a significant difference 
between rural and urban Head Start parent's group means when comparing their level of family learning.

A t-test for independent samples was used to test hypothesis 2: Urban Head Start families will rate themselves higher than rural families on their perceived overall emotional, social, and physical well-being. A t-test was selected because there was one independent variable, geographic location, divided into two categories: rural and urban families. There was also one dependent variable, perceived overall family member wellbeing, which was a quantitative variable. To meet the criteria for an independent t-test the hypothesis must include one independent variable, divided into two categories, one quantitative dependent variable, and each participant can only be tested once. This test was used to see if there was a significant difference between rural and urban Head Start parent's group means when comparing their overall family member well-being.

\section{Hypothesis 3: Rural Head Start families will identify more problems or} difficulties when facing transitions than urban Head Start families was tested using a ttest for independent samples. A t-test was selected because there was one independent variable, geographic location, divided into two categories: rural and urban families. There was also one dependent variable, family engagement in transitions, which is a quantitative variable. To meet the criteria for an independent $t$-test the hypothesis must include one independent variable, divided into two categories, one quantitative dependent variable, and each participant can only be tested once. This test was used to see if there was a significant difference between rural and urban Head Start parent's group means when comparing their overall family engagement in transitions. 
A t-test was used to test hypothesis 4: Urban Head Start families will exhibit higher levels of perceived family engagement by scoring themselves higher overall on the parental involvement survey and each of the four individual PFCE family engagement outcomes the survey measures: parent-child relationships, families as lifelong educators, family connection to peers and community, and families as advocates. A t-test was selected because there was one independent variable, geographic location, divided into two categories: rural and urban families. There were also four dependent variables: parent child relationships, families as lifelong educators, family connection to peers and community, and families as advocates and leaders all measured using the PASS survey. To meet the criteria for an independent t-test the hypothesis must include one independent variable, divided into two categories, one quantitative dependent variable, and each participant can only be tested once. This hypothesis provides one independent variable and four dependent variables that were measured separately using four independent t-tests. In addition, they were combined using the overall PASS survey score. An independent t-test was completed to compare the differences between the group means on all parental involvement measures. 


\section{Chapter 4: Results}

The purpose of this chapter is to examine the differences between rural and urban families specifically related to family engagement using the seven family engagement outcomes provided by the Head Start PFCE Framework. This chapter is divided into three sections. First, demographic data are reported on respondents. Second, descriptive data are provided for the independent and the dependent variables. Finally, this chapter reports the results of data analyses using independent t-tests for the four study hypothesis. A total of 848 Head Start parents were provided surveys and invited to participate in this study. Out of the 848 surveys and invitations, 419 Head Start parents responded. This makes the response rate for this study $49 \%$.

Before the data were analyzed using independent t-tests, a pre-analysis screening was conducted to assure the data being analyzed met the assumptions needed to obtain valid results using independent t-tests. There were six assumptions considered prior to using independent t-tests (Coolidge, 2012). Three assumptions were met prior to data collection. First, the data being analyzed had one independent variable that consisted of two categorical independent groups. Second, the dependent variables only measured continuous data. Finally, independence of observation was maintained because there was not a relationship between the rural and urban Head Start families that were sampled.

During pre-analysis screening, the final three assumptions were met. The fourth assumption for doing independent t-tests states there should not be any significant outliers. Data screening revealed 48 cases exceeded the criterion for outlier detection and were list-wise deleted. The fifth assumption, homogeneity of variance, was found using Levene's test. Levene's test found each family engagement variable had a non- 
significant value, $p>.05$. Normal distribution of the data was the final assumption used to determine if an independent $\mathrm{t}$-test was appropriate. A test of normality was conducted using the Kolmogorov-Smirinov test. This test indicated there were some variables that were not normally distributed. However, this result is normal when using it with larger sample sizes (>200) because significant results can occur when there are small deviations from normality. Significance does not mean the deviation from normality is enough to bias the results (Field, 2009). In addition, when reviewing the skewness and kurtosis of the variables the values were reviewed and the values were between the +1 and -1 values. These are appropriate levels to be considered normally distributed. The final sample consisted of 338 Head Start parents that reduced the response rate to $40 \%$.

\section{Demographic Data}

The demographic data for the 338 participating Head Start parents are discussed in this section. In terms of gender, $91.4 \%$ of the respondents were female $(n=309)$ and $8.6 \%$ of the respondents were male $(\mathrm{n}=29)$. The larger percentage of female respondents were similar to other studies completed on family engagement that found response rates of females to be over $90 \%$ of the returned studies (Kohl, Lengua, \& McMahon, 2000; LaForett et al., 2010).

The respondents' ages ranged from the youngest participant at 18 years of age to the oldest participant at 60 years of age. The mean age of participants was at 30 years $(S D=7)$. This mean is slightly less than other studies completed on family engagement

of Head Start parents where means averaged 32-33 years of age (Fantuzzo, McWayne, \& Perry, 2004; Fantuzzo, Tighe, \& Childs, 2000; McWayne et al., 2008). 
In terms of race, $88.3 \%$ of the participants identified themselves as White $(\mathrm{n}=$ 293), 5.4\% were Black or African American $(\mathrm{n}=18), 1.5 \%$ were American Indian and Alaska Native $(n=5), 1.2 \%$ were Asian $(n=4), .3 \%$ were Native Hawaiian and Other Pacific Islander $(\mathrm{n}=1)$, and 3.3\% $(\mathrm{n}=11)$ identified themselves using the "Other" category (see Table 3 for the participants race).

Table 3

Race Characteristics

\begin{tabular}{lcc}
\hline Race & $\mathrm{n}$ & Valid \% \\
\hline White & 293 & 88.3 \\
Black or African American & 18 & 5.4 \\
$\begin{array}{l}\text { American Indian and Alaska } \\
\text { Native }\end{array}$ & 5 & 1.5 \\
$\begin{array}{l}\text { Asian } \\
\text { Native Hawaiian and Other }\end{array}$ & 4 & 1.2 \\
$\begin{array}{l}\text { Pacific Islander } \\
\text { Other }\end{array}$ & 1 & .3 \\
\hline
\end{tabular}

Note. $\mathrm{N}=332$

It should be noted when focusing on the demographic variable of race the proportion of participants who reported their race as "White" was extremely high in comparison to other studies completed on Head Start parents and family engagement (Fantuzzo, McWayne, \& Perry, 2004; Fantuzzo, Tighe, \& Childs, 2000; McWayne et al., 2008). These demographic findings were anticipated by this researcher and noted in the aforementioned method of inquiry section in Chapter 1 as one of the reasons this sample was chosen. Although this sample was slightly less than the average population for southwest Missouri where the population is predominately Caucasian (91.8\% or greater) 
in both rural and urban areas, it helps support this study's relevance because these findings are less likely contributed to other factors, such as cultural differences (U.S. Department of Commerce United States Census Bureau [U.S. Census Bureau], 2013).

Participants' education level was examined and the results reflect that the highest level of educational achievement reported in this analysis was an associate's degree ( $\mathrm{n}=$ $51,15.1 \%)$. However, most participants in this study identified themselves as either a high school graduate $(n=103)$ or a high school graduate with some college courses $(n=$ 118). The complete educational levels of participants in this study are presented in Table 4. These educational levels were comparable to the educational levels of other study participants in family engagement Head Start research (Fantuzzo, McWayne, \& Perry, 2004; Fantuzzo, Tighe, \& Childs, 2000; McWayne et al., 2008).

Table 4

\section{Education Levels}

\begin{tabular}{lll}
\hline Level of Education & $\mathrm{n}$ & Valid \%
\end{tabular}

Less than high school

High school graduate

Some college, no degree

Associate's degree
66

103

118

51
19.5

30.5

34.9

15.1

Note. $\mathrm{N}=338$

Each participant was asked to identify their marital status on the survey. Most participants reported being married $(n=132,39.1 \%)$. The second largest group identified themselves as single $(n=93,27.5 \%)$. The smallest group of participants identified by marital status were widows $(n=2, .6 \%)$. Table 5 presents the demographic 
results for marital status. Previous research on Head Start families and family engagement indicates no noticeable consistency related to marital status of participants. In some studies, the majority of the participants were single; whereas, in other studies the majority of the participants were married (Fantuzzo, McWayne, \& Perry, 2004; Fantuzzo, Tighe, \& Childs, 2000; McWayne et al., 2008).

Table 5

Marital Status

\begin{tabular}{lcc}
\hline Marital Type & $\mathrm{n}$ & Valid \% \\
\hline Single & 93 & 27.5 \\
Married & 132 & 39.1 \\
Separated & 25 & 7.4 \\
Widowed & 2 & .6 \\
Divorced & 50 & 14.8 \\
Living with Partner & 36 & 10.7
\end{tabular}

Note. $\mathrm{N}=338$

\section{Descriptive Statistics for Variables}

Independent variable. There was one independent variable identified for this study: geographic location. This independent variable was divided into two categories: rural and urban families whose children attend Head Start. There were nine communities in southwest Missouri chosen to be rural sites. These included: Ashgrove, Butterfield, Crane, Fairgrove, Fordland, Greenfield, Kissee Mills, Reed Springs, and Seymour. There was one Head Start center in each of these nine communities. All nine of these rurally located Head Start centers participated in this study. At the time of data collection, there 
were 225 families whose children were currently enrolled in Head Start services in these rurally located classrooms (Shinn-Brown, 2012). Springfield, Missouri was the one community chosen to be the urban site. This site was chosen based upon the 2010 Census Bureau's urban-rural classification system that stated Springfield's population of 160,660 met the qualifications to be considered an urban area (http://www.census.gov/geo/www/ua/2010urbanruralclass.html). There were 20 classrooms in this urban area and seven Head Start centers. All of these urban located classrooms and Head Start centers were asked to participate in this study. At the time of data collection, there were 623 families whose children were currently enrolled in Head Start services in these classrooms (Shinn-Brown, 2012).

It should be noted a larger number of surveys were provided to urban Head Start classrooms. This was done because the researcher wanted the number of sites sampled to be comparable in both rural and urban areas. There were nine Head Start sites sampled in rural southwest Missouri and seven Head Start sites sampled in urban southwest Missouri. The sample discrepancy between the two categories was due to the number of children attending each Head Start site. The urban Head Start sites chosen had more children attending their program $(n=623)$ than the rural sites $(n=225)$. Therefore, there was an anticipated larger rate of return for urban Head Start sites sampled. This researcher recognizes it is most efficient to have equality in group size. However, there is a benefit gained by studying more Head Start parents, even if they all belong to the same group. In addition, since the data was normally distributed, analysis was able to be completed taking into account the inequality in sample sizes. 
The independent variable geographic location was broken down to include an $\mathrm{n}$ of 241 urban Head Start families and an n of 97 rural Head Start families. The urban Head Start classrooms had a rate of return of $39 \%$ and the rural Head Start classrooms had a rate of return of $43 \%$. There were 29 urban and rural Head Start classrooms used in this study. Table 6 provides the return rate for each Head Start classroom surveyed.

Table 6

Participants by Head Start Center Classroom

\begin{tabular}{|c|c|c|}
\hline $\begin{array}{l}\text { Geographic Location of } \\
\text { Each Classroom }\end{array}$ & $\mathrm{n}$ & Valid \% \\
\hline Rural Classroom 1 & 7 & 2.1 \\
\hline Rural Classroom 2 & 4 & 1.2 \\
\hline Rural Classroom 3 & 10 & 3.0 \\
\hline Rural Classroom 4 & 7 & 2.1 \\
\hline Rural Classroom 5 & 15 & 4.4 \\
\hline Rural Classroom 6 & 10 & 3.0 \\
\hline Rural Classroom 7 & 17 & 5.0 \\
\hline Rural Classroom 8 & 9 & 2.7 \\
\hline Rural Classroom 9 & 18 & 5.3 \\
\hline Urban Classroom 1 & 22 & 6.5 \\
\hline Urban Classroom 2 & 9 & 2.7 \\
\hline Urban Classroom 3 & 25 & 7.4 \\
\hline Urban Classroom 4 & 10 & 3.0 \\
\hline Urban Classroom 5 & 5 & 1.5 \\
\hline Urban Classroom 6 & 5 & 1.5 \\
\hline
\end{tabular}




\begin{tabular}{lcc} 
Urban Classroom 7 & 16 & 4.7 \\
Urban Classroom 8 & 17 & 5.0 \\
Urban Classroom 9 & 19 & 5.6 \\
Urban Classroom 10 & 4 & 1.2 \\
Urban Classroom 11 & 6 & 1.8 \\
Urban Classroom 12 & 14 & 4.1 \\
Urban Classroom 13 & 6 & 1.8 \\
Urban Classroom 14 & 9 & 2.7 \\
Urban Classroom 15 & 20 & 5.9 \\
Urban Classroom 16 & 13 & 3.8 \\
Urban Classroom 17 & 4 & 1.2 \\
\hline Urban Classroom 18 & 24 & 7.1 \\
Urban Classroom 19 & 8 & 2.4 \\
\hline Urban Classroom 20 & 5 & 1.5 \\
\hline Note. N = 338 & &
\end{tabular}

Dependent variables. There were seven family engagement variables used as dependent variables in this research: family well-being, parent-child relationships, families as lifelong educators, families as learners, family engagement in transitions, family connections to peers and community, and families as advocates and leaders. Please refer to Table 7 for descriptive statistics for the dependent variables. Table 7 Descriptive Statistics for Dependent Variables

\begin{tabular}{lllll}
\hline Independent Variable & Minimum & Maximum & $M$ & $S D$
\end{tabular}




\begin{tabular}{|c|c|c|c|c|}
\hline 1. Family Well-Being & 0 & $80^{* *}$ & 49.70 & 11.45 \\
\hline $\begin{array}{l}\text { 2. Parent-Child } \\
\text { Relationships }\end{array}$ & 4 & $20 *$ & 6.25 & 1.71 \\
\hline $\begin{array}{l}\text { 3. Families as } \\
\text { Lifelong Educators }\end{array}$ & 8 & $40^{*}$ & 15.75 & 4.08 \\
\hline $\begin{array}{l}\text { 4. Families as } \\
\text { Learners }\end{array}$ & 1 & $7 * *$ & 2.46 & .97 \\
\hline $\begin{array}{l}\text { 5. Family } \\
\text { Engagement in } \\
\text { Transitions }\end{array}$ & 0 & $16^{* *}$ & 12.70 & 2.16 \\
\hline $\begin{array}{l}\text { 6. Family } \\
\text { Connections to } \\
\text { Peers and } \\
\text { Community }\end{array}$ & 4 & $20 *$ & 10.83 & 3.00 \\
\hline $\begin{array}{l}\text { 7. Families as } \\
\text { Advocates and } \\
\text { Leaders }\end{array}$ & 8 & $40 *$ & 16.59 & 3.51 \\
\hline
\end{tabular}

Note. $\mathrm{N}=338 . M=$ Mean; $S D=$ Standard deviation. $*$ higher scores indicate more barriers. **lower scores indicate more barriers.

Family well-being. The Family Member Well-Being Index (FMWB) was used to measure the overall well-being of Head Start families (McCubbin \& Patterson, 1983). The FMWB had a possible range of $0-80$ with an average of $50(S D=11)$. The FMWB asked eight questions using a 10-point Likert scale. The higher a participant scored on this instrument the higher the participant's overall family well-being. Table 8 provides the descriptive statistics for each of the eight items on the Family Member Well-Being Index that measured family well-being.

Table 8

Descriptive Statistics for Family Well-Being Measured by the FMWB Index

\begin{tabular}{lllll}
\hline Item & Minimum & Maximum & $M$ & $S D$ \\
\hline How concerned or worried about your health & 0 & 10 & 6.25 & 2.73 \\
have you been? & & & & \\
How relaxed or tense have you been? & 0 & 10 & 4.92 & 2.28 \\
How much energy, pep, vitality have you & 0 & 10 & 5.23 & 1.90 \\
felt? & & & &
\end{tabular}


$\begin{array}{lllll}\text { How depressed or cheerful have you been? } & 0 & 10 & 5.83 & 2.00\end{array}$

$\begin{array}{lllll}\text { How afraid have you been? } & 0 & 10 & 7.79 & 1.98\end{array}$

$\begin{array}{lllll}\text { How angry have you been? } & 0 & 10 & 7.03 & 2.02\end{array}$

$\begin{array}{lllll}\text { How sad have you been? } & 0 & 10 & 6.80 & 2.40\end{array}$

$\begin{array}{lllll}\text { How concerned or worried about the health } & 0 & 10 & 5.60 & 2.94\end{array}$

of another family member have you been?

Note. $\mathrm{N}=338 . M=$ Mean; $S D=$ Standard deviation. Higher scores indicate fewer barriers.

Parent-child relationships. The second dependent variable, parent-child relationships, was measured using items 4, 14, 16, and 19 from the Parent and School Survey (Ringenberg et al., 2005). The range of scoring for these four items were 4-20 with an average of $6.25(S D=1.71)$. Table 9 provides descriptive statistics for the four items on the PASS survey used to measure parent-child relationships.

Table 9

Descriptive Statistics for Parent-Child Relationships Measured by the PASS Survey

\begin{tabular}{lllll}
\hline Item & Minimum & Maximum & $M$ & $S D$ \\
\hline $\begin{array}{l}\text { I frequently explain difficult ideas to my child when } \\
\text { she/he doesn't understand. }\end{array}$ & 1 & 5 & 1.57 & .85 \\
$\begin{array}{l}\text { There are many children's books in our house. } \\
\text { My child misses school several days in a 3 month }\end{array}$ & 1 & 5 & 1.30 & .68 \\
$\begin{array}{l}\text { time period. } \\
\text { Reading books is a regular activity in our home. }\end{array}$ & 1 & 5 & 2.00 & 1.14 \\
\end{tabular}

Note. $\mathrm{N}=338 . M=$ Mean; $S D=$ Standard deviation. Higher scores indicate more barriers.

Families as lifelong educators. Families as lifelong educators was the third variable. It was measured using items $1,2,5,9,12,15,18$, and 23 on the Parent and School Survey (Ringenberg et al., 2005). The range of scoring for these eight items was 8-40 with an average of $15.75(S D=4.08)$. Table 10 provides descriptive statistics for 
the eight items on the PASS survey used to measure the variable families as lifelong educators.

Table 10

Descriptive Statistics for Families as Lifelong Educators Measured by the PASS Survey

\begin{tabular}{|c|c|c|c|c|}
\hline Item & Minimum & Maximum & $M$ & $S D$ \\
\hline $\begin{array}{l}\text { I feel very comfortable visiting my child's Head } \\
\text { Start center. }\end{array}$ & 1 & 5 & 1.31 & .75 \\
\hline $\begin{array}{l}\text { My child's school work is always displayed in } \\
\text { our home }\end{array}$ & 1 & 5 & 1.46 & .82 \\
\hline $\begin{array}{l}\text { Every time my child does something well at } \\
\text { school I compliment him } / \text { her. }\end{array}$ & 1 & 5 & 1.21 & .56 \\
\hline I read to my child every day. & 1 & 5 & 1.91 & .85 \\
\hline $\begin{array}{l}\text { I have visited my child's classroom several } \\
\text { times in the past year. }\end{array}$ & 1 & 5 & 2.20 & 1.18 \\
\hline $\begin{array}{l}\text { In the past } 12 \text { months I have attended activities } \\
\text { at my child's school several times. }\end{array}$ & 1 & 5 & 2.55 & 1.64 \\
\hline $\begin{array}{l}\text { I don't understand the in-home activities and/or } \\
\text { assignments my child brings home. }\end{array}$ & 1 & 5 & 1.85 & 1.08 \\
\hline $\begin{array}{l}\text { In the past } 12 \text { months I have volunteered at my } \\
\text { child's preschool at least } 3 \text { times. }\end{array}$ & 1 & 5 & 3.68 & 1.29 \\
\hline
\end{tabular}

Note. $\mathrm{N}=338 . M=$ Mean; $S D=$ Standard deviation. Higher scores indicate more barriers.

Families as learners. Families as learners was ascertained through the demographic questionnaire by asking "what is the highest degree or level of education you have completed (a) less than high school (b) high school graduate (includes equivalency) (c) some college, no degree (d) Associate's degree (e) Bachelor's degree (f) $\mathrm{PhD}(\mathrm{g})$ graduate or professional degree". The average participant was a high school graduate $(S D=.97)$.

Family engagement in transitions. The Family Coping Coherence Index (FCCI) was used to measure how Head Start families dealt with transitions (McCubbin et al., 1982). The FCCI had a possible range of $0-16$ with an average of $13(S D=2)$. The 
FCCI asked four questions using a 5-point Likert scale. The higher a participant scored on this scale the better the participant is at engaging in transitions. Table 11 provides the descriptive statistics for each of the four items on the Family Coping Coherence Index that measured family engagement in transitions.

Table 11

Descriptive Statistics for Family Engagement in Transitions Measured by the FCCI Instrument

\begin{tabular}{lllll}
\hline Item & Minimum & Maximum & $M$ & $S D$ \\
\hline Accepting stressful events as a fact of life. & 0 & 4 & 2.97 & .87 \\
$\begin{array}{l}\text { Accepting that difficulties occur unexpectedly. } \\
\text { Defining the family problem in a more positive }\end{array}$ & 0 & 4 & 3.13 & .79 \\
$\begin{array}{l}\text { way so that we do not become too discouraged. } \\
\text { Having faith in God. }\end{array}$ & 0 & 4 & 3.19 & .77 \\
\end{tabular}

Note. $\mathrm{N}=338 . M=$ Mean; $S D=$ Standard deviation. Higher scores indicate fewer barriers.

Family connections to peers and community. Family connections to peers and community was the sixth dependent variable. It was measured using items 10, 11, 20, and 24 on the Parent and School Survey (Ringenberg et al., 2005). The range of scoring for these four items was 4-20 with an average of $10.83(S D=3)$. Table 12 provides descriptive statistics for the four items on the PASS survey used to measure the variable family connections to peers and community.

Table 12

Descriptive Statistics for Family Connections to Peers and Community Measured by PASS 


\begin{tabular}{llllc}
\hline Item & Minimum & Maximum & $M$ & $S D$ \\
\hline $\begin{array}{l}\text { I talk with other parents frequently about } \\
\text { educational issues. }\end{array}$ & 1 & 5 & 3.09 & 1.04 \\
$\begin{array}{l}\text { My child attends community programs } \\
\text { regularly. }\end{array}$ & 1 & 5 & 3.35 & 1.19 \\
$\begin{array}{l}\text { If my child was having trouble in preschool I } \\
\begin{array}{l}\text { would not know how to get extra help for } \\
\text { him/her. }\end{array}\end{array}$ & 1 & 5 & 1.89 & 1.17 \\
$\begin{array}{l}\text { I know about many programs for children in my } \\
\text { community. }\end{array}$ & 1 & 5 & 2.56 & 1.21 \\
\hline
\end{tabular}

Note. $\mathrm{N}=338 . M=$ Mean; $S D=$ Standard deviation. Higher scores indicate more barriers.

Families as advocates and leaders. Families as advocates and leaders was the seventh dependent variable. It was measured using items $3,6,7,8,13,17,21$, and 22 on the Parent and School Survey (Ringenberg et al., 2005). The range of scoring for these eight items was 8-40 with an average of $16.59(S D=3.51)$. Table 13 provides descriptive statistics for the eight items on the PASS survey used to measure the variable families as advocates and leaders.

Table 13

Descriptive Statistics for Families as Advocates and Leaders Measured by PASS Survey

\begin{tabular}{lllll}
\hline Item & Minimum & Maximum & $M$ & $S D$ \\
\hline $\begin{array}{l}\text { If my child misbehaved at school, I would know } \\
\text { about it soon afterward. }\end{array}$ & 1 & 5 & 1.51 & .84 \\
$\begin{array}{l}\text { Talking with Head Start administrators makes me } \\
\text { uncomfortable. }\end{array}$ & 1 & 5 & 1.56 & .84 \\
$\begin{array}{l}\text { I always know how well my child is doing in } \\
\text { school. }\end{array}$ & 1 & 5 & 1.71 & 1.90 \\
$\begin{array}{l}\text { I am confused about my legal rights as a parent } \\
\text { of a student. }\end{array}$ & 1 & 5 & 1.74 & 1.09 \\
$\begin{array}{l}\text { I have made suggestions to my child's teachers } \\
\text { about how to help my child learn. }\end{array}$ & 1 & 5 & 2.56 & 1.20 \\
$\begin{array}{l}\text { Talking with my child's current teacher makes } \\
\text { me somewhat uncomfortable. }\end{array}$ & 1 & 5 & 1.38 & .73 \\
$\begin{array}{l}\text { I know the policy governing Head Start well. } \\
\text { naln }\end{array}$ & 1 & 5 & 2.49 & 1.10 \\
\hline
\end{tabular}


In the past 12 months I have attended several

1

5

$\begin{array}{ll}4.25 & .89\end{array}$

Head Start Policy Council Meetings.

Note. $\mathrm{N}=338 . M=$ Mean; $S D=$ Standard deviation. Higher scores indicate more barriers.

\section{Results of Hypotheses}

Hypothesis 1. Hypothesis one Urban Head Start families will rate themselves higher than rural families on their level of educational attainment was tested using a ttest for independent samples. This hypothesis tested whether urban families have a higher level of educational attainment compared to rural Head Start families. The t-test for independent samples indicated that, on average, urban Head Start families level of educational attainment was higher $(M=2.49, S E=.061)$ than rural Head Start families $(M=2.38, S E=1.04)$. However, this difference was not significant $t(336)=.891, \mathrm{p}>$ .05 .

Hypothesis 2. A t-test for independent samples was used to test hypothesis two Urban Head Start families will rate themselves higher than rural families on their perceived overall emotional, social, and physical well-being. Hypothesis 2 measured the variable family well-being using the Family Member Well-Being Index. This hypothesis tested whether urban families have a higher score on overall family well-being than their rural counterpart. The t-test for independent samples was completed and did not validate this hypothesis. Findings indicated, on average, rural families had greater overall family well-being $(M=51.02, S E=1.24)$ than urban families $(M=49.15, S E=.72)$. This difference was not significant $t(336)=-1.361, \mathrm{p}>.05$.

Hypothesis 3. Hypothesis three Rural Head Start families will identify more problems or difficulties when facing transitions than urban Head Start families was tested using a t-test for independent samples. Hypothesis 3 measured the variable family 
engagement in transitions using the Family Coping Coherence Index. This hypothesis posited that urban families would have a higher score on their ability to adjust to transitions than their rural counterpart. The t-test for independent samples was completed and did not find a difference between the two groups. On average, there was not a significant difference $t(336)=-.06, \mathrm{p}>.05$ between rural $(M=12.71, S E=.23)$ and urban families $(M=12.70, S E=.14)$.

Hypothesis 4. A t-test was used to test hypothesis four Urban Head Start families will exhibit higher levels of perceived family engagement by scoring themselves higher overall on the parental involvement survey and each of the four individual PFCE family engagement outcomes the survey measures: parent-child relationships, families as lifelong educators, family connection to peers and community, and families as advocates. Hypothesis 4 measured the variables: parent-child relationships, families as lifelong educators, family connections to peers and community, and families as advocates and leaders using the PASS survey. This hypothesis posited that urban families will score higher on the parent involvement survey than their rural counterparts. First, using the score from the overall PASS survey a t-test for independent samples was conducted to determine the group difference between rural and urban families on their perceived levels of family engagement. Results indicated, on average, urban families exhibited higher levels of perceived family engagement with higher scores achieved on the parent involvement survey $(M=50.11, S E=.56)$ than their rural counterparts $(M=47.58, S E=$ .980). This difference was significant $t(336)=2.33, \mathrm{p}<.05$. Figure 5 provides a bar graph to illustrate the group differences. 


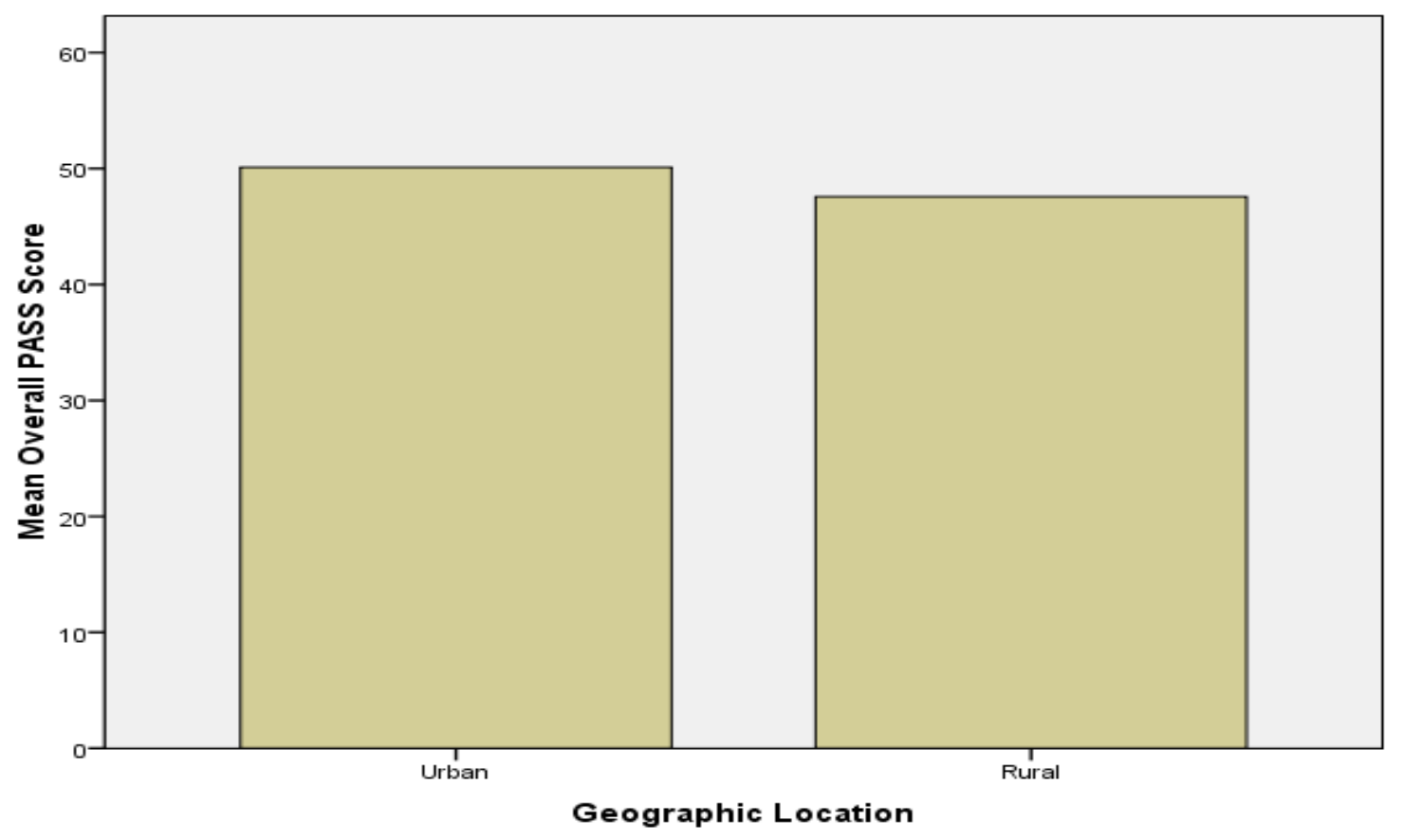

Figure 5. Mean differences between rural and urban Head Start families on their perceived level of family engagement.

Second, each individual family engagement variable was analyzed separately. It should be noted that although the overall PASS survey score found significant differences between rural and urban Head Start families on their perceived level of family engagement, when analyzing each individual variable used in this hypothesis only two out of the four variables were significant. The first significant variable found was urban families were more likely to perceive themselves as advocates and leaders $(M=16.85, S E$ $=.22)$ than rural families $(M=15.94, S E=.37)$. This difference was found to be significant $t(336)=2.164, \mathrm{p}<.05$. Lifelong educators was the second variable found to be significant $t(336)=2.128, \mathrm{p}<.05$. Urban families had a higher level of perceived family engagement when looking at the variable families as lifelong educators $(M=$ $16.05, S E=.27)$ than rural families $(M=15.01, S E=.40)$. Table 14 provides the results from the four hypothesis and seven dependent variables measured in this study. Table 14 
Results of Hypotheses Testing

\begin{tabular}{|c|c|c|c|c|c|}
\hline $\begin{array}{l}\text { PFCE Family Engagement } \\
\text { Outcomes }\end{array}$ & $\begin{array}{l}\text { Hypotheses } \\
\text { Number }\end{array}$ & $\begin{array}{l}\text { Urban } \\
\text { Mean }\end{array}$ & $\begin{array}{l}\text { Rural } \\
\text { Mean }\end{array}$ & $\begin{array}{c}\text { t- } \\
\text { value }\end{array}$ & Sig \\
\hline 1. Family Well-Being & 2 & 49.15 & 51.02 & -1.36 & .17 \\
\hline 2. Parent-Child Relationships & 4 & 6.34 & 6.01 & 1.63 & .10 \\
\hline $\begin{array}{l}\text { 3. Families as Lifelong } \\
\text { Educators }\end{array}$ & 4 & 16.05 & 15.01 & 2.128 & .03 \\
\hline 4. Families as Learners & 1 & 2.49 & 2.38 & .89 & .37 \\
\hline $\begin{array}{l}\text { 5. Family Engagement in } \\
\text { Transitions }\end{array}$ & 3 & 12.70 & 12.71 & -.06 & .96 \\
\hline $\begin{array}{l}\text { 6. Family Connections to Peers } \\
\text { and Community }\end{array}$ & 4 & 10.96 & 10.53 & 1.20 & .23 \\
\hline $\begin{array}{l}\text { 7. Families as Advocates and } \\
\text { Leaders }\end{array}$ & 4 & 16.85 & 15.94 & 2.164 & .03 \\
\hline
\end{tabular}

Note. $\mathrm{N}=338 . \mathrm{p}$-value with $*(* \mathrm{p}<.05 ; * * \mathrm{p}<.01)$. 


\section{Chapter 5: Discussion}

This chapter will discuss the results and implications of this study. An overview of the findings of this research will be provided. There will be a discussion about these results in comparison to other findings and current research on family engagement. Implications of this study will be discussed from an ecological systems theory. Limitations and strengths of this study will be discussed and recommendations will be made for future research. Finally, practice and policy implications of this dissertation for early childhood educators and social workers will be examined.

\section{Results}

This study explored the differences in family engagement with geographically diverse Head Start parents. Geographic location was used as the independent variable and was divided into two groups: rural and urban. Rural and urban Head Start sites were used to determine if there were differences in family engagement using the outcomes provided by the new Parent, Family, Community Engagement (PFCE) Framework (2011) developed by the Office of Head Start designed to improve children's educational outcomes, learning gains, and developmental sustainability. This study was the first known research completed on Head Start family engagement using the new PFCE Framework's Family Engagement Outcomes.

The PFCE Framework highlighted seven family engagement outcomes that Head Start felt were necessary to achieve a child's school readiness. These included: family well-being, parent-child relationships, families as lifelong educators, families as learners, family engagement in transitions, family connections to peers and community, and families as advocates and leaders. These seven family engagement outcomes provided 
by the PFCE Framework were used as the dependent variables in this research study.

Using these variables, four hypotheses were developed. Below are the results of the main findings of this study in consideration of current family engagement research.

Hypothesis 1 posited urban Head Start families have a higher level of educational attainment than their rural counterparts. This hypothesis was not supported by study results. Educational attainment was found to not vary significantly between rural and urban families. Although past research has not been done to look at the differences in rural and urban families educational attainment, there has been research suggesting overall educational attainment influences family engagement outcomes (McWayne et al., 2008). These findings were used to support this hypothesis. In addition, this hypothesis was derived from the known proximity differences found in resources for training and educational opportunities between the two groups in southwest Missouri. From this knowledge, it was assumed because urban Head Start families were closer to educational resources they would have a higher level of educational attainment. However, proximity to resources did not appear to influence educational attainment. There was no difference found in educational attainment between the two groups, thus supporting previous research suggesting family engagement is influenced only when differences are found.

Two positive conclusions can be drawn from findings that indicate similarity between educational attainment of rural and urban Head Start families. First, this could indicate although there might be more opportunities for training and academic attainment in urban southwest Missouri, rural families are able to access training and academic resources to meet their needs as well. Second, with no difference found in educational attainment between the two groups this factor can receive less focus as a potential barrier 
in family engagement. Therefore, with both rural and urban families having comparable levels of educational attainment this factor should not be considered to influence overall family engagement outcomes in southwest Missouri.

Hypothesis 2 stated urban families would have a higher level of perceived family well-being. This hypothesis was not supported by the study results. Family well-being was not found to vary significantly between rural and urban Head Start families. Previous research on family well-being has indicated other characteristics such as the educational level and mental health status of parents can influence a family's overall well-being (Jacobs \& Harvey, 2005; LaForett et al., 2010). Past research has not considered geographic location as a characteristic influencing family well-being.

Although there has not been research comparing how geographic location influences family well-being, there has been a limited amount of previous research on rural and urban families overall family well-being. These studies do not support the current research and have shown differences between rural and urban family well-being. Findings from one study suggested rural families were less likely to access mental health services compared to findings from another study that found the opposite to be true of urban families. Both studies suggested this influenced their overall family well-being (Cohen \& Hesselbart, 1993; Thompson, 2005). Discrepancies between this study and past research might be due to the population sampled. Previous studies sampled populations from multiple states. The current study examines one region that has numerous homogeneous characteristics in both the rural and urban sites sampled. More research needs to be completed using both rural and urban families, in different locations, for comparison in the same study to accept or reject the findings reported in this study. 
Hypothesis 3 posited rural families would have more difficulty when facing transitions than urban families. This hypothesis was not supported by the findings. Rural families and urban families did not differ significantly when facing transitions. Past research has not considered the variable geographic location as an indicator influencing family engagement in transitions. However, previous research on a family's engagement in transitions has identified a family's socioeconomic status as an indicator of decreased family engagement. The lower the socioeconomic status the less likely family engagement will take place (McIntyre et al., 2007; Schulting et al., 2005).

Since rural southwest Missouri families face more socioeconomic barriers than urban southwest Missouri families, an assumption was made rural families would face more difficulty engaging in transitions (MERIC, 2012). This study defined transitions as parental support for their child's learning and development as they transitioned to new learning environments, such as kindergarten. This assumption was not validated. One reason for this finding might be because this measured a family's engagement in transitions, prior to the biggest transition, a child's transition to kindergarten. More research needs to be done using geographic location as a variable that influences family engagement in transitions to accept or reject this study's findings. In addition, it would be beneficial to measure this outcome after a child's transition to kindergarten. This research should be noted when considering what characteristics should be stressed when trying to increase family engagement in the southwest Missouri Head Start program. Because no difference between the groups was found, perhaps less attention to this variable is warranted when Head Start administrators determine which PFCE Family Engagement Outcomes should be emphasized in rural and urban locations. 
Hypothesis 4 stated urban Head Start families would score themselves higher than rural families overall on the PASS survey as well as the variables parent-child relationships, families as lifelong educators, family connection to peers and community, and families as advocates. This hypothesis was partially supported by the results of this study. Significant differences in the overall parental involvement behaviors between urban and rural Head Start families were found.

This was the first research that considered geographic location as a characteristic influencing overall family engagement. However, past research was used to develop this hypothesis from findings of 2,258 Head Start parents, children, and teachers. This study indicated neighborhood factors were significantly related to a child's developmental outcomes (Vaden-Kiernan et al., 2010). This researcher hypothesized if neighborhood factors could impact developmental outcomes they might also influence family engagement that is considered a factor in a child's developmental readiness for school. Fantuzzo and colleagues (2004) supported this idea in their study on family involvement and child attainment by concluding future studies on family engagement should focus on outcomes from rural and urban samples. This study supports these ideas by finding geographic location does have a significant impact on a parent's overall family engagement level.

The second component of hypothesis 4 focused on the relationship between the individual variables parent-child relationships, families as lifelong educators, family connection to peers and community, and families as advocates and how they were influenced by geographic location. These variables have not been used in prior research comparing geographic locations. However, previous research has shown all four of these 
variables to be indicators for increased family engagement (Annunziata et al., 2006; Auerbach, 2010; Fan \& Williams, 2010; Hiatt-Michael, 2006). When finding differences in these outcomes, based upon geographic location, only two of the four outcomes were found to be significant. These included: families as lifelong educators and families as advocates and leaders. In both variables, the urban families were shown to be more likely than their rural counterparts to be lifelong educators, advocates, and leaders in their child's educational process.

The finding of significant difference in the overall PASS score and the variables families as lifelong educators and families as advocates and leaders; whereas, the variables parent child relationships and family connections to peers and communities were not found significantly different might be due to the instrument used. The PASS Survey is a new instrument that has only had one reliability and validity test completed. In addition, the six PASS constructs defined in the instrument have never been used to measure the specific variables found in the PFCE framework. An assumption can be made that although the instrument is valid in providing an overall understanding of family engagement, when divided into its individual constructs to measure specific variables, the construct definitions might not accurately represent the construct variable. More research needs to be done using these seven variables and this instrument to draw further conclusions. Since this is the first time the PFCE Outcomes have been analyzed to measure overall family engagement, Head Start policy planners should review the seven variables and their definitions to make sure they are accurately representing the definition of family engagement. 
Although only two of the seven individual PFCE outcomes used as variables in this study found differences between rural and urban Head Start families, this researcher believes the most foundational question was answered. There was a significant difference found in overall family engagement based upon a family's geographic location. For over two decades, Head Start administrators in southwest Missouri have seen dissimilarity between rural and urban Head Start families (Sivils-Dickey, 2009). However, there was no empirical evidence to support their hypothesis. This research should encourage southwest Missouri Head Start administrators to trust their practice wisdom to inform and guide policies in their region. In addition, it provides some modest evidence of differences that could support beginning dialogue with rural and urban Head Start sites about the individual needs of their communities.

\section{Theory Implications}

Ecological systems theory provided the conceptual framework for this study. This theory asserts the ecological environment, conceived as a nested arrangement of concentric structures, each contained within the next, referred to as the micro, meso, exo, and macro systems are foundational in understanding the human experience (Bronfenbrenner, 1979). Past Head Start research has focused on individuals in the Head Start program, emphasizing the micro level, rather than on the actual environment that these individuals develop and grow. There is little understanding on how environmental changes influence the developing Head Start family. Below is a discussion of each sub-system in the ecological environment and how these structures apply to current research findings. 
The first ecological structure of the Head Start environment is the micro-system. The micro-system was defined in this research as the child and their relationship to their immediate family, Head Start teachers, and peers. The micro-systems focus was on the Head Start setting where the child engages in particular activities and roles (Bronfenbrenner, 1976). The new PFCE Framework identified the program environment as a micro-system area that impacts successful family engagement ("The Head Start Parent", 2011). However, current Head Start programs in southwest Missouri are using the same activities and Head Start employee roles in both rural and urban sites to meet the child's individual needs. Examples of this include both rural and urban children are exposed to identical curriculum, similar hours of operation, and the same program environment activities. Findings from this study indicate there are differences between rural and urban Head Start children. To be effective, OACAC Head Start administrators and employees should consider reexamining the activities and roles played by Head Start teachers and advocates in rural areas to meet the individual environmental needs of the children they serve.

The second ecological structure of the Head Start environment is the mesosystem. The meso-system was defined in this study as the interaction between the child, family, and the local Head Start program. The meso-system's focus was on the interrelationship between the Head Start setting and the family (Bronfenbrenner, 1976). The new PFCE Framework researched in this study recognized the meso-system in its framework by stating family partnerships was a program impact area that could influence family engagement outcomes ("The Head Start Parent", 2011). In light of current 
research findings, it is important to recognize these interrelationships are different for rural and urban Head Start families.

Head Start programs in southwest Missouri at this time are not recognizing these differences by using the same policies to develop family partnerships. Examples of current family partnership policies include parent educational nights and in-home visits with family advocates. Findings from this study indicate using the same activities might not be an effective way to engage all families. To be effective, OACAC Head Start administrators and employees should consider reexamining the activities and roles played by Head Start teachers and advocates in rural areas to enhance family partnership behavior.

The third ecological structure of the Head Start environment is the exo-system. For the purpose of this study, the exo-system was used to describe whether the Head Start child lives in a rural or urban community. While it doesn't immediately contain the Head Start family, it recognizes how the community setting in which the person is found influences the Head Start family (Bronfenbrenner, 1977). The new PFCE Framework does not identify the community setting of the Head Start family as a way to build positive family engagement outcomes (“The Head Start Parent”, 2011). This study's findings indicate by not recognizing the community setting of the Head Start family, the Head Start program is missing a key component in family engagement. To begin the process of including the community, OACAC Head Start could develop individual community boards in each Head Start location. The purpose of this board would be to focus on each individual community's resources and needs and how these could be integrated into the Head Start classroom. In addition, future revisions to the PFCE 
Framework should include adding the community environment as a program area that impacts family engagement outcomes. This addition would serve to recognize the differences in each community setting to help bring more awareness to how it influences the individual Head Start community.

The final ecological structure of the Head Start environment used in this research was the macro-system. For the purpose of this research the macro-system was used to describe how national Head Start policies affect family engagement in rural and urban communities. The macro-system is the blueprint given by the national Office of Head Start on how to effectively engage families in all Head Start locations. The new PFCE Framework recognizes the macro-system by identifying program leadership as a key component in building positive relationships with families ("The Head Start Parent", 2011). Findings from this study suggest that this blueprint may not be a one-size fits all answer for rural and urban Head Start programs. Differences found in engagement indicate national policies might be affecting families differently in rural and urban areas. Therefore, the national Office of Head Start should examine how the outline given to all programs might not meet the needs of every Head Start. Considerations should be made to provide each site the flexibility to implement and structure their environment in a way that meets the individual needs of the family's they serve.

\section{Limitations and Strengths}

There were several limitations and assumptions made in this study. One limitation was the chosen method of data collection. This study collected data from takehome surveys placed in each Head Start child's take-home folder. In reviewing the educational level of the participants, half of the participants had a high school degree or 
less. Therefore, participants reading levels might have impacted comprehension of every question. Because the surveys were sent home, participants did not have the opportunity to get clarification on items that could have caused them to inaccurately interpret the question. Second, there was no way to insure the intended participant was the one who actually responded. The survey did not ask them to identify their relationship to the child on the questionnaire; therefore, the researcher was not able to confidently ascertain that the parent, or guardian, completed the survey. Third, only self-reported measures were used. Using self reported measures, it was possible the participant might report behavior that did not coincide with their actual family engagement behaviors.

Purposive sampling of Head Start parents was completed on 29 Head Start classrooms in 10 communities located in southwest Missouri. This sampling strategy had limitations. The first limitation can be seen in the generalizability of the results. Only Head Start parents in southwest Missouri were chosen to participate in this study. In examining preschool education, there were many types of preschool settings that incorporated family engagement into their policies and practice. Using only OACAC Head Start families may not be generalizable to other preschool settings. Another limitation of this sampling strategy was the lack of diversity found in southwest Missouri. Unlike other areas in Missouri, the population of southwest Missouri is predominately white (91.8\% or greater) in both rural and urban areas (U.S. Department of Commerce United States Census Bureau [U.S. Census Bureau], 2013). Therefore, the findings of this research may not be transferable to families with diversity found in other Head Start locations. 
The PASS survey was another limitation. Only one reliability and validity test had been conducted using this instrument. In addition, the six PASS constructs defined in the instrument had never been used to measure the specific variables found in the PFCE framework. Since this researcher found significance in the overall family engagement score between rural and urban families, but did not find significance in all individual variables, the validity of the data could have been limited by the degree of validity and reliability of the instrument. An assumption could be made that although the instrument was valid in providing an overall understanding of family engagement, when divided into its individual constructs to measure specific variables, the construct definitions might not have accurately represented the individual construct variable.

The final limitation for this study was the response rate. Using survey research, it is common to have low response rates from participants. This disadvantage was shown in our response rate. The actual rate of return for this study was $49 \%$. However, the usable response rate was only $40 \%$. These return rates are lower than what most researchers feel is adequate (Rubin \& Babbie, 2010). However, it should be noted they were in the appropriate range using the table developed by Bartlett, Kotrlik \& Higgins (2001) for determining minimum returned sample sizes.

Although there were several limitations, there were also strengths found in this research. First, this study was unique due to the lack of racial and ethnic diversity found in both rural and urban Head Start families. Unlike other studies conducted on Head Start families, this study had a high percentage of the same race and ethnicity (Fantuzzo, McWayne, \& Perry, 2004; Fantuzzo, Tighe, \& Childs, 2000; McWayne et al., 2008). Because of this, assumptions cannot be made stating differences were due to diversity 
based upon race and ethnicity between the two groups. Second, by allowing the takehome survey to go home with the child the Head Start parents had the opportunity to read and answer the questions at their own pace. Third, there was not any identifying information on the Head Start survey. By sampling participants this way, they were provided a greater sense of anonymity that could lead to a more accurate description of their family engagement activities. In addition, there was a lower chance of introducing researcher bias when sampling the respondents since the researcher was not present when the surveys were completed.

\section{Future Research Recommendations}

Gaining a better understanding of family engagement characteristics that deter or encourage the continued development of a child's school readiness outcomes is essential. The current study did this by introducing another characteristic influencing family engagement; geographic location. While the identification of specific characteristics that affect family engagement is important, future research should move this agenda further by focusing on specific types of family engagement activities and policies that serve to increase or decrease family engagement levels to bridge the rural and urban divide.

For example, currently OACAC Head Start asks parents to participate in voluntary in-home services provided by Head Start family advocates. Although these family advocates have specific things they address each visit, they do not have an evidenced-based curriculum to do this. Future research should focus on specific techniques, activities, and policies preschool centers are using to engage families, and how these techniques are influencing family engagement levels. It should be noted family engagement techniques and activities should be researched on diverse Head Start 
samples and should be modified to meet the individual characteristics of each Head Start location.

The second area of future study should focus on the differences found between rural and urban locations when engaging Head Start families. There have been numerous studies that have found differences in families based upon the demographic variable, geographic location (Allen, 2008; Bender, Fedor, \& Carlson, 2011; Hope \& Bierman, 1998, Simpson \& Braun, 2007). However, specific research done on geographic differences and their impact on family engagement is absent from the research. Fantuzzo and colleagues (2004) highlighted this in their discussion of future research almost a decade ago and to date this is the only study recognizing this as a needed area of research development. Future studies should continue the focus on rural and urban differences by examining other aspects of the PFCE Framework such as the program environment, family and community partnerships, and teaching and learning activities ("The Head Start Parent", 2011). These studies should be done to help prove the legitimacy of the new Head Start PFCE Framework.

In addition to specific research focusing on geographic differences and family engagement, it is important for future research to focus on how rural and urban communities help to influence children's overall school experience and sustain their learning throughout their formative education. To do this, future research needs to move past only acknowledging there is a rural and urban divide and begin to study the unique characteristics of each location to meet the individual needs of each community and its families. One way to do this is to create pilot sites in both rural and urban communities and have local community members review the curriculums and adapt those curriculums 
to meet the needs of the community. A second way to do this would be for Head Start administrators to only provide a broad framework for each Head Start location to follow. For example, when looking at family engagement, Head Start administrators could make this a goal, but not specify to each area how to achieve this goal. Then each local Head Start community would be tasked with how to develop this for their community. The goal of doing this would be to provide each Head Start location with the opportunity to tailor their families and community's uniqueness into how to best engage families. Research should then be completed to evaluate each sites family engagement levels.

The third area of future research focuses on the three Head Start frameworks that recognize family engagement as a key component to a Head Start child's development. These include: the Revised Framework for Programs Serving Infants and Toddlers and Their Families, The Head Start Child Development and Early Learning Framework, and The Parent, Family, and Community Engagement (PFCE) Framework. All three frameworks identify family engagement as a goal. Only one of the three frameworks, the PFCE Framework, allows researchers the ability to introduce specific measurement markers used for systematic evaluation to obtain family engagement outcomes. The present study was the first to use these outcomes to scientifically measure family engagement. Future research should analytically evaluate family engagement through the definitions provided in each framework to better understand the influence diverse geographical locations have on the framework definitions. To do this, the Revised Framework for Programs Serving Infants and Toddlers and Their Families and The Head Start Child Development and Early Learning Framework need specific measurement markers to evaluate family engagement through each framework. 
The final area of further research should take family engagement a step further through focusing solely on a better understanding of the new PFCE Framework (2011) developed by the Office of Head Start. The Office of Head Start identified seven family engagement outcomes that were loosely based on Epstein's (1995) work on the six types of parental involvement effective in connecting families, schools, and communities. The present study did not find differences between rural and urban families on all of the seven family engagement outcomes identified by the PFCE Framework. However, it did find an overall difference in rural and urban areas using the PASS instrument.

This could have been due to several reasons. First, in some individual areas of family engagement, identified by the PFCE Framework, there might not be any differences in how rural and urban families engage. Second, and more concerning of the two reasons, would be the current PFCE Framework has several family engagement variables that did not accurately measure the overall family engagement outcome. The reason this researcher is concerned about this was because the overall parent involvement score reflected differences between rural and urban families. However, when individual variables identified by the PFCE framework were analyzed, not all variables found differences. Future research studies should focus on each specific variable identified by the PFCE Framework as a variable to achieve family engagement and determine whether these variables are accurately measuring overall family engagement outcomes.

\section{Practice and Policy Implications}

The findings of this study in context with previous research have significant implications on Head Start family engagement practices and policies. Taken as a whole, the results of this study indicate quality family engagement is interwoven with 
environmental factors surrounding the developing Head Start child. These findings have direct implications described below for Head Start administrators, classroom teachers, and Head Start families. Practice and policy implications from this study will also be discussed for social workers to help reintroduce them to the field of early childhood education.

For Head Start practitioners, family engagement has been a foundational component for the Head Start community since its inception. Recently, Head Start has reiterated their focus on this component by creating the PFCE Framework. While this framework is a step in the right direction, specific practice techniques need to be developed for the Head Start practitioner. One area that needs further specialization is how to meet the individual needs of families based upon the environment they reside.

Presently, OACAC Head Start is using the same techniques to engage all Head Start families. Results from this study indicate family engagement differences between geographic locations. Therefore, a one-size-fits-all family engagement policy is not effective for all Head Start sites. To change this, OACAC Head Start administrators should consider holding meetings with Head Start teachers and parents from each location to develop individual goals to increase family engagement. These goals should focus on recognizing what is currently working in each Head Start location. With this knowledge, areas that are not seen as effective should be eliminated and new agreed upon goals should be introduced.

The difference in family engagement based upon geographic location in this study also draws attention to the current use of the Head Start Policy Council. Presently, there is one Head Start Policy Council in southwest Missouri. Members include: Head Start 
administrators, Head Start parents, and community participants. The purpose of this council is to discuss and approve Head Start policy for the entire OACAC Head Start program. Results of this study indicate there are environmental differences found in Head Start sites. Therefore, instead of having one Head Start Policy Council, OACAC administrators should consider creating councils in each Head Start location. This would serve to encourage discussions on the individual needs of each Head Start to help develop a stronger Head Start program.

For social work practitioners, the results of these findings can be applied differently to practice. First, a key component in social work practice is effective engagement. Findings indicated engagement levels are different based upon the environmental variable-geographic location. These results should reinforce to the social work practitioner the validity of the person-in-the-environment concept. When engaging families, social work practitioners should start where the client is to build effective rapport that helps to create lasting client change.

In addition, for social work practitioners who work in southwest Missouri there is another consideration. Because of the seemingly homogeneous population of people found in urban and rural areas, it is often easy to use the same practice techniques on both locations. These findings reinforce to social workers in southwest Missouri that although they may look similar on the outside, there are geographical differences in family engagement that should be taken into consideration when developing treatment plans and implementing services.

Second, engagement is one of the seven steps in the planned change process used by social work practitioners on how best to meet the needs of their clients. Numerous 
social work researchers have found the planned change process as an effective way to help clients (Kirst-Ashman, Karen, \& Hull, 2008). However, social work practitioners have not shared this expertise with early childhood educators to help formulate evidencebased practice on how to do this with Head Start families. To empower change and provide the best resources to the vastly evolving Head Start family, social workers must consider joining with preschool professionals as they serve to create new ways to engage geographically diverse families.

There are several simple things social workers can do immediately to reintroduce themselves to early childhood education. First, the Head Start program uses mental health professionals to meet the emotional needs of the children they serve. Licensed clinical social work professionals should contact their local Head Start agency and become a provider for Head Start children. Second, every Head Start program requires community representatives to serve on their Head Start Policy Council. Social work professionals should contact their local Head Start administrators and ask to serve in this capacity. Third, the Head Start program needs volunteers to help in the Head Start program. The Code of Ethics requires social workers to engage in pro bono activities. Volunteering in a Head Start program is an important way to meet this ethical standard.

The long term solution for re-engaging social work practitioners into the early childhood arena involves the professional integration of the social work profession into the Head Start milieu. OACAC Head Start should reexamine the use of social workers as a means to increase family engagement. Findings from this research support the social work person-in-environment perspective by recognizing the environmental influences on family engagement. The one OACAC position that is currently used to engage families 
is the family advocate. The family advocate does this through in-home visits and case management activities. Although these are traditional social work activities, there are presently no social workers in this job. When OACAC administrators were asked to reflect on why this is, they state it is because they do not provide competitive wages for social workers. The results of low wages have taken a toll on OACAC Head Start as seen by the continued high turnover rates in family advocates (Shinn-Brown \& Bauer, 2009).

High turnover rates not only cause administrators the stress of having to cover unfilled positions and frequently hire, it places a huge financial burden on the OACAC Head Start program. This is because the family advocate role requires a number of hours of expensive new worker training. Anecdotally, one could argue paying higher wages to family advocates would decrease the turnover rate. The money they would save in training and on new employee orientation activities could make up for the increase in wages. By doing this, they would increase the likelihood of hiring social workers who were trained to implement the person-in environment perspective. This perspective could serve in meeting the community family engagement needs found in this study. OACAC administrators should review their budget to determine if this is a feasible option.

\section{Conclusions}

The purpose of this study was to gain a better understanding of differences in engagement among geographically diverse Head Start families. Significant differences were found between overall family engagement outcomes of rural and urban Head Start parents. Urban Head Start parents perceived themselves as having a higher level of family engagement than their rural counterparts. To collect this data, the new Head Start PFCE Framework was used. This was the first known research study to use the new 
PFCE Framework. Dependent variables were identified from the PFCE Framework's seven family engagement outcomes. Survey data indicated only two out of the seven PFCE family engagement outcomes had significant differences based upon the environmental variable, geographic location.

The findings of this study raise concern due to the differences found in overall family engagement and the seven family engagement outcomes identified by the PFCE framework. This is because while there were differences found in overall engagement levels of rural and urban families, these differences were not consistent when measuring each of the seven family engagement outcomes identified by the new Head Start PFCE Framework. To create the child outcome identified by the PFCE Framework stating "children are ready for school and sustain development and learning gains through third grade" more research on these variables needs to be done ("The Head Start Parent", 2011). However, this research provides the Head Start community a strong foundation to begin this process. 


\section{References}

Allen, M. D. (2008). Attributes of effective head start mental health consultants: A mixed methods study or rural and urban programs (Doctoral dissertation). Retrieved from

http://books.google.com/books/about/Attributes_of_effective_Head_Start_menta. html?id=2YhMugjEypEC

Amato, P. R., \& Zuo, J. (1992, Summer). Rural poverty, urban poverty, and psychological well-being. The Sociological Quarterly, 33, 229-240. Retrieved from http://www.jstor.org/stable/4121143

Anderson-Butcher, D., Stetler, G., \& Midle, T. (2006). A case for expanded schoolcommunity partnerships in support of positive youth development. Children \& Schools, 28, 155-163.

Annunziata, D., Hogue, A., Faw, L., \& Liddle, H. A. (2006, February). Family functioning and school success in at-risk, inner-city adolescents. Journal of Youth and Adolescence, 35, 105-113. doi: 10.1007/s10964-005-9016-3

Arsneault, S. (2006). Implementing welfare reform in rural and urban communities: Why place matters. The American Review of Public Administration, 36, 173-188. doi: $10.1177 / 0275074005280315$

Ascher, C. (1988). Improving the school-home connection for poor and minority students. The Urban Review, 20(), 109-123.

Auerbach, S. (2007). From moral supporters to struggling advocates: Reconceptualizing parent roles in education through the experience of working-class families of color. Urban Education, 42, 250-283. 
Auerbach, S. (2007). Visioning parent engagement in urban schools: Role constructions of Los Angeles administrators. Journal of School Leadership,17, 699-735.

Auerbach, S. (2010, November). Beyond coffee with the principal: toward leadership for authentic school-family partnerships. Journal of School Leadership, 20, 728-757.

Azzi-Lessing, L. (2010, July). Growing together: Expanding roles for social work practice in early childhood settings. Social Work, 55, 255-263.

Barnes, G. P., Parker, W. A., Lyon, T. C., Drum, M., \& Coleman, G. C. (1992, MarchApril). Ethnicity, location, age, and fluoridation factors in baby bottle tooth decay and caries prevalence of head start children. Public Health Reports, 107, 167-173. Retrieved from http://www.jstor.org/stable/4597096

Barnes, H. V., Guevara, M. D., Garcia, G., Levin, M., \& Connell, D. B. (1999, April). How do head start staff characteristics relate to parent involvement and satisfaction?. Poster session presented at the Society for Research in Child Development Biennial Meeting, Albuquerque, NM.

Barnett, S. (2012, January 11). Lack of economic mobility adds urgency to the pre-k debates [Web log message]. Retrieved from http://preschoolmatters.org/2012/01/11/lack-of-economic-mobility-adds-urgencyto-the-pre-k-debates/

Bartlett, J. E., Kotrlik, J. W., \& Higgins, C. C. (2001, Spring). Organizational research: Determining appropriate sample size in survey research. Information Technology, Learning, and Performance Journal, 19, 43-50. 
Belanger, K., \& Stone, W. (2008). The social service divide: Service availability and accessibility in rural versus urban counties and impact on child welfare outcomes. Child Welfare, 87, 101-124.

Bender, S. L., Fedor, M., \& Carlson, J. (2011). Examining protective factors and risk factors in urban and rural head start children. Journal of Community Psychology, 39, 908-921. doi: 10.1002/jcop.20477

Boyd, R., \& Lopez, M. (2002). The head start mental health research consortium (Head Start Bulletin \#73). Retrieved from Head Start Bulletin Enhancing Head Start Communication: http://eclkc.ohs.acf.hhs.gov/hslc/ttasystem/teaching/eecd/Domains\%20of\%20Child\%20Development/Social\%20and \%20Emotional\%20Development/edudev_art_00115_072305.html\#intro

Brinson, T. D. (2011). The impact of head start directors' leadership practices on parental involvement (Doctoral dissertation). Retrieved from www.capella.edu Brofenbrenner, U. (1971, January). Day care USA: A statement of principles. Peabody Journal of Education, 48, 86-95. Retrieved from http://www.jstor.org/stable/1492438

Bronfenbrenner, U. (1976, October). The experimental ecology of education. American Educational Research Association, 5, 5-15. Retrieved from http://www.jstor.org/stable/1174755

Bronfenbrenner, U. (1977, July). Toward an experimental ecology of human development. American Psychologist, 513-531.

Bronfenbrenner, U. (1979). The ecology of human development. Cambridge, MA: Harvard University Press. 
Brookes, S. J., Summers, J. A., Thornburg, K. R., Ispa, J. M., \& Lane, V. J. (2006). Building successful home visitor-mother relationships and reaching program goals in two early head start programs: A qualitative look at contributing factors. Early Childhood Resesarch Quarterly, 21, 25-45. doi: 10.1016/j.ecresq.2006.01.005

Brown, J. R., Knoche, L. L., Edwards, C. P., \& Sheridan, S. M. (2009). Professional development to support parent engagement: A case study of early childhood practitioners. Early Education \& Development, 20, 482-506. doi:

$10.1080 / 10409280902783475$

Brown, R.A., Worthman, C.M., Costello, E.J., \& Erkanli, A. (2006). The Life Trajectory Interview for Youth (LTI-Y): Method development and psychometric properties of an instrument to assess life-course models and achievement. International Journal of Methods in Psychiatric Research, 15, 192-206.

Brown, R., Copeland, W. E., Costello, E. J., Erkanli, A., \& Worthman, C. M. (2009). Family and community influences on educational outcomes among Appalachian youth. Journal of Community Psychology, 37, 795-808. doi: 10.1002/jcop.20331

Bryk, A. S., \& Schneider, B. (2003, March). Trust in schools: A core resource for school reform. Educational Leadership, 60, 40-44.

Burgess, S.R., Hecht, S.A. and Lonigan, C.J. (2002). Relations of the home literacy environment (HLE) to the development of reading-related abilities: A one-year longitudinal study, Reading Research Quarterly, 37, 408-26. 
Canby, A. (2003). Affordable housing and transportation: Creating new linkages benefiting low-income families. Housing Facts \& Findings, 5(2), 1-8. Retrieved from http://content.knowledgeplex.org/kp2/img/cache/kp/14773.pdf

Capizzano, J., \& Fiorillo, A. (2004). young children and the rural information gap: The weakness of major data sources for examining the well-being of rural children (Rural Early Childhood Report No. 1). Retrieved from Mississippi State University National Center for Ruraly Early Childhood Learning Initiatives: http://www.earlychildhood.msstate.edu/reports/Dec_04/report-dec04.pdf

Castro, D. C., Bryant, D. M., Peisner-Feinberg, E. S., \& Skinner, M. L. (2004). Parent involvement in head start programs: the role of parent, teacher and classroom characteristics. Early Childhood Research Quarterly, 19, 419-430. doi: 10.1016/j.ecresq.2004.07.005

Center for Early Childhood Mental Health Consultation Georgetown University Center for Child and Human Development. (n.d.). http://www.ecmhc.org/principles.html Clark, S. L. (2012). In search of housing: Urban families in rural contexts. Rural Sociology, 77, 110-134. doi: 10.1111/j.1549-0831.2011.00069.x

Cohen, P., \& Hesselbart, C. (1993). Demographic factors in the use of children's mental health services. American Journal of Public Health, 83, 49-52.

Coll, C. G., Akiba, D., Palacios, N., Bailey, B., Silver, R., DiMartino, L., \& Chin, C. (2002, July-September). Parental involvment in children's education: Lessons from three immigrant groups. Parenting: Science and Practice, 3, 303-324. 
Conduct Problems Prevention Research Group. (1995). Technical reports for the construct development for the measures for year 2 outcome analyses. Unpublished technical report.

Coolidge, F. L. (2012). Statistics: A gentle reminder. Thousand Oaks, CA: Sage. Corcoran, K., \& Fischer, J. (2000). Measures for clinical practice: Volume 1 couples, families, and children (3rd ed.). New York, NY: The Free Press.

Cotton, K., \& Wikelund, K. R. (1989). Parent involvement in education. School improvement research series (SIRS). (Based on work sponsored wholly, or in part by the office of Educational Research and Improvement (OERI), U.S. Department of Education-under contract number 400-86-0006). Retrieved from Education Northwest: http://educationnorthwest.org/resource/825

Currie, J., \& Thomas, D. (1995, June). Does head start make a difference?. The American Economic Review, 85, 341-364.

Daniel-White, K. (2002). Reassessing parent involvement: Involving language minority parents in school work at home. Working Papers in Educational Linguistics, 18, 29-50. Retrieved from http://www.gse.upenn.edu/wpel.

DeBaryshe, D.B. and Binder, J.C. (1994). Development of an instrument for measuring parental beliefs about reading aloud to young children. Perceptual and Motor Skills, 78, 1303-11.

Delgado-Gaitan, C. (1991). Involving parents in the schools: A process of empowerment. American Journal of Education, 100, 20-46. Retrieved from http://www.jstor.org/stable/1085651 
Driebe, N. M., \& Cochran, M. M. (1996, June 20-23). Barriers to parent involvement in head start programs. Paper presented at the Head Start National Research Conference, Washington, DC.

Driessen, G., Smit, F., \& Sleegers, P. (2005, August). Parent involvement and educational achievement. British Educational Research Journal, 31, 509-532. doi: 10.1002/berj.2005.31.issue-4/issuetoc

Durham, R. E., \& Smith, P. (2006). Nonmetropolitan status and kindergarteners' early literacy skills: Is there a rural disadvantage?. Rural Sociology, 71, 625-661.

Epstein, J. (1992). School and family partnerships. In M.C. Alkin (Ed.), Encyclopedia of educational research (6th ed., pp. 1139-1151). New York: Macmillan.

Epstein, J. L. (1995, May). School/family/community partnerships: Caring for the children we share. Phi Delta Kappa International, 76, 701-712. Retrieved from http://www.jstor.org/stable/20405436

Fagan, J., \& Iglesias, A. (1999). Father involvement program effects on fathers, father figures, and their head start children: A quasi-experimental study. Early Childhood Research Quarterly, 14, 243-269.

Fan, X. (2001). Parental involvement and students' academic achievement: A growth modeling analysis. Journal of Experimental Education, 70, 27-61.

Fan, W., \& Williams, C. M. (2010, January). The effects of parental involvement on students' academic self-efficacy, engagement and intrinsic motivation. Educational Psychology, 30, 53-74. doi: 10.1080/01443410903353302 
Fantuzzo, J., McWayne, C., \& Perry, M. A. (2004). Multiple dimensions of family involvement and their relations to behavioral and learning competencies for urban, low-income children. School Psychology Review, 33, 467-480.

Fantuzzo, J., Perry, M. A., \& Childs, S. (2006). Parent satisfaction with educational experiences scale: A multivariate examination of parent satisfaction with early childhood education programs. Early Childhood Research Quarterly, 21, 142152. doi: 10.1016/j.ecresq.2006.04.002

Fantuzzo, J., Tighe, E., \& Childs, S. (2000). Family involvement questionnaire: A multivariate assessment of family participation in early childhood education. Journal of Educational Psychology, 92, 367-376. doi: 10.1037//00220663.92.2.367

Field, A. (2009). Discovering statistics using SPSS (3rd ed.). Thousand Oaks, CA: Sage . Folbre, N. (2008). Valuing children: Rethinking the economics of the family. Cambridge: Massachusetts: Harvard University Press.

Frankel, A. J. (1997, March/April). Head start and social work. Families in Society: The Journal of Contemporary Human Services, 172-183.

Friedman, P. (2004, March). Transportation needs in rural communities. Rural Assistance Center, 2(1), 1-9. Retrieved from http://76.12.61.196/publications/transportationneedsINRAC.htm

Gamm, L., Stone, S., \& Pittman, S. (2010). Mental health and mental disorders-a rural challenge; A literature review. Rural Healthy People, 97-114.

Grace, C., Shores, E. F., Zaslow, M., Brown, B., Aufseeser, D., \& Bell, L. (2006). Rural disparities in baseline data of the early childhood longitudinal study: A 
chartbook (Rural Early Childhood Report No. 3). Mississippi State, MS:

Natiional Center for Rural Early Childhood Learning Initiatives, Mississippi State University Early Childhood Institute.

Greenberg, P. (2004). Three core concepts of the war on poverty: Their origins and significance in head start. In E. Zigler \& S. J. Styfco (Eds.), The head start debates (pp. 61-84). Baltimore, MD: Paul H Brooks.

Grolnick, W. S., Benjet, C., Kurowski, C. O., \& Apostoleris, N. H. (1997). Predictors of parent involvement in children's schooling. Journal of Educational Psychology, $89,538-548$.

Harvard Family Research Project. (2006). Family involvement in early childhood education (No. 1 ). Retrieved from Harvard Family Research Project: www.hfrp.org

Henderson, A. T., \& Mapp, K. L. (2002). A new wave of evidence the impact of school, family, and community connections on student achievement (Institute of Education Sciences, U.S. Department of Education). Retrieved from SEDLAdvancing Research, Improving Education: http://www.sedl.org/pubs/catalog/items/fam33.html

Hertz, R., \& Ferguson, F. I. (1996). Childcare choice and constraints in the United States: Social class, race, and the influence of family views. Journal of Comparative Family Studies, 27, 249-280.

Hiatt-Michael, D. B. (2006). Reflections and directions on resaerch related to familycommunity involvement in schooling. School Community Journal, 16, 7-30.

Hill, N.E., \& Craft, S.A. (2003). Parent-school involvement and school performance: 
Mediated pathways among socioeconomically comparable African American and Euro-American families. Journal of Educational Psychology, 95, 74-83.

Hope, T. L., \& Bierman, K. L. (1998). Patterns of home and school behavior problems in rural and urban settings. Journal of School Psychology, 36, 45-58.

Hong, S., \& Ho, H.Z. (2005). Direct and indirect longitudinal effects of parental involvement on student achievement: Second order latent growth modeling across ethnic groups. Journal of Educational Psychology, 97, 32-42.

Howes, C., \& Droege, K. (1994, December). Child care costs in the United States and industrialized nations. Pediatrics, 94, 1081-1083.

Hulsey, L., Aikens, N., Kopack, A., West, J., Moiduddin, E., \& Tarullo, L. (2011). Head start children, families, and programs: Present and past data from FACES (OPRE Report 2011-33a). Washington, DC: Office of Planning, Reserach and Evaluation, Administration for Children and Families, US Department of Health and Human Services.

Illinois Head Start Association. (n.d.). History of project head start. Retrieved from http://ilheadstart.org

Jacobs, N., \& Harvey, D. (2005). Do parents make a difference to children's academic achievement? Differences between parents of higher and lower achieving students. Educational Studies, 31, 431-448. doi: 10.1080/03055690500415746

James, D. E. et al. (1985). Characteristics of the kansas parental satisfaction scale among two samples of married parents. Psychological Reports, 57, 163-169. 
Kagan, J. (2002, April). Empowerment and education: Civil rights, expert-advocates, and parent politics in head start, 1964-1980. Teachers College Record, 104, 516562.

Kalifeh, P., Cohen-Vogel, L., \& Grass, S. (2011). The federal role in early childhood education: Evolution in goals, governance, and policy instruments of project head start. Educational Policy, 25, 36-64. doi: 10.1177/089594810387413

Keppel, G., \& Wickens, T. D. (2004). Design and analysis a researcher's handbook (4th ed.). Upper River Saddle, NJ: Pearson Prentice Hall.

Kim, K., \& Rohner, R. P. (2002). Parental warmth, control, and involvement in schooling: Predicting academic achievement among Korean American adolescents. Journal of Cross-Cultural Psychology, 33, 127-140. doi: $10.1177 / 0022022102033002001$

Kirst-Ashman, Karen \& Hull, Grafton H. (2008). Understanding generalist practice $\left(5^{\text {th }}\right.$ ed.). Pacific Grove, CA: Brooks Cole.

Kohl, G. O., Lengua, L. J., \& McMahon, R. J. (2000). Parent involvement in school conceptualizing multiple dimensions and their relations with family and demographic risk factors. Journal of School Psychology, 38, 501-523.

Koren, P. E., DeChillo, N., \& Friesen, B. J. (1992). Measuring empowerment in families whose children have emotional disabilities: A brief questionnaire. Rehabilitation Psychology, 37, 305-321.

Kreider, R., \& Ellis, R. (2009). Living arrangements of children: 2009 (Current Population Reports, P70-126). Washington, DC: U.S. Census Bureau. 
Kupermine, G. P., Darnell, A. J., \& Alvarez-Jimenez, A. (2008). Parent involvement in the academic adjustment of Latino middle and high school youth: Teacher expectations and school belonging as mediators. Journal of Adolescence, 31, 469483. doi: 10.1016/j.adolescence.2007.09.003

LaForett, D. R., Mendez, J. L., \& Porter, F. (2010). Parent involvement, parental depression, and program satisfaction among low-income parents participating in a two-generation early childhood education program. Early Education \& Development, 21, 517-535. doi: 10.1080/10409280902927767

Lamb-Parker, F., Piotrkowski, C. S., Baker, A. J., Kessler-Sklar, S., Clark, B., \& Peay, L. (2001). Understsanding barriers to parent involvment in head start: A reserachcommunity partnership. Early Childhood Research Quarterly, 16, 35-41.

Lasser, J., \& Fite, K. (2011). Universal preschool's promise: Success in early childhood and beyond. Early Childhood Education Journal, 39, 169-173. doi: 10.1007/s10643-011-0449-x

Lawson, M. A. (2003, January). School-family relations in context: Parent and teacher perceptions of parent involvement. Urban Education, 38, 77-133. doi: $10.1177 / 00042085902238687$

Levitan, S. A. (1969, September). The community action program: A strategy to fight poverty. Annals of the American Academy of Political and Social Science, 385, 63-75. Retrieved from http://wwww.jstor.org/stable/1037537

Liu, J., Jones, S., Sun, H., Probst, J., \& Cavicchia, P. (2010). Diet, physical activity, and sedentary behaviors as risk factors for childhod obesity: An urban and rural comparison (Grant Award No 5 U1CRH03711-06-00). Retrieved from US 
Department of Health and Human Services Health Resources and Service Administration: http://www.ask.hrsa.gov/detail_materials.cfm?ProdID=4523

Love, J. M., Kisker, E. E., Ross, C., Schochet, P. Z., Brooks-Gunn, J., Boller, K., Paulsell, D., ... Berlin, L. (2001). Building their futures: How early head start programs are enhancing the lives of infants and toddlers in low-income families. Retrieved from U.S. Department of Health \& Human Services Administration for Children \& Families Office of Planning, Research \& Evaluation: http://www.mathematica-mpr.com/PDFs/buildingvol1.pdf

Maher, E. J., \& Frestedt, B. (2008). Differences in child care quality in rural and nonrural areas. Journal of Research in Rural Education, 23(4), 1-13. Retrieved from http://www.jrre.psu.edu/articles/23-4

Mapp, K. L. (2003, Spring). Having their say: Parents describe why and how they are engaged in their children's learning. School Community Journal, 13, 35-64.

Marjoribanks, K. (1994). Families, schools and children's learning: A study of children's learning environments. International Journal of Educational Research, 21, 439552.

Marjoribanks, K. (2005). Family environments and children's outcomes. Educational Psychology: An International Journal of Experimental Psychology, 25, 647-657. doi: $10.1080 / 01443410500344704$

Mattingly, M. J., Johnson, K. M., \& Schaefer, A. (2011). More poor kids in more poor places children increasingly live where poverty persists (Issue Brief No. 38). Retrieved from Carsey Institute: http://carseyinstitute.unh.edu/CarseySearch/search.php?id=176 
McCubbin, H. I., Larsen, A., \& Olson, D. (1982). Family coping coherence index (FCCI). In Family assessment: Resiliency, coping and adaptation-inventories for research and practice ( pp. 703-712). Madison: University of Wisconsin System.

McCubbin, H., \& Patterson, J. (1983). Family member well-being index (FMWB). In H. I. McCubbin, A. I. Thompson, \& M. A. McCubbin (Eds.), Family assessment: Resiliency, coping, and adaptation-inventories for research and practice (pp. 753-782). Madison: University of Wisconsin System.

McCubbin, H., Thompson, A., \& McCubbin, M. (1996). Family assessment: resiliency, coping and adaptation: inventories for research and practice. Madison, WI: University of Wisconsin.

McIntyre, L. L., Eckert, T. L., Fiese, B. H., DiGennaro, F. D., \& Wildenger, L. K. (2007, August). Transition to kindergarten: Family experiences and involvement. Early Childhood Education Journal, 35, 83-88. doi: 10.1007/s10643-007-0175-6

McKay, R. H., Condelli, L., Ganson, H., Barnett, B. J., McCouley, C., \& Plantz, M. C. (1985). The impact of head start on children, families and communities: Final report of the head start evaluation, synthesis and utilization project. Washington, D.C.: U.S. Department of Health and Human Services.

McKey, R. H., Pai-Samant, S., \& Sorongon, A. (2002, June 26). Curricula being used in head start programs: Who gets what?. Paper presented at the Sixth National head Start Research Conference, Washington, D.C.. Abstract retrieved from http://www.acf.hhs.gov/programs/opre/hs/faces/pres_papers/curriculum_being/cu rriculum_being.pdf 
McWayne, C. M. (2011, June 7-8). Family engagement during preschool: A multidimensional look across diverse measures, cultural groups, \& head start sites. Paper presented at the Presentation to the Advisory Committee on Head Start Research and Evaluation, Washington, D.C..

McWayne, C., Campos, R., \& Owsianik, M. (2008). A multidimensional, multilevel examiniation of mother and father involvement among culturally diverse head start families. Journal of School Psychology, 46, 551-573. doi:

10.1016/j.jsp.2008.06.001

Mendez, J. L. (2010). How can parents get involved in preschool? Barriers and engagement in education by ethnic minority parents of children attending head start. Cultural Diversity and Ethnic Minority Psychology, 16, 26-36. doi: $10.1037 / \mathrm{a} 0016258$

MERIC: Missouri Economic Research and Information Center. (2012). Quarterly census of employment. Retrieved from http://www.missourieconomy.org/indicators/

Mertler, C. A., \& Vannatta, R. A. (2005). Advanced and multivariate statistical methods (3rd ed.). Glendale, CA: Pyrzak.

Mills, K. (1999). Something better for my children: How head start has changed the lives of millions of children. New York, NY: Plume.

National Association of Social Workers. (2008). Preamble to the code of ethics. Retrieved from National Association of Social Workers: http://www.socialworkers.org/pubs/code/code.asp 
National Association of Social Workers. (2012). Rural social work (Abstracts Social Work Speaks, 6th edition). Retrieved from National Association of Social Workers: http://www.naswdc.org/resources/abstracts/abstracts/rural.asp?print=1\& National Center for Rural Early Childhood Learning Initiatives Mississippi State University. (2005). Mental health and family life among kindergarten children in rural areas (Rural Early Childhood Brief No. 3). Retrieved from Mississippi State University Early Childhood Institute Professional Development, Technicial Assistance, and Early Childhood Services Research: http://www.earlychildhood.msstate.edu/reports/briefs/605_brief_mentalhealth.pdf

Office of Head Start National Center on Parent, Family and Community Engagement. (2011). Family engagement and ongoing child assessment (Grant \#90HC0001). Retrieved from Office of Head Start The National Center on Parent, Family, and Community Engagement: http://eclkc.ohs.acf.hhs.gov/hslc/ttasystem/family/center

Office of Planning Research and Evaluation. (2011). Family-provider relationships: A multidisciplinary review of high quality practices and associations with family, child, and provider outcomes (GS1050030R). Washington, DC: U.S. Government Printing Office.

O’Connor, A. (2001). Poverty knowledge: social science, social policy, and the poor in twentieth-century U.S. history. Princeton, New Jersey: Princeton University Press.

O’Hare, W., Manning, W., Porter, M., \& Lyons, H. (2009). Rural children are more likely to live in cohabitating-couple households (Policy Brief No. 14). Retrieved 
from Carsey Institute: http://www.carseyinstitute.unh.edu/publications/PB14cohab.pdf

Palm, G., \& Fagan, J. (2008, October-December). Father involvment in early childhood programs: review of the literature. Early Child Development and Care, 178, 745759. doi: $10.1080 / 0300440802352137$

Pennsylvania Head Start Association. (n.d.). Head start history: 1965-present. Retrieved from http://www.paheadstart.org/UserFiles/File/General_History.pdf

Radloff, L. (1977). The CES-D scale: A self-report depression scale for research in the general population. Journal of Applied Psychological Measurement, 1, 385-401.

Raikes, H., Green, B. L., Atwater, J., Kisker, E., Constantine, J., \& Chazan-Cohen, R. (2006). Involvement in early head start home visiting services: Demographic predictors and relations to child and parent outcomes. Early Childhood Research Quarterly, 21, 2-24. doi: 10.1016/j.ecresq.2006.01.006

Raudenbush, S., \& Bryk,A . S. (2002). Hierarchical linear models: Applications and data analysis methods (2nd ed.). Thousand Oaks, C A: Sage.

Raver, C., Li-Grining, C., Metzger, M. W., Jones, S. M., Zhai, F., \& Solomon, B. (2009). Targeting children's behavior problems in preschool classrooms: A clusterrandomized controlled trial. Journal of Consulting and Clinical Psychology, 77, 302-316. doi: 10.1037/a0015302

Ray, B. (2008-09, Winter). The state of human services in rural america. Perspectives On Poverty, Policy, \& Place, 1-14. Retrieved from http://ruralcommittee.hrsa.gov.nacpubs.asp 
Redding, S., Murphy, M., \& Sheley, P. (2011). Handbook on family and community engagement (U.S. Department of Educaton's Office of Elementary and Secondary Education-Award \#S283B050057). Retrieved from Academic Development Institute: www.families-schools.org

Ringenberg, M., Funk, V., Mullen, K., Wilford, A., \& Kramer, J. (2005). The test-retest reliability of the parent and school survey (PASS). The School Community Journal, 15, 121-134.

Rohner,R.P.(1990). Handbook for the study of parental acceptance and rejection. Storrs,CT:RohnerResearch.

Roggman, L. A., Boyce, L. K., Cook, G. A., Christiansen, K., \& Jones, D. (2004, Winter). Playing with daddy: Social toy play, early head start, and developmental outcomes. Fathering, 2, 83-108.

Rollinson, P. (2007, June). A rural problem, too. Planning, 73, 20-24.

Rubbin, A., Babbie, E.R. (2010). Research methods for social work. Belmont, CA: Brooks/Cole.

Schulting, A. B., Malone, P. S., \& Dodge, K. A. (2005). The effect of school-based kindergarten transition policies and practices on child academic outcomes. Developmental Psychology, 41, 860-871. doi: 10.1037/0012-1649.41.6.860

Scott, K. H. (2006, October 25). Family engagement [Californa preschool planning toolkit, section 6d] (Educational Standards). Retrieved from Plan 4 Preschool: http://www.plan4preschool.org/about/contributor_docs/AIR 
Sheldon, S. B. (2007, May/June). Improving student attendance with school, family, and community partnerships. The Journal of Educational Research, 100, 267-275.

Shinn-Brown, K. (2012, September 12). OACAC head start management reportenrollment (Fact Sheet). Springfield, MO: Author.

Shinn-Brown, K., \& Bauer, D. (2009, March). 2009 community assessment. Paper presented at the Head Start Policy Council, Springfield, MO.

Silver, H., \& Silver, P. (1991). An educational war on poverty: American and British policy making, 1960-1980. Cambridge, MA: Cambridge University Press.

Simpkins, S. D., Weiss, H. B., McCartney, K., Kreider, H. M., \& Dearing, E. (2006, January-March). Mother-child relationship as a moderator of the relation between family educational involvement and child achievement. Parenting: Science and Practice, 6, 49-57.

Simpson, E., \& Braun, B. (2007). Dental health among rural, low-income families: Implications for policy and programs. Retrieved from US Department of Agriculture National Institute of Food and Agriculture: http://www.nifa.usda.gov/nea/food/pdfs/oral_health.pdf

Sivils-Dickey, T. (2009, October). Personal interview.

Spera, C., Wentzel, K. R., \& Matto, H. C. (2009). Parental aspirations for their children's educational attainment: Relations to ethnicy, parental education, children's academic performance, and parental perceptions of the school climate. Journal of Youth \& Adolescence, 38, 1140-1152. doi: 10.1007/s10964-008-9314-7 
St. Clair, L., \& Jackson, B. (2006). Effect of family involvement training on the language skills of young elementary children from migrant families. The School Community Journal, 16, 31-41.

St. George, C. Y. (2010, Winter). How can elementary teachers collaborate more effectively with parents to support student literacy learning?. Delta Kappa Gamma Bulletin, 76, 32-38.

Swick, K. J., \& Williams, R. D. (2006, April). An analysis of Bronfenbrenner's bioecological perspective for early childhood educators: Implications for working with families experiencing stress. Early Childhood Education Journal, 33, 371378. doi: 10.1007/s10643-006-0078-y

Sy, S. R., \& Schulenberg, J. E. (2005). Parent beliefs and children's achievement trajectories during the transition to school in Asian American and European American families. International Journal of Behavioral Development, 29, 505515. doi: 10.1080/01650250500147329

The Head Start parent, family, and community engagement framework: Promoting family engagement and school readiness, from prenatal to age 8. (2011). Retrieved from http://www.acf.hhs.gov/programs/ohs/policy/im2011/pfceframework.pdf

The National Advisory Committee on Rural Health and Human Services. (2007). The 2007 report to the secretary: Rural health and human service issues. Retrieved from US Department of Health and Human Services Health Resources and Service Administration: ftp://ftp.hrsa.gov/ruralhealth/NACReport2007.pdf 
The Westinghouse Learning Corporation and Ohio University. (1969). The impact of head start: An evaluation of the effects of head start on children's cognitive and affective development

Thompson, R. (2005). The course and correlates of mental health care received by young children: Descriptive data from a longitudinal urban high-risk sample. Children and Youth Services Review, 27, 39-50. doi: 10.1016/j.childyouth.2004.07.003

United States Census Bureau. (2000). U.S. Census 2000, Summary File 3. Retrieved January 11, 2007, from http://factfinder.census.gov.

U.S. Census Bureau. (2007). American community survey 2007-2009 (Table BO9008). Washington, DC: U.S. Government Printing Office.

U.S. Department of Commerce United States Census Bureau. (2013). State and county quickfacts. Retrieved from http:/quickfacts.census.gov/qfd/states/29/29225.html

U.S. Department of Education. (1989). Parent involvment in education, school improvement research series (SIRS). Based on work sponsored wholly, or in part by the Office of Educational Research and Improvement (OERI) (under Contract Number 400-86-0006). Washington, DC: U.S. Government Printing Office.

U.S. Department of Education's Office of Elementary and Secondary Education to the Academic Development Institute and the Center on Innovation \& Improvement. (2011). Handbook on family and community engagement (Award \#S283B050057). Retrieved from School Community Network: www.familiesschools.org

U.S. Department of Health and Human Services \& Administration for Children and Families, Head Start. (2006). Head Start program performance standards and 
other regulations (Policy Brief 1305.4). Retrieved from Head Start:

http://eclkc.ohs.acf.hhs.gov/hslc/standards/Head\%20Start\%20Requirements/1305/ 1305.4\%20Age\%20of\%20children\%20and\%20family\%20income.htm

U.S. Department of Health and Human Services Administration for Children and Families. (2006, April). Research to practice program performance measures for head start programs serving infants and toddlers (Policy Brief). Retrieved from U.S. Department of health and Human Services Administration for Chidlren and Families Office of Head Start:

http://eclkc.ohs.acf.hhs.gov/hslc/mr/opre/prgm_perf_measure_4pg.pdf

U.S. Department of Health and Human Services U.S. Department of Education. (2010).

State issues and innovations in creating integrated early learning and development systems a follow-up to early childhood 2010: Innovations for the next generation (HHSS283200800002C). Washington, DC: U.S. Government Printing Office.

U.S. Department of Health and Human Services, Administration for Children \& Families, Office of Head Start. (2010). Head start program fact sheet (Fact Sheet). Retrieved from Office of Head Start: http://www.acf.hhs.gov/programs/ohs/about/fy2010.html

U.S. Department of Health and Human Services, Administration for Children and Families, Office of Head Start. (n.d.). Program services. Retrieved from http://www.acf.hhs.gov/programs/ohs/programs/index.html

U.S. Department of Health and Human Services. (02/09/2012). 2012 HHS poverty guidelines. Retrieved from http://aspe.hhs.gov/poverty/12poverty.shtml 
U.S. Department of Health and Human Services. (2003). Strengthening head start: What the evidence shows. Retrieved from http://aspe.hhs.gov/hsp/strengthenheadstart03/index.htm

U.S.Department of Health and Human Services, Administration for Children and Families, Administration on Children, Youth and Families, Head Start Bureau. (2001). Head start program performance standards and other regulations (). Washington, DC: U.S. Government Printing Office.

U.S. Department of Health and Human Services \& Administration for Children and Families Office of Head Start. (2011). Head start approach to school readiness. Retrieved from US Department of Health and Human Services \& Administration for Children \& Families Office of Head Start: http://eclkc.ohs.acf.hhs.gov/hslc/sr/approach

United States Department of Agriculture Economic Research Service The Economics of Food, Farming, Natural Resources, and Rural America. (2011). Rural income, poverty, and welfare: Poverty demographics. Retrieved from http://www.ers.usda.gov/Briefing/IncomePovertyWelfare/PovertyDemographics.h tm

United States Department of Agriculture Economic Research Service the Economics of Food, Farming, Natural Resources, and Rural America. (2011). Rural income, poverty, and welfare: Poverty geography. Retrieved from http://www.ers.usda.gov/Briefing/incomepovertywelfare/povertygeography.htm United States Department of Agriculture Economic Research Services The Economics of Food, Farming, Natural Resources, and Rural America. (2011). Rural income, 
poverty, and welfare: Poverty geography. Retrieved, from

http://www.ers.usda.gov/Briefing/incomepovertywelfare/povertygeography.htm

United States Government Printing Office. (2007). United States of America

congressional record proceedings and debates of the 110th congress first session

(Volume 153-Part 8). Washington, DC: U.S. Government Printing Office.

Vaden-Kiernan, M., D’Elio, M. A., Obrien, R. W., Tarullo, L. B., Zill, N., \& Hubbell-

McKey, R. (2010, March). Neighborhoods as a developmental context: a

multilvel analysis of neighborhood effects on Head Start families and children.

American Journal of Community Psychology, 45, 49-67. doi: 10.1007/s10464-

009-9279-z

Vandergriff-Avery, M., Anderson, E. A., \& Braun, B. (2004). Resiliency capacities among rural low-income families. Families in Society, 85, 562-569.

Vargas, C. M., Monajemy, N., Khurana, P., \& Tinanoff, N. (2002). Oral health status of preschool children attending head start in Maryland, 2000. Pediatric Dentistry, 24, 257-263.

Washington, V., \& Oyemade Bailey, U. J. (1995). Project head start: Models and strategies for the twenty-first century. New York, NY: Garland Publishing.

Weigel, D. J., Martin, S. S., \& Bennett, K. K. (2006). Mothers' literacy beliefs:

Connections with the home literacy environment and pre-school children's literacy development. Journal of Early Childhood Literacy, 6, 191-210. doi: $10.1177 / 1468798406066444$

Weiss, H. B., Lopez, M. E., \& Rosenberg, H. (2011). Bringing families to the table: Recommendations and next steps from the National Policy Forum for Family, 
School, and Community Engagement (U.S Department of Education under contract number ED-04-CO-0039/0001). Retrieved from Harvard Family Research Project: www.hfrp.org

Westmoreland, H., Bouffard, S., O'Carroll, K., \& Rosenberg, H. (2009). Data collection instruments for evaluating family involvment. Retrieved from Harvard Family Research Project: www.hfrp.org

Wilkinson, G.S. (1993). The wide range achievement test: Administration manual. Wilmingham, DE: Wide Range.

Williams, M., Unrau, Y. A., \& Grinnell, R. M. (1998). Introduction to social work research. Itasca, IL: F.E. Peacock Publishers.

Wiseman, A.M. (2009). Perceptions of community and experiences in school: Understanding the opportunities, resources, and education within one neighborhood. Early Childhood Education Journal, 36,333-338.

Wiseman, M. (1996). State strategies for welfare reform: The Wisconsin story. Journal of Policy Analysis and Management, 15, 515-546.

Woodcock, R., \& Muñoz-Sandoval, A. (2001). Woodcock-Muñoz Language Survey normative update, English and Spanish forms. Itasca, IL: Riverside Publishing.

Wong, S. W., \& Hughes, J. N. (2006). Ethnicity and language contributions to dimensions of parent involvement. School Psychology Review, 35, 645-662.

Wooley, M., \& Grogan-Kaylor, A. (2006). Protective family factors in the context of neighborhood: Promoting positive school outcomes. Family Relations, 55, $93-$ 104.

Yan, W., \& Lin, Q. (2005). Parent involvement and mathematics achievement: Contrast 
across racial and ethnic groups. Journal of Educational Research, 99, 116-127.

Zeak, G. L. (2006). Experiencing variety and change in head start parent involvement polcies and practices: Personal and professional perspectives (Doctoral dissertation). Retrieved from www.capella.edu

Zigler, E., \& Muenchow, S. (1992). Head start: The inside story of America's most successful educational experiment. New York, NY: BasicBooks.

Zigler, E., \& Styfco, S. J. (Eds.). (1993). Head start and beyond. New Haven, CT: Yale University Press. 


\section{Appendix A}

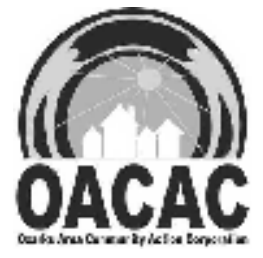

\section{Approval Letter}

\section{Ozarks Area Community Action Corporation Carl Rosenkranz, Executive Director}

February 8, 2013

To Whom It May Concern:

I have reviewed and approved for Amanda Keys to conduct a research study for her dissertation, "Engagement of Geographically Diverse Head Start Families," by collecting surveys from OACAC Head Start and Early Head Start families.

If I can provide additional information, please contact me by e-mail at kshinnbrown@ oacac-caa.org.

Sincerely,

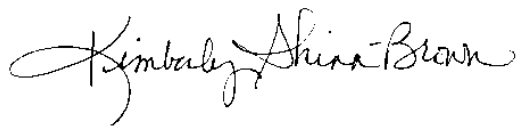

Kimberly Shinn-Brown, Director

OACAC Head Start-Early Head Start 


\section{Appendix $B$}

\section{Email Notification to Head Start Sites}

From: Teresa Sivils-Dickey [tdickey@oacac-caa.org]

Sent: Monday, March 04, 2013 1:52 PM

To: 'RITTER HEAD START 1'; 'RITTER HEAD START 2'; 'RITTER HEAD START 3'; 'Stewart 5 Education'; 'STEWART HEAD START 4'; 'STEWART HEAD START 6'; 'WEST CHESTNUT HEAD START 1'; 'WEST CHESTNUT HEAD START 2'; 'WEST CHESTNUT HEAD START 3'; 'WEST CHESTNUT HEAD START 4'; 'GOLDEN HEAD START'; 'GRANT TRAINING CENTER 1'; 'GRANT TRAINING CENTER 2'; 'Broadway HS'; 'DOUGLAS HEAD START 1'; 'DOUGLAS HEAD START 2'; 'DOUGLAS HEAD START 3'; Fairgrove HS; Fordland HS; Ashgrove HS; Greenfield HS; Butterfield Education; Crane HS; Reeds Spring HS; Kissee Mills HS

Cc: Amanda Keys; Kimberly Shinn-Brown; Diane Bauer; Bethany Monier; Bobbie Hunnell; Charity Warden; Christy Griffith; Ellena Stotler; Janet Wilson; Janita Breedlove; Julie Martin; Kandy Loehr; Liesl Aldridge; Melissa Hopkins; Susan Lamy

Subject: FW: Research Project

Amanda Keys is doing a research project on Head Start and needs our assistance. She is also on the Policy Council. She has made a schedule to visit your center to bring you parent surveys. What she needs us to help with is allowing her to visit your center and place the surveys in the children's take home folder or sign in/out book. In addition, the center that collects the most surveys will receive a $\$ 100.00$ check for their classroom. Second place will receive $\$ 75.00$ and third place will receive $\$ 25.00$. Note: to determine a winner the researcher will look at the percentages of returns and it will not be based upon the number of students in each classroom to give all classrooms an equal opportunity to win.

If the teachers/family advocates want to remind parents to complete the survey, she will leave a slip/note to do so. However you do not have to do this. Finally, she will provide the teacher with a self-addressed/stamped envelope to mail them to me the week of April 1, 2013. The parents will need to return the surveys by March 28, 2013.

If you need to contact Amanda, I am copying her on this email and you can directly contact her by email. If the time/day that she has you scheduled for will not work, please let her know as soon as possible.

Thank you for your help!!!

March 18th:

8:30am: Broadway Head Start

9:30 am: Douglas Head Start

10:30 am: Golden Head Start

11:30 am: Grant Head Start

12:30 pm: Ritter Head Start

1:30 pm: Stewart Head Start

2:30 pm: W Chestnut Head Start

March 19th:

8:30 am: Fairgrove, Missouri

10:30 am: Fordland, Missouri

12:00 pm: Seymour, Missouri

March 20th:

8:30 am: Ash Grove, Missouri

10:00 am: Greenfield, Missouri

1:00 pm: Butterfield, Missouri

March 21st:

8:30 am: Crane, Missouri

10:00 am: Reed Springs, Missouri

11:30 am: Kissee Mills, Missouri

Teresa Dickey

Family and Community Partnerships Director

OACAC Head Start/Early Head Start

215 S. Barnes

Springfield, MO 65802

Office: $417-864-3430$

toll free 1-866-282-3430

Fax: 417-864-3449

tdickey@oacac-caa.org

High Quality Services for Children and Families

This email originated from OACAC Head Start. This email and any attachments may contain confidential information, which is intended only for the use of the individual or entity named above. If you are not the intended recipient, please notify the sender immediately and delete the email. State and federal law prohibit you from making further disclosure of this information without specific written consent of the person to whom it pertains, or as otherwise permitted by law. 
Appendix $C$

Reminder Notification

Reminder: If you are willing to participate in the "Family Engagement of Geographically Diverse Head Start Families" research, please send in your survey in the sealed manila envelope provided by:

March 28, 2013

Please remember your Head Start Center will benefit from your participation. The following amounts will be awarded based upon center percentages:

First Prize: $\quad \$ 100.00$ for classroom supplies

Second Prize: $\quad \$ 75.00$ for classroom supplies

Third Prize: $\quad \$ 25.00$ for classroom supplies

(If you have already done this thank you and you do not need to complete another survey)

If you have any questions about this, please feel free to contact Amanda Keys at 417-350-9009. Thanks so much for your willingness to participate in this voluntary research project! 


\title{
Appendix D
}

\author{
Consent to Participate in Research Study \\ University of Missouri-Columbia \\ Social Work Program \\ Research Title: Engagement of Geographically Diverse Head Start Families \\ Principal Investigator: Amanda Keys, MSW Faculty Advisory: Dr. Colleen Galambos, MSW, PhD \\ Contact Information: \\ 818 Barwick Pl \\ Willard, MO 65781 \\ Contact Information: \\ 523 Clark Hall \\ Email: amkf6c@mail.missouri.edu \\ Phone: 417-350-9009 \\ School of Social Work \\ University of Missouri \\ Columbia, MO 65211-4470 \\ Email: galambosc@missouri.edu \\ Phone: (573) 882-3701
}

\section{Introduction}

You have been asked to participate in a research study that is part of the requirement for the degree of a $\mathrm{PhD}$ in Social Work at the University of Missouri-Columbia for Amanda Keys. Before you agree to participate in this study, it is important you read about and understand the study and the procedures it involves. If you have any questions about this study, or your role in the study, please feel free to contact Amanda Keys. You will need to sign this form giving us permission for you to be involved in this study. Taking part in this study is entirely your choice. There will not be any negative consequences for failing to complete this survey.

\section{Purpose of this Study}

The reason for this study is to examine family engagement in rural and urban Head Start families. You have been asked to participate in this study because you presently have one or more children attending OACAC Head Start.

\section{Description of Procedures}

If you decide to take part in this study, you will be asked to fill out a questionnaire which will ask some personal information. This questionnaire will take about 15 minutes to complete. Any information about you will be kept confidential. To protect your privacy, you will not be asked to disclose any identifiable information. Therefore, please do not put your name or your children's names on the questionnaire. In addition each Head Start site will be assigned a coded number to protect your information further. A manila envelope should have been provided and the assigned coded number is listed on the outside of the envelope to identify your Head Start location. To protect your information, please make sure you include your questionnaire as well as your signature of informed consent in the sealed manila envelope. Once you have completed the questionnaire, please put the sealed manila envelope in your child's backpack to return to your child's head Start location. In addition, the Head Start site which has the most questionnaires returned to them will receive $\$ 100.00$ for use in their classroom to provide educational supplements for your children.

The deadline for completion is March, 28, 2013.

\section{What are the risks?}

We estimate that the potential risks of this study are minimal. However, you may experience some psychological discomfort when answering questions about family engagement.

\section{What are the benefits?}

It is not anticipated that you will experience any direct benefits from this study. Nevertheless, your participation in this research will help investigators identify characteristics of family engagement in Head Start families. This information may be useful in developing future Head Start programs. Refusal to participate will involve no penalty or loss of benefits to which the subject is otherwise entitled. The subject may request his/her survey be destroyed and not be included in the research at any time without penalty or loss of benefits to which the subject is otherwise entitled.

\section{How will my privacy be protected?}

Information about you will be coded. Your name will not appear on the questionnaire. The information will be returned to the investigator in a sealed manila envelope. The information gathered will be accessible only by the investigators and will be kept in a locked facility. You will not be identified by name in any publications that result from this research. All information from this study will be destroyed 7 years after the study ends.

For questions about the subjects' rights, concerns, complaints or comments as a research participant please contact: 483 McReynolds Hall E-Mail: umcresearchcirb@missouri.edu

Columbia, MO 65211 Website: http://www.research.missouri.edu/cirb/index.htm 


\section{Consent to Participate}

If you want to participate in this study, you are required to sign below as an indication of your willingness to participate:

I have read and understand the information on this form. I have been encouraged to ask questions and all my questions have been answered to my satisfaction. I have also been informed this is a voluntary study and I do not have to complete this study. By signing this form, I voluntarily agree to participate in this study.

Printed Name of Participant 


\section{Appendix E}

\section{Head Start Parent Survey-1}

\section{Directions: Please circle one of the following answers under each question.}

1. What Is Your Ethnicity?
a. African American
b. Asian
c. Hispanic
d. Pacific Islander
e. White
f. Other (please specify:

2. What is your race? For purposes of this question, persons of Spanish/Hispanic/Latino origin may be of any race.
a. White
b. Black or African American
c. American Indian and Alaska Native
d. Asian
e. Native Hawaiian and Other Pacific Islander
f. Other race

3. What is your age?

4. What is the highest degree or level of education you have completed?
a. Less than high school
b. High school graduate (includes equivalency)
c. Some college, no degree
d. Associate's degree
e. Bachelor's degree
f. PhD
g. Graduate or professional degree

5. What is your marital status?
a. Single (never married)
b. Married
c. Separated
d. Widowed
e. Divorced
f. Living with partner

6. What is your gender?
a. Female
b. Male

Directions: Below are several statements followed by answers. Please read them and circle the answer that best describes how much you agree with the statement. It is most helpful if you try to answer honestly and accurately. This information helps us plan how to make the program as helpful to parents as possible.

\begin{tabular}{|l|l|c|c|c|c|c|}
\hline & & $\begin{array}{r}\text { Strongly } \\
\text { Agree }\end{array}$ & $\begin{array}{r}\text { Agre } \\
\text { e }\end{array}$ & $\begin{array}{r}\text { Partiall } \\
\text { y Agree } \\
\text { Partially } \\
\text { pisagree }\end{array}$ & $\begin{array}{c}\text { Dis- } \\
\text { agree }\end{array}$ & $\begin{array}{r}\text { Strongl } \\
\text { y } \\
\text { Disagree }\end{array}$ \\
\hline 1. & I feel very comfortable visiting my child's school. & $\mathbf{1}$ & $\mathbf{2}$ & $\mathbf{3}$ & $\mathbf{4}$ & $\mathbf{5}$ \\
\hline 2. & My child's school work is always displayed in our home (e.g. & $\mathbf{1}$ & $\mathbf{2}$ & $\mathbf{3}$ & $\mathbf{4}$ & $\mathbf{5}$ \\
\hline
\end{tabular}




\begin{tabular}{|c|c|c|c|c|c|c|}
\hline & hang papers on the refrigerator). & & & & & \\
\hline 3. & $\begin{array}{l}\text { If my child misbehaved at school, I would know about it soon } \\
\text { afterward. }\end{array}$ & 1 & 2 & 3 & 4 & 5 \\
\hline 4. & $\begin{array}{l}\text { I frequently explain difficult ideas to my child when she/he } \\
\text { doesn't understand. }\end{array}$ & 1 & 2 & 3 & 4 & 5 \\
\hline 5. & $\begin{array}{l}\text { Every time my child does something well at school I } \\
\text { compliment him/her. }\end{array}$ & 1 & 2 & 3 & 4 & 5 \\
\hline 6. & $\begin{array}{l}\text { Talking with Head Start administrators makes me } \\
\text { uncomfortable. }\end{array}$ & 1 & 2 & 3 & 4 & 5 \\
\hline 7. & I always know how well my child is doing in school. & 1 & 2 & 3 & 4 & 5 \\
\hline 8. & I am confused about my legal rights as a parent of a student. & 1 & 2 & 3 & 4 & 5 \\
\hline 9. & I read to my child every day. & 1 & 2 & 3 & 4 & 5 \\
\hline 10. & I talk with other parents frequently about educational issues. & 1 & 2 & 3 & 4 & 5 \\
\hline 11. & $\begin{array}{l}\text { My child attends community programs (e.g. YMCA, park/rec, } \\
\text { community theatre) regularly. }\end{array}$ & 1 & 2 & 3 & 4 & 5 \\
\hline 12. & $\begin{array}{l}\text { I have visited my child's classroom several times in the past } \\
\text { year. }\end{array}$ & 1 & 2 & 3 & 4 & 5 \\
\hline 13. & $\begin{array}{l}\text { I have made suggestions to my child's teachers about how to } \\
\text { help my child learn. }\end{array}$ & 1 & 2 & 3 & 4 & 5 \\
\hline 14. & There are many children's books in our house. & 1 & 2 & 3 & 4 & 5 \\
\hline 15. & $\begin{array}{l}\text { In the past } 12 \text { months I have attended activities at my child's } \\
\text { school several times (e.g. family nights, fun nights } \\
\text { performances, awards nights). }\end{array}$ & 1 & 2 & 3 & 4 & 5 \\
\hline 16. & My child misses school several days in a 3 month time period. & 1 & 2 & 3 & 4 & 5 \\
\hline 17. & $\begin{array}{l}\text { Talking with my child's current teacher makes me somewhat } \\
\text { uncomfortable. }\end{array}$ & 1 & 2 & 3 & 4 & 5 \\
\hline 18. & I don't understand the assignments my child brings home. & 1 & 2 & 3 & 4 & 5 \\
\hline 19. & Reading books is a regular activity in our home. & 1 & 2 & 3 & 4 & 5 \\
\hline 20. & $\begin{array}{l}\text { If my child was having trouble in preschool I would not know } \\
\text { how to get extra help for him/her. }\end{array}$ & 1 & 2 & 3 & 4 & 5 \\
\hline 21. & I know the policy governing Head Start well. & 1 & 2 & 3 & 4 & 5 \\
\hline 22. & $\begin{array}{l}\text { In the past } 12 \text { months I have attended several Head Start } \\
\text { Policy Council Meetings. }\end{array}$ & 1 & 2 & 3 & 4 & 5 \\
\hline 23. & $\begin{array}{l}\text { In the past } 12 \text { months I volunteered at my child's preschool at } \\
\text { least } 3 \text { times. }\end{array}$ & 1 & 2 & 3 & 4 & 5 \\
\hline 24. & I know about many programs for children in my community. & 1 & 2 & 3 & 4 & 5 \\
\hline
\end{tabular}

How difficult do the follow issues make involvement with your child's preschool?

\begin{tabular}{|l|l|l|l|l|}
\hline & & $\begin{array}{l}\text { A } \\
\text { lot }\end{array}$ & Some & $\begin{array}{l}\text { Not an } \\
\text { Issue }\end{array}$ \\
\hline 25. & Lack of Time & $\mathbf{1}$ & $\mathbf{2}$ & $\mathbf{3}$ \\
\hline 26. & Time of Programs & $\mathbf{1}$ & $\mathbf{2}$ & $\mathbf{3}$ \\
\hline 27. & Small Children & $\mathbf{1}$ & $\mathbf{2}$ & $\mathbf{3}$ \\
\hline 28. & Transportation & $\mathbf{1}$ & $\mathbf{2}$ & $\mathbf{3}$ \\
\hline 29. & Work Schedule & $\mathbf{1}$ & $\mathbf{2}$ & $\mathbf{3}$ \\
\hline 30. & $\begin{array}{l}\text { Other (Specify: } \\
\text { ) }\end{array}$ & $\mathbf{1}$ & $\mathbf{2}$ & $\mathbf{3}$ \\
\hline
\end{tabular}

Directions: Decide to what degree you either agree or disagree with each statement about your family. $0=$ Strongly disagree, $4=$ Strongly Agree.

\begin{tabular}{|l|l|l|l|l|l|l|}
\hline $\begin{array}{l}\text { When we face problems or difficulties in } \\
\text { our family we come by: }\end{array}$ & $\begin{array}{l}\text { Strongly } \\
\text { disagree }\end{array}$ & Disagree & Neutral & Agree & $\begin{array}{l}\text { Strongly } \\
\text { Agree }\end{array}$ \\
\hline 1. & Accepting stressful events as a fact of life. & $\mathbf{0}$ & $\mathbf{1}$ & $\mathbf{2}$ & $\mathbf{3}$ & $\mathbf{4}$ \\
\hline 2. & Accepting that difficulties occur & $\mathbf{0}$ & $\mathbf{1}$ & $\mathbf{2}$ & $\mathbf{3}$ & $\mathbf{4}$ \\
\hline
\end{tabular}




\begin{tabular}{|l|l|l|l|l|l|l|}
\hline & unexpectedly. & & & & & \\
\hline 3. & $\begin{array}{l}\text { Defining the family problem in a more } \\
\text { positive way so that we do not become too } \\
\text { discouraged. }\end{array}$ & $\mathbf{0}$ & $\mathbf{1}$ & $\mathbf{2}$ & $\mathbf{3}$ & $\mathbf{4}$ \\
\hline 4. & Having faith in God. & $\mathbf{0}$ & $\mathbf{1}$ & $\mathbf{2}$ & $\mathbf{3}$ & $\mathbf{4}$ \\
\hline
\end{tabular}

Directions: For each of the eight statements below, please note that the words at each end of the 0 to 10 scale describe opposite feelings. Please fill in the response along the bar which seems closed to how you have generally felt during the past month.

1. How concerned or worried about your health have you been? (During the past month)

$\begin{array}{lllllllllll}\text { Not CONCERNED } \\ \text { At all } & 1 & 2 & 3 & 4 & 5 & 6 & 7 & 8 & 9 & \text { Cery } \\ \text { CONCERNED }\end{array}$

2. How relaxed or tense have you been? (During the past month)

Very

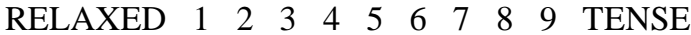

3. How much energy, pep, vitality have you felt? (During the past month)

No energy at all $\quad$ Very energetic

LISTLESS $\quad \begin{array}{llllllllllll}1 & 2 & 3 & 4 & 5 & 6 & 7 & 8 & 9 & \text { DYNAMIC }\end{array}$

4. How depressed or cheerful have you been? (During the past month) Very

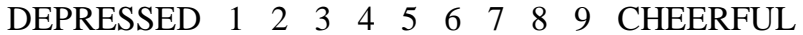

5. How afraid have you been? (During the past month)

Not $\quad$ Very

AFRAID $\quad \begin{array}{lllllllllll}1 & 2 & 3 & 4 & 5 & 6 & 7 & 8 & 9\end{array}$

6. How angry have you been? (During the past month)

Not ANGRY Very

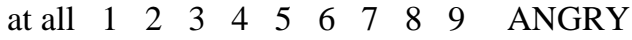

7. How sad have you been? (During the past month)

Not SAD Very

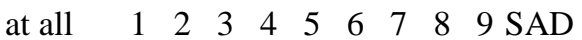

8. How concerned or worried about the health of another family member have you been? (During the past month)

Not CONCERNED

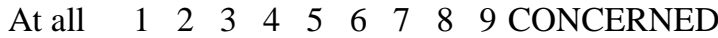


VITA

Amanda M. Keys, MSW, LCSW is currently the Director of Field Education for Southwest Baptist University. Ms. Keys has held this position since fall 2011. Prior to her work for SBU, Ms. Keys worked in a variety of roles with children who have been abused and neglected for over ten years. Her prior positions included being an out-ofhome-care worker for the state of Missouri. In this position, Ms. Keys was responsible for a caseload of approximately 80 children and biological parents. Her next position was as a specialized case manager for the state of Missouri. Ms. Keys was responsible for supporting children who were severely emotionally disturbed in treatment foster homes. Upon promotion, Ms. Keys was a residential coordinator of specialized teams. In this position, Ms. Keys was responsible for the residential placement of approximately 400 children in the southwest region of the state of Missouri.

In her last job before transitioning to SBU, Ms. Keys held an administrative position in a private child welfare agency for five years. In this position, Ms. Keys was responsible for providing programmatic oversight for private child welfare workers, specialized treatment foster care workers, and intensive family reunification workers. Additionally, Ms. Keys had numerous opportunities to provide field instruction experiences for BSW and MSW students. These students were referred to the agency Ms. Keys worked for by private and public universities in the Springfield, Missouri area. 